\title{
Direct Measurements of
} Solids: High Temperature Sensing

Phase II

Experimental Development and Testing on Furnace-Heated Steel Blocks

D. K. Lemon

D. S. Daly

December 1985

Prepared for the U.S. Department of Energy under Contract DE-AC06-76RLO 1830

Pacific Northwest Laboratory

Operated for the U.S. Department of Energy by Battelle Memorial Institute 


\title{
DISCLAIMER
}

This report was prepared as an account of work sporisored by an agency of the United States Government. Neither the United States Government nor any agency thereof, nor any of their employees, makes any warranty, express or implied, or assumes any legal liability or responsibility for the accuracy, completeness, or usefulness of any information, apparatus, product, or process disclosed, or represents that its use would not infringe privately owned rights. Reference herein to any specific commercial product, process, or service by trade name, trademark, manufacturer, or otherwise, does not necessarily constitute or imply its endorsement, recommendation, or favoring by the United States Government or any agency thereof. The views and opinions of authors expressed herein do not necessarily state or reflect those of the United States Government or any agency thereof.

\author{
PACIFIC NORTHWEST LABORATORY \\ operated by \\ BATTELLE \\ for the \\ UNITED STATES DEPARTMENT OF ENERGY \\ under Contract DE-AC06-76RLO 1830
}

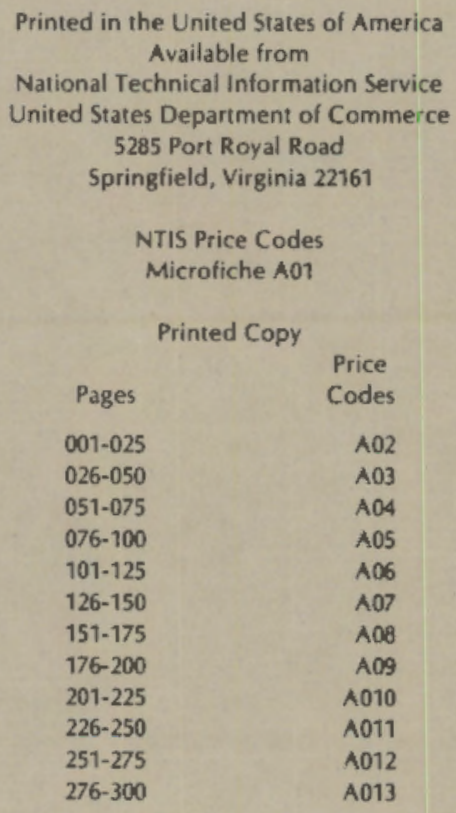




\section{DIRECT MEASUREMENT OF SOLIDS: HIGH TEMPERATURE SENSING \\ PHASE II \\ EXPERIMENTAL DEVELOPMENT AND TESTING \\ ON FURNACE-HEATED STEEL BLOCKS}

DK Lemon

DS Daly

December 1985

Prepared for

The U.S. Department of Energy

under Contract DE-AC06-76RLO 1830 
,

b

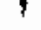

I 


\section{EXECUTIVE SUMRARY}

\section{BACKGROUND}

This program was initiated at Pacific Northwest Laboratory (DNL) as a cooperative effort between the Department of Energy (DOE/Office of Industrial Programs) and the American Iron and steel Institute (AISI). The purpose of the joint program is to develop and demonstrate technology that would enable the U.S. steel industry to improve the energy use efficiency of several energy-intensive production processes. The program supports DOE's mission of promoting and facilitating energy conservation in the industrial sector. Implemention of such technology in the field will improve the overall productivity and competitiveness of the U.S. steel industry.

Throughout the program there has been close coordination between the office of Industrial Programs, AISI, and PNL. Project review meetings are attended by representatives from each organization. Since this program is related to work being conducted at the National Bureau of standards (NBS), representatives from NBS are regularly consulted and included in the review meetings.

The program has been jointly funded and monitored by DOE and AISI. In addition to funding support, the AISI has provided in-kind services in the form of steel samples and technical consultation.

\section{OBJECTIVES}

It was determined that one means of achieving the program's purpose would be to develop technology (specifically sensors and instrumentation) capable of determining the internal temperature profiles of high temperature steel slabs, billets, strands, etc. The following objectives were therefore established:

1. Identify sensing methods and analysis techniques.

2. Develop and test a practical sensing/measurement system on furnace-heated blocks.

3. Extend the sensing/measurement system to cast ingots having liquid-phase cores.

4. Field test the technology and facilitate technology transfer to industry. 


\section{PROGRAM STRUCTURE AND PROGRESS IN PRIOR YEARS}

Phase I of the prograrn, Analytical and Experimental Eyaluation, was directed to accomplishing the first objective. The work analytically and experimentally evaluated the sensing methods available. The recommendation from Phase $I$ was that an electromagnetic acoustic transducer (EMAT) be developed to transmit and receive ultrasonic pulses in the hot steel. The selected approach would calibrate the ultrasonic pulse velocity to the average profile temperature. Temperature gradient information would be derived from the average profile temperature estimate, surface temperature measurements, and a simple temperature gradient model.

The Phase I work was reported in April, 1984. (see references.)

Phase II of the program is focussed on the second objective and is entitled, Experimental Development and Testing Furnaceheated Steel_Blocks. This report covers the Phase II work conducted in FY85. Phase II will continue into FY86.

\section{ACCOMPLISHMENTS IN PHASE II FOR FY85}

The Phase II work was initiated in FY84 by subcontracting with a qualified vendor to develop shear and longitudinal wave EMATs and the associated electronics. By the third month of FYB5 the EMATs were received and their evaluation commenced. Test samples of ARMCO iron, 1008 steel, and 1038 steel were received from AISI companies. The blocks were instrumented with thermocouples so that actual temperature profiles could be measured for comparison with ultrasonic data. Small sections from each block were tested under isothermal conditions to determine their fundamental velocity-versus-temperature characteristics. A data acquisition system was set up to record the digitized ultrasonic signals and the thermocouple readings concurrently throughout a test.

In anticipation of future testing, methods and molds were developed for casting 100 pound ingots at PNL. Three ingots were cast and then sectioned to visually determine the size of the shrinkage cavity and the porosity. These ingots solidified quickly. Future ingots must be four or five times larger if liquid-cored ingots are to be ultrasonically tested: Additional casting and testing of ingots were deferred until later phases of the program.

The three test blocks were heated to temperatures as high as 1000 degrees celsius and interrogated with the EMATs. The shear wave EMAT provided strong signals from room temperature to the curie temperature where the steel became nonmagnetic. The longitudinal wave EMAT produced detectable signals in a 
narrow temperature range where the surface layer was below the curie temperature and the interior was nonmagnetic. The work demonstrates that it is possible to measure time of flight on hot steel at temperatures typical of many production conditions.

Average profile temperatures were predicted and compared to observed average temperatures. The predicted temperature was estimated using the ultrasonic measurements and the temperature/ velocity calibrations. The observed average temperature was estimated from the thermocouple measurements. Error estimates for the predicted temperatures showed that measurement error intrinsic to the instruments was small. The intrinsic accuracy of the measurement techniques indicated that an eventual accuracy of 20 degrees Celsius may be possible.

\section{CONCLUSIONS AND RECOMRENDATIONS}

Conclusions :

1. Using average velocity measurements to estimate average profile temperature shows promise and merits further investigation.

2. The current generation of EMATs can transmit and detect signals in steel below the magnetic transition temperature.

3. Techniques for calibrating ultrasonic velocity to internal temperature need further development.

4. EMATs are inadequate ultrasonic transmitters for these applications. A high energy, pulsed laser capable of generating more intense ultrasonic signals should be investigated as a transmitter.

Recommendations :

1. PNL's FY86 work should concentrate on developing and testing an EMAT receiver with improved sensitivity and ability to withstand repeated exposure to high temperatures. Tests should be conducted on steel at temperature of at least 1100 , and potentially, as high as 1300 degrees Celsius.

2. The new generation EMAT receiver should be evaluated with a laser pulser at PNL and subsequently at the National Bureau of Standards.

3. After the EMAT has been evaluated, PNL should work with DOE/OIP and AISI to define the manner in which PNL should continue to work to meet objectives \#3 and \#4 listed above. 


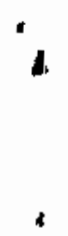

$d$

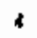

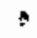

•

$\bullet$ 


\section{TABLE OF CONTENTS}

Page

1.0 INTRODUCTION $1-1$

1.1 Purpose and Objectives 1-1

1.2 Benefits $1-2$

1.3 Summary of Phase I Work $1-2$

2.0 EXPERIMENTAL DEVELOPMENT AND TESTING

ON FURNACE-HEATED BLOCKS $2-1$

2.1 Approach 2-1

2.2 EMAT Development 2-2

2.2.1 General Theory of EMAT Operation 2-2

2.2.2 EMAT Development 2-4

2.3 Characterization of Steel Specimens 2-4

2.3.1 Test Specimen Description 2-4

2.3.2 Thin Rod Method for Determining

2.3.3 Thin Rod Velocity Versus Temperature

Data for Steel Samples 2-8

2.4 Experimental Methods and Data Collection
on Furnace-Heated Blocks

2.4.1 The Furnace and Heating Procedure 2-11

2.4.2 The EMAT and Thermocouple Data
Acquisition System

2.4.3 Temperature Measurement Procedures 2-14

2.4.4 Waveform Data Acquisition Procedures 2-15

3.0 WAVEFORM ANALYSIS SOFTWARE 3-1

3.1 Software Overview 3-1

3.2 Data File Structure 3-1

3.3 Fortran Programs $3-1$

3.3.1 Program RDCHECK 3-1

3.3.2 Program RDSTEEL $3-2$

3.3.3 Program TOF $3-3$

3.3.4 Program GRID $3-4$

3.3 .5 Program RAW 3-5

3.3.6 Graph Production Programs 3-5

4.0 DATA ANALYSIS AND RESULTS 4-1

4.1 Experiments on 1008 Steel 4-1

4.2 Experiments on 1038 steel 4-7

4.3 Experiments with Armeo Iron 4-12 
TABLE OF CONTENTS

(cont'd)

$\underline{\text { Page }}$

4.4 Estimating Average Internal Temperature from Velocity Measurements

4.4.1 Approach

4.4.2 Estimation of Intrinsic Instrument Measurement Errors

$4-24$

$4-24$

$4-25$

$4-26$

4.5 Results of Temperature Estimations

$5-1$

5.0 CONCLUSIONS AND RECOMMENDATIONS

$5-1$

5.1 Conclusions

5.2 Recommendations

$5-2$

6.0 REFERENCES

$6-1$

APPENDIX A: CASTING OF SMALL INGOTS

A-1 


\section{LIST OF FIGURES}

Page

2.1 Construction and Operation of a Shear Wave EMAT

$2-3$

2.2 Construction and Operation of a Longitudinal Wave EMAT

$2-5$

2.3 Photograph of the EMATs Configured for Testing on Hot steel Blocks

$2-6$

2.4a Graph of Thin Rod shear wave Velocity Versus Temperature with and without Thermal Expansion Correction Graph

2.4b Graph of Temperature vs. Shear velocity Calibration Data for Two Different Thin Rod Tests

2.5 Photograph of a Hot steel Block being

Removed from the Furnace

2.6 Block Diagram of the EMAT and Temperature Data Acquisition system

2.7 Detailed Diagram of the EMAT and Its Pulser/ Receiver system

2.8 Close-up View of the Thermocouples Embedded in the 1008 steel Block

2.9 Graph of Pulses from a Calibrated Time Mark Generator to Verify Calibration of the Waveform Digitizer

2.10 Detailed Graph of Two Successive Pulses from the Time Mark Generator

4.1 Plots of Longitudinal Mode Waveforms from the 1008 steel Block

4.2 A Smooth Graph of Local Temperature Versus Thermocouple Location Versus Average Temperature for the 1008 steel Test

4.3 Graph of the Supporting Observations for the Temperature Surface shown in Figure 4.2 


\section{LIST OF FIGURES}

(cont'd)

Page

4.4 Graph of the Thermocouple Temperature Minus the Average Temperature as a Function of Location and Average Temperature

4.5 Graph of Average Longitudinal Velocity Versus Average Temperature for the 1008 Steel Block

4.6 Selected Shear Mode Waveforms from the 1008 Steel Block Test

4.7 Graph of Shear Wave Velocity Versus Average Temperature for 1008 Steel

4.8a Graph of the Temperature Surface as a Function of Location and Average Temperature for 1008 steel

$4.8 \mathrm{~b}$ Graph of Observations that Support the Smoothed Surface in Figure $4.8 \mathrm{a}$

4.9 Graph of Local Temperature Minus Average Temperature as a Function of Location and Average Temperature

4.10 Examples of Shear Mode Waveforms from a 1038 Steel Block Test

4.11 Graph of Shear Wave Velocity Versus Temperature for a 1038 Steel Test

4.12a Graph of Temperature Surface for the Armco Iron Block Test

4.12b Graph of the Observations that Support the Armco Iron Temperature Surface (4.12a)

4.13 Surface Showing the Local Temperature Minus Average Temperature Versus Average Temperature and Location

4.14 Examples of Longitudinal Mode Waveforms from the Armco Iron Block Test 


\section{LIST OF FIGURES}

(cont'd)

Page

4.15a Temperature Surface for an Armco Iron Test Showing Local Temperature as a Function of Location and Average Temperature for the Longitudinal Wave Subset

4.15b Graph of Observations that Support the Temperature surface in Figure 4.15a

$4-20$

4.16 Graph of Local Temperature Minus Average Temperature for an Armco Iron Longitudinal Test

4.17 Selected Shear Mode Waveforms for the Armco Iron Tests

4.18 Graph of Measured Average Shear Velocity Vs. Measured Average Temperature for an Armco Iron Shear wave Test

4.19 Plot of Average Estimated Temperature Versus Actual Temperature for a 1008 Steel Test

4.20 Plot of shear wave Velocities vs. Temperature for Three Replications with 1008 Steel

4.21a Graph of Measured and Predicted Temperature Versus Velocity for a 1038 steel Test

$4.2 \mathrm{lb}$ Graph of Predicted Temperature Versus Measured Temperature for a 1038 Steel Test 4-29

4.22a Graph of Measured and Predicted Temperature Versus Shear Velocity for an Armco Iron Test 4-30

4.22b Graph of Predicted Versus Measured Temperature for an Armco Iron shear EMAT Test 


\section{LIST OF TABLES}

Page

2.1 Velocity Calibration Data for 1008 Thin Rod Tests

$2-9$

2.2 Time Intervals for Calibration Pulses

$2-17$

4.1 Velocity as a Function of Temperature for the 1008 steel

$4-6$

4. 2 Velocity Versus Temperature Data for 1038 Steel

$4-16$

4.3 Velocity Values for the Armco Iron Test

$4-24$

4.4 Measured Shear Velocity and standard Deviation or Measurement Errors for 1008 steel

$4-26$

4.5 Measured and Predicted Average Block Temperature and Average Shear Wave Velocity for 1008 steel 


\section{ACKNOWLEDGEMENTS}

This work has been accomplished through the combined efforts of many individuals. The authors acknowledge and appreciate their respective contributions. The testing, data acquistion, and analysis were greatly aided by the efforts of Dick Pappas, Paul Sperline, John Dovey. Support in the heating and casting of samples and metallurgical analysis was given by Dick Nelsen, Don Montgomery, and Keith Clark. The authors also recognize and appreciate the timely and thorough clerical support of Kay williamson in preparing this report for publication.

This program is administered by the office of Industrial Programs of the U.S. Department of Energy. Dr. James Fulton has been the cognizant program manager. We appreciate the support and guidance given by the management at OIP.

This project is a cooperative effort between the Department of Energy and the American Iron and Steel Institute (AISI). We acknowledge the guidance and technical support received from the AISI committee chaired by Dr. James $R$. Cook. The technical assistance received from Dr. Bernard E. Droney, an AISI research associate, was particularly valuable. 


\section{SECTION 1.0 \\ INTRODUCTION}

\subsection{PURPOSE AND OBJECTIVES}

The purpose of this R\&D program is to help the United states' metals industries conserve energy in energy intensive production processes. Because significant energy savings would be possible if the average temperature or the temperature profile could be measured for hot bodies; e.g., ingots, slabs, blooms, or strands, this program will evaluate methods to estimate internal temperatures in hot steel bodies.

To achieve this purpose the following objectives were established:

1. Identify sensing methods that can estimate the average temperature or temperature gradient profile within a hot solid body, initially focussing on steel production.

Phase I focussed on this objective and a method was selected employing ultrasonic electromagnetic, acoustic transducers (EMATs) to measure temperature-dependent ultrasonic velocities.

2. Develop and test a practical sensing/measurement system. Develop and test prototypes of EMAT sensors and supporting electronics on blocks furnace-heated to 1100 degrees celcius.

In Phase II (FY85) EMAT sensors were developed and tested on steel heated to 1000 degrees Celsius. This report describes the work done to meet this objective.

The FY86 work will focus on developing an EMAT receiver to detect laser-generated ultrasonic pulses in steel heated to 1100 degrees $C$, with heating to 1300 degrees $C$ attempted. A high energy laser will generate the ultrasonic pulse because a laser can produce higher energy signals than an EMAT.

3. Extend the laser-EMAr velocity measurement system to ingots having liguid-phase cores.

4. Field testing and technology transfer. In coordination with AISI and DOE, PNL will field-harden the measurement system for trial use in a steel production plant. After field testing, PNL will aid in further application and transfer of the technology to the steel industry. 


\subsection{BENEFITS}

The United states metals industries are the largest industrial consumer of energy with annual consumption exceeding 5.0 quads. A large portion of this energy is used to heat solids. Therefore, a small savings of heating energy would significantly reduce costs to the industry. For example, a recent study completed by Battelle Columbus [1] suggested that the development and wide acceptance of a technology for measuring temperature profiles could save the U.S. steel industry $90 \times 10^{12}$ Btu/year.

The development and use of a device for measuring average temperature or the temperature gradient in a hot body could result in considerable energy savings:

Soaking Pits - Ready times could be accurately determined, firing rates optimized, fuel consumption reduced, and productivity and product quality improved.

Reheat Furnaces - Reheat furnaces could be precisely controlled to achieve better fuel economy and improve metallurgical control.

Rolling Mills - Older mills could be adapted to automatic control for productivity increases and improvements in metallurgical and dimensional control. Dimensional control could be improved in modern mills with automatic control based on better temperature information. (Temperature models presently lack throughbar temperature gradient information.)

Annealing - Increased control of individual coils would be possible.

Continuous casting - A measurement of the temperature gradient of the solidifying metal could maximize productivity without sacrificing internal quality.

Ingot Production - Ingot movement and stripping could be accurately controlled to maximize productivity.

Kiln Fifing - Process controls activated by sensing mechanisms to prevent overfiring would save significant amounts of energy.

\subsection{SUMMARY OF PHASE I WORK}

During the first phase of this project, the following tasks were accomplished:

- Evaluated Time-of-Elight Tomography: The first technical approach investigated the use of time-of-flight tomography to image the ultrasonic velocities over a two-dimensional cross-section of the test specimen. since the velocity 
varies predictably with temperature, velocities can be converted to temperatures. Analysis showed that time-of-flight tomography does not work on flat plate geometries. Consequently, it is not feasible for this project though it is a viable technique for other situations.

- Developed an Alternative Approach: An alternative approach was developed using multiple ultrasonic measurements to empirically estimate the independent parameters of a general analytical model (or equation) of the temperature profile. The general model was derived from knowledge of the particular type of specimen being tested, such as a continuously cast strand, slab prior to reheating, etc.

- Studied Metallurgical Factors: A literature review revealed what other investigators had learned about velocity and attenuation of ultrasound in iron and steel at elevated temperatures. This information confirmed that it was possible to make velocity and attenuation measurements in steel to the melting temperature. This was significant because the technical approach relied on such measurements.

- Evaluated Types of Transducers: Lasers, contact type, buffer rod transducers, and electromagnetic transducers (EMATs) were evaluated for generating and receiving ultrasonic pulses in hot steel. The literature reported measurements made with both the buffer rod and EMAT transducers. A potential supplier of high temperature EMATs for the subsequent phases of work was identified.

- Performed an Experimental Evaluation of the Approach: The feasibility of estimating temperature using EMATs was evaluated. A block of continuously cast 1038 steel was heated on one side and cooled on the opposite side to create a linear temperature profile. The temperature profile was measured directly using thermocouples. Time-of-flight measurements using longitudinal and shear ultrasonic waves were made. Comparisons of the ultrasonic and temperature data showed that this approach was reasonable.

At the end of Phase $I$, it was concluded that temperature predictions using ultrasonic techniques is a viable technical approach for determining internal temperature profiles in hot steel objects. For the plate-like geometries considered in this project, the recommended approach combines multiple ultrasonic velocity measurements with a general profile model to yield a specific temperature profile estimate for each test made. AISI and DOE/OIP recommended that PNL proceed with Phase II of the project. 


\section{SECTION 2.0}

\section{EXPERIMENTAL DEVELOPMENT AND TESTING ON FURNACE-HEATED BLOCKS}

\subsection{APPROACH}

The technical approach is based on the knowledge that ultrasonic pulse velocity decreases with increasing temperature. Hence, for an isothermal specimen, the ultrasonic pulse velocity can be directly converted to specimen temperature. (There are hysteresis effects on heating and cooling in the phase change regions, but generally the relationship is single valued.) In actual applications, the specimens are not isothermal but have a varying internal temperature profile.

In the many important cases, such as slab reheating, knowing the average internal temperature could improve the energy efficiency of the process. In such cases the average ultrasonic pulse velocity can be related to the average internal temperature.

The average ultrasonic velocity is estimated from two measurements: the time required for an ultrasonic pulse to travel through the hot steel block, and the thickness of the block. The time of flight measurement is made with the EMAT sensor and electronics. In the FY85 portion of Phase II the thickness measurements of the hot steel estimated using thermal contraction/expansion equations and cold block thickness.

In applications such as controlling continuous casters, it is necessary to know the internal temperature gradient of the specimen. Since liquid phase steel may be present, it is desirable to detect the presence of molten steel as well.

Determining internal gradients requires more knowledge of the specimen. The approach combines ultrasonic velocity measurements, surface temperature measurements, and the thermal history of the particular specimen being tested into a model that also contains specific velocity/temperature calibration data, phase transformation temperatures and magnetic properties for various alloys. When each new block or body is tested, the general information would be combined with specific block measurements to yield an estimated temperature profile.

Early in Phase II it was thought that ultrasonic attenuation might yield useful temperature information. The work to date has shown that the amplitude of the ultrasonic echoes is strongly influenced by several factors that cannot be independently controlled or measured. Hence, attenuation may not be useful for internal temperature estimation. 
The Phase II work and the results of other researchers indicate that both longitudinal wave and shear wave mode EMATs may be necessary to cover the 0 to 1100 degree $C$ temperature range. Shear wave EMATs are inherently more efficient on magnetic materials because of the orientation of the magnetic fields. consequently, they are applicable when the surface is magnetic (approx. 770 degrees Celsius or less.) The austenitic phase strongly attenuates shear waves, decreasing their usefulness at the higher temperatures. Conversely, longitudinal wave mode EMATs are more efficient on non-magnetic materials, again because of magnetic field shape and attenuation. The initial approach will employ longitudinal-mode EMATs for higher temperature, non-magnetic specimens and shear-mode EMATs for specimens that are magnetic, at least on the outer surface.

\subsection{EMAT DEVELOPKENT}

\subsubsection{General Theory of EMAT Operation}

Electromagnetic Acoustic Transducers (EMATs) using electromagnetic forces generate elastic waves in metals. Every EMAT has two basic components, an electromagnet or a permanent magnet and a coil. Their shape and orientation determine whether the EMAT generates and detects shear, longitudinal or surface waves. To generate an ultrasonic pulse or elastic wave, the magnet sets up a magnetic field either perpendicular or parallel to the surface of the test block. The coil is then pulsed with a burst of current which, in turn, induces a burst of eddy currents to flow in the surface of the test block. When currents flow in the presence of a magnetic field, they experience a force (the Lorentz force) that is perpendicular to both the eddy current and magnetic field vector directions. This causes an elastic wave to propagate into the block.

Figure 2.1 shows the construction and operation of a shear wave EMAT. Panel 2.1a is an artist's drawing of a shear wave EMAT. In panel 2.1b, the magnetic field is perpendicular to the surface of the block. The coil is wound in a spiral fashion parallel to the test surface. When the coil is pulsed, eddy currents flow in a circular pattern in the test block as shown in Figure 2.1c. The Lorentz force, perpendicular to both the magnetic field and the current vectors, is directed either inward or outward radially depending on which direction the current is flowing. The Lorentz force causes an elastic deformation (called a shear or transverse wave because the particle vibration is transverse to the direction of propagation) that propagates into the block. The shear wave velocity is governed by the shear modulus and the density at each point along the path. 


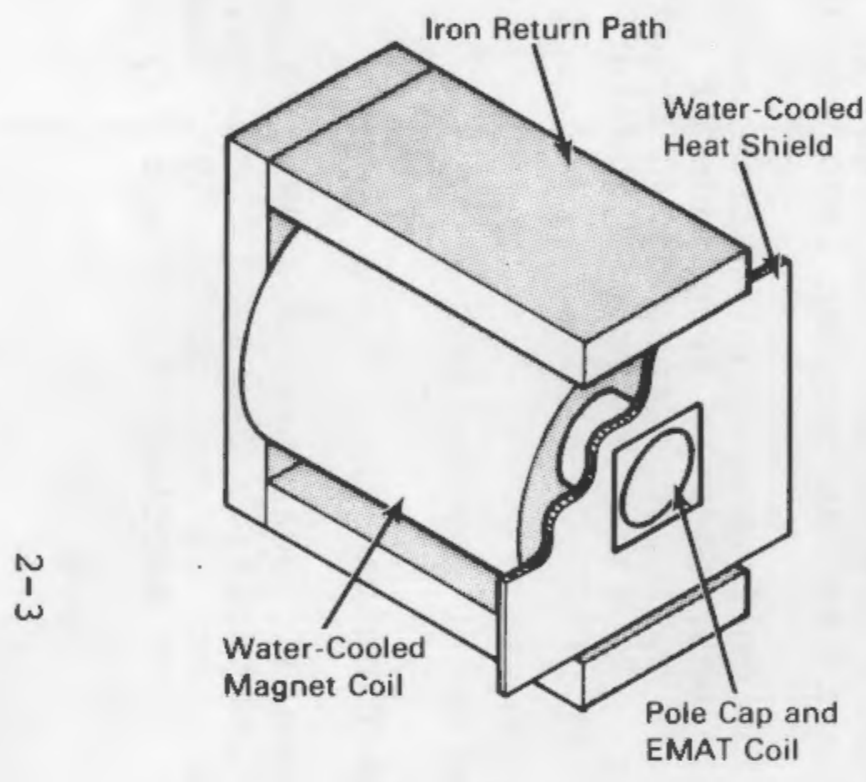

a. 3-D Sketch Showing Overall Shape

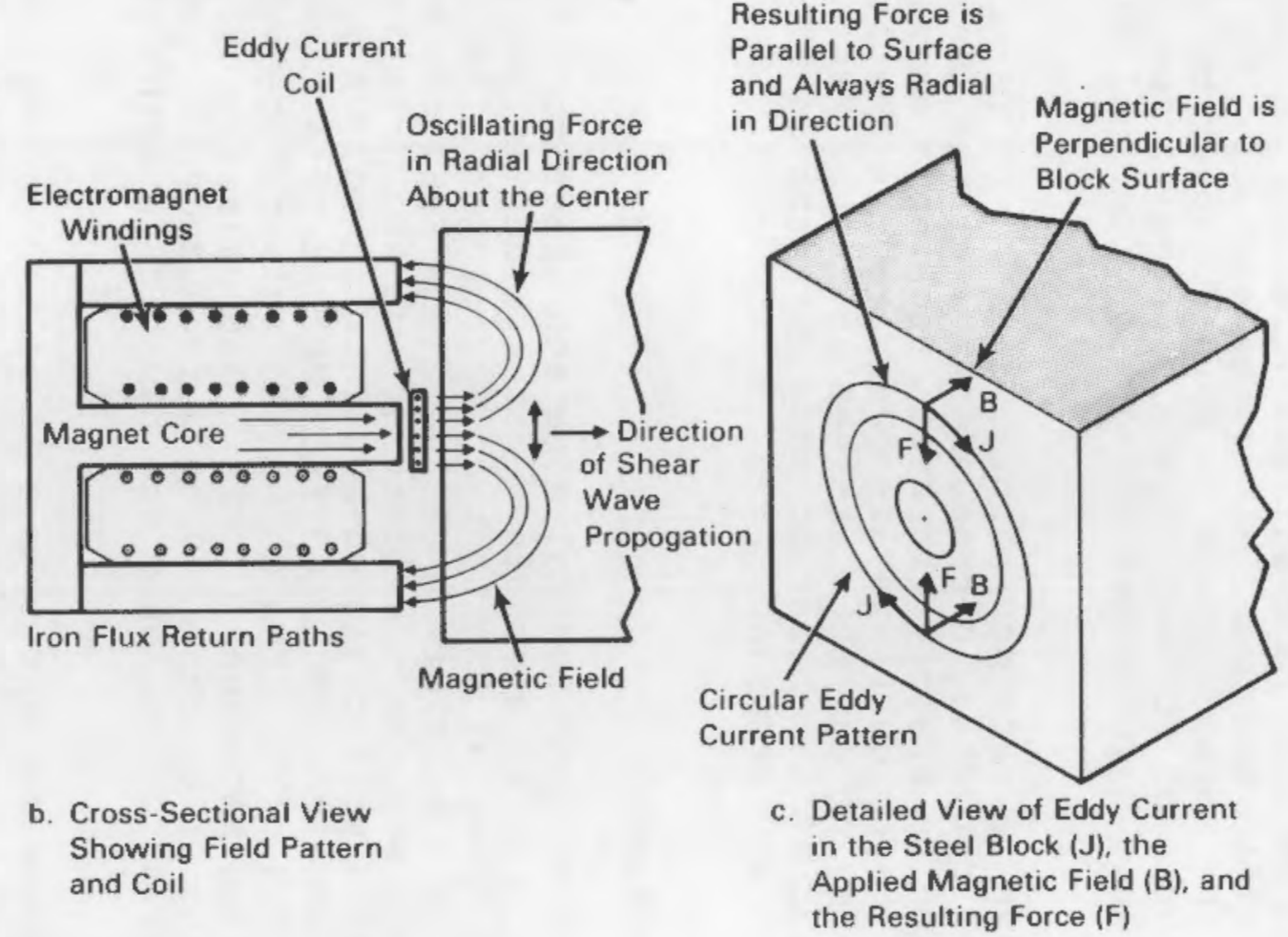

Figure 2.1. Construction and Operation of a Shear Wave EMAT. 
In Figure 2.2 the operation of a longitudinal EMAT is illustrated. The magnet provides a field parallel to the surface. The coil is wound so that near-surface wires run perpendicular to the magnetic field and parallel to the surface. As shown in Figure 2.2C, the Lorentz force is perpendicular to the surface. Hence a burst of current causes a surge in the Lorentz force that generates a compressional or longitudinal wave into the block.

An ultrasonic wave is recorded through an EMAT by reversing the process. The returning ultrasonic wave in the test block causes the surface to sharply vibrate. Because a magnetic field is present, eddy currents are generated in the block and by induction, opposing currents are set up in the EMAT coil. The voltage caused by the burst of eddy currents in the coil is then amplified and recorded.

\subsubsection{EMAT Development}

During Phase II both longitudinal mode and shear mode EMATs were developed. They were obtained using a design/procurement arrangement with Material Engineering Associates of San Leandro, California. MEA is a subsidiary of the Sigma Research Company. Dr. Bruce Maxfield was the president of MEA and principal engineer when the EMATs were designed and fabricated. A pulser/ amplifier unit was also purchased from MEA at this time. Figure 2.3 is a photograph of the EMATs and the pulser/receiver configured for testing hot steel blocks. The pulser provided three cycle bursts of current having a frequency of typically $1 \mathrm{MHz}$. The receiver's frequency was tunable to match the transmitted signal.

A 100- to 125-ampere current from a 28-volt DC power supply was typically used to excite the EMATs. The magnetic field produced at the EMAT pole faces was between 2000 and 4000 gauss.

The steel magnet poles and coils were cooled internally by circulating water. The electromagnets were made of square copper tubing wound into a coil shape and cooled by circulating water through the tubing. To avoid shorting, the tubing was wrapped in insulating tape prior to winding.

\subsection{CHARACTERIZATION OF STEEL SPECIMENS}

\subsubsection{Test Specimen Description}

Test specimens of 1038 steel, 1008 steel and ARMCO iron were supplied by AISI member companies. The 1038 specimen, an unrolled, continuously cast section, was nomimally 5 inches square and 10 inches long. The 1008 section, approximately 6 inches 


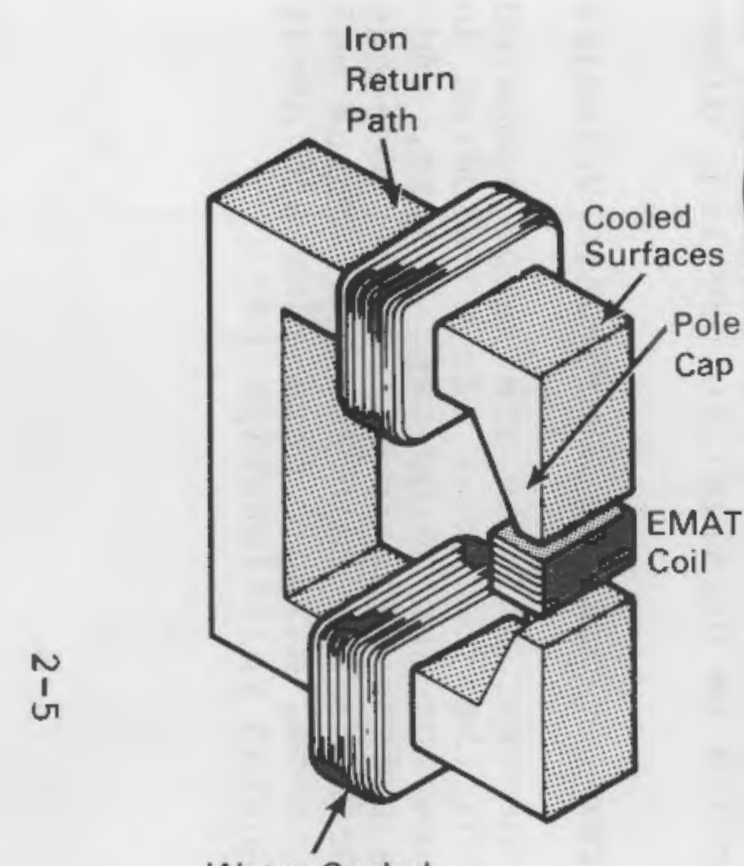

Water-Cooled

Magnet Coil
a. 3-D Sketch of Overall Shape

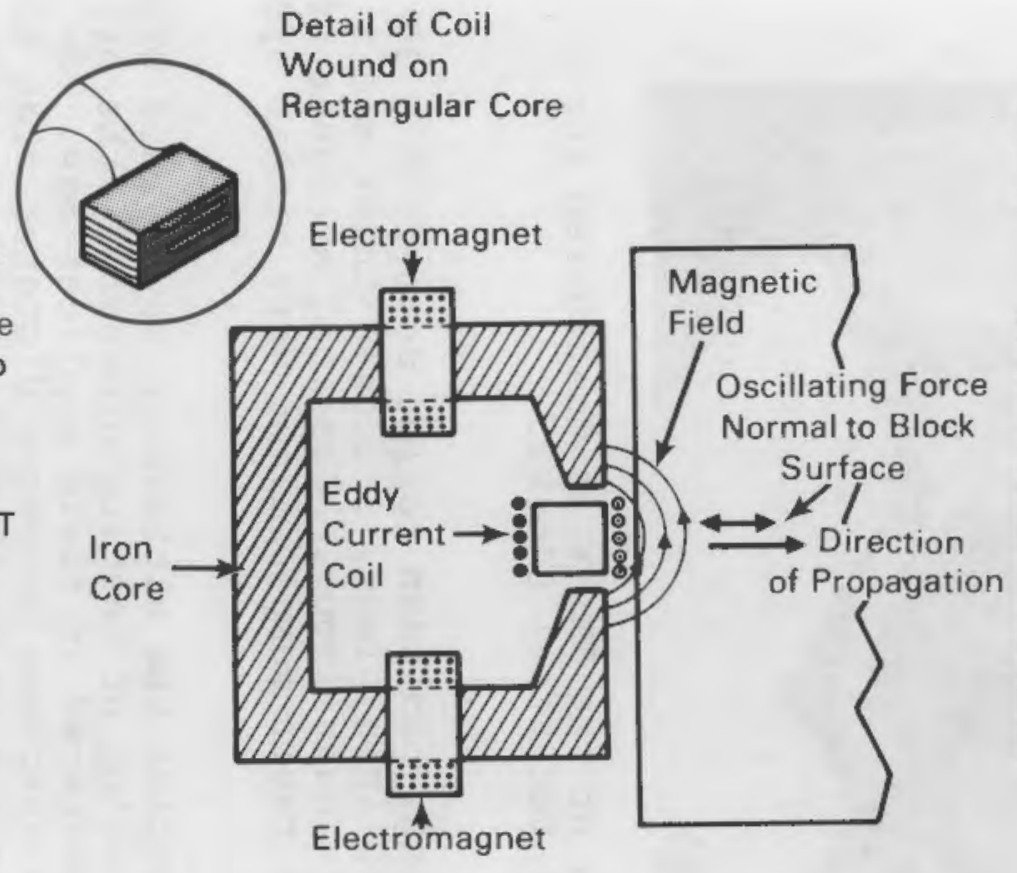
b. Cross-Sectional View Showing Field Pattern and Coil

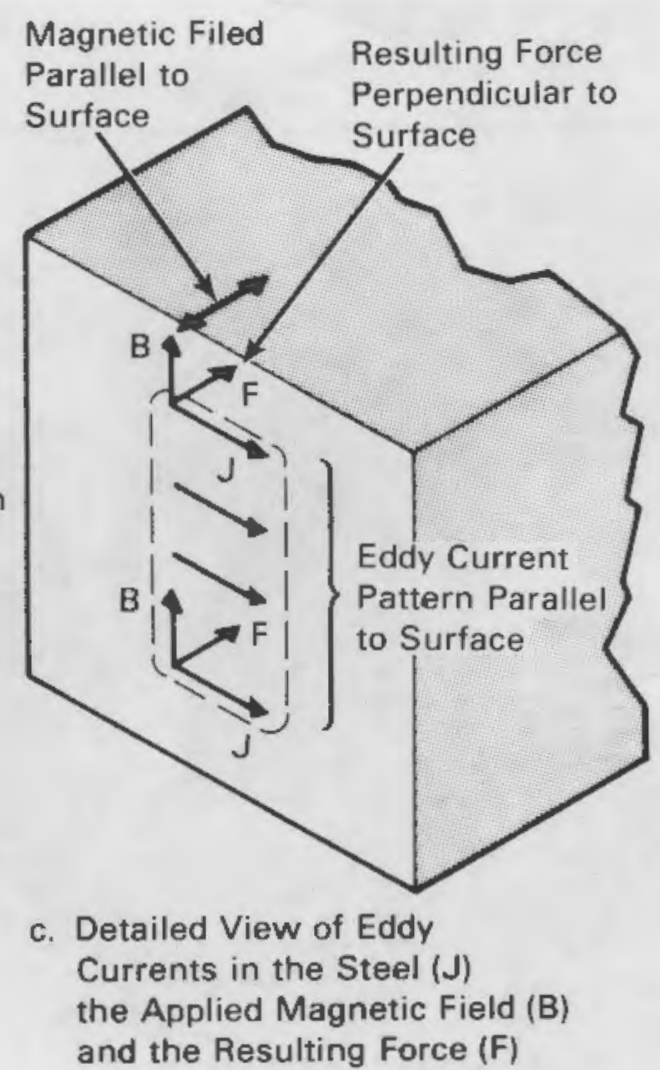

Figure 2.2. Construction and Operation of a Longitudinal Wave EMAT. 


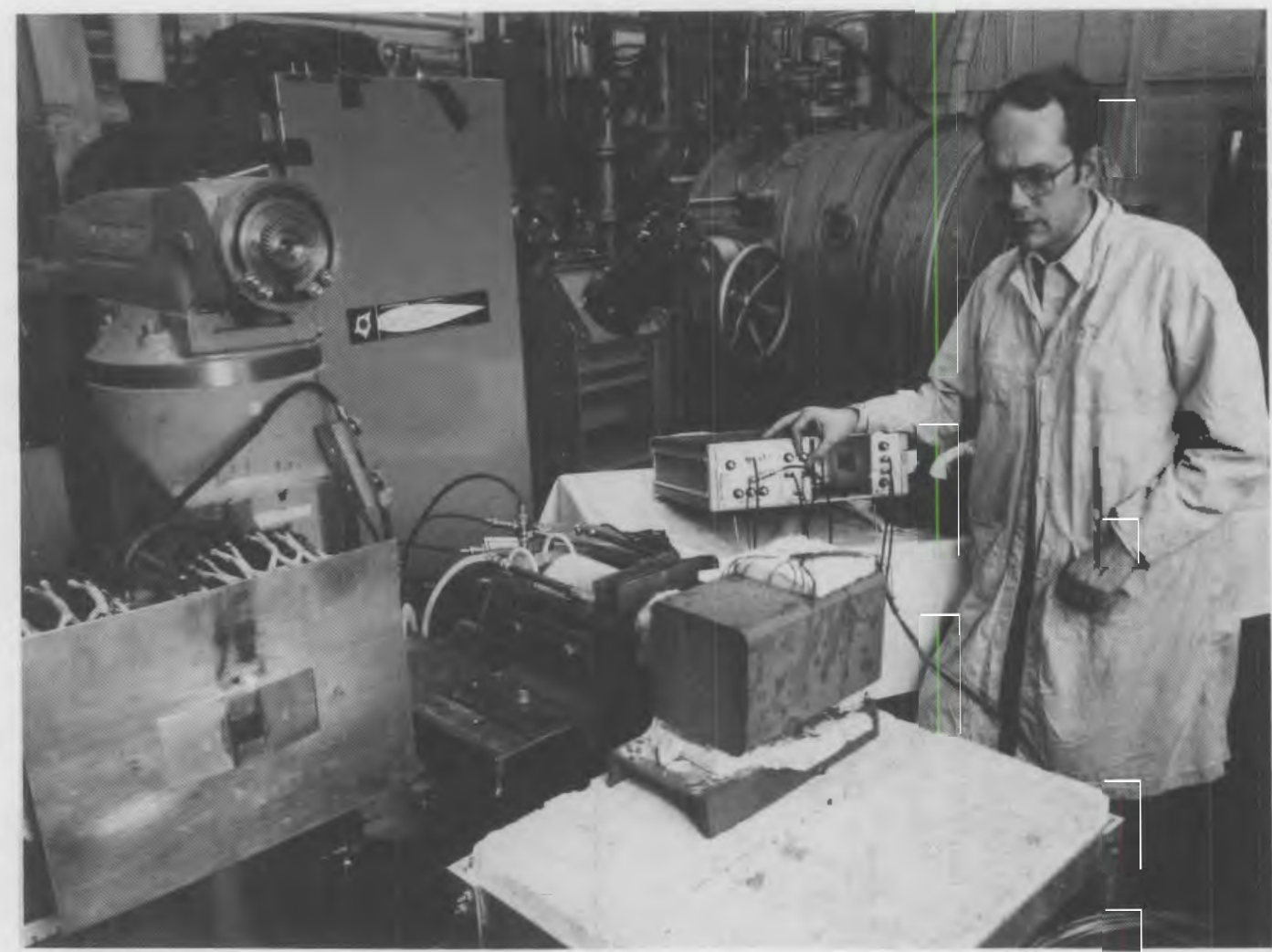

Figure 2.3. Photograph of the EMATs as Configured for Testing on Hot steel Blocks.

square and 11 inches long, had been rolled down from a 30 inch square ingot. The ARMCO iron piece, 3 inches thick and 8 inches square, was taken from a cast ingot. Chemical analyses of the specimens verified that their compositions were within specifications for each alloy.

On the 1008 and 1038 samples the ultrasonic waves were propagated perpendicular to the rolling or casting dimension, the orientation that would be encountered in field applications. On the ARMCO iron section, the specimen geometry dictated that the ultrasonic testing direction be parallel to the long dimension of the ingot.

\subsubsection{Thin Rod Method for Determining ultrasonic Velocities}

When the dimensions of the test objects are large compared to the ultrasonic wavelength, the specimens are considered unbounded. This is the case for the large test blocks, and consequently two wave modes exist. The longitudinal mode has velocity $V_{I}$ and the shear mode has velocity $V_{S}$. These velocities are related to the fundamental elastic constants and density of the material by the following relationships [2]: 


$$
V_{L}=\left[\frac{\lambda+2 \mu}{\rho}\right]^{1 / 2}
$$

and

$$
\mathrm{V}_{\mathrm{S}}=[\mu / \rho]^{1 / 2}
$$

where $\mu$ and $\lambda$ are the Lame constants and $\rho$ is the density. The purpose of the calibration tests is to determine the dependence of $v_{L}$ and $v_{S}$ with temperature and alloy.

The method used for estimating velocities over a temperature range employed a long thin rod made from the test block material. Typically a rod was 0.80 inches in diameter and 1.25 inches long. The rod was spot-welded onto the end of a 18-inch magnetostrictive rod of similar diameter. The thin rod specimen was inserted into a controllable tube furnace where nearly isothermal conditions were created. The actual tube furnace temperature was measured with a calibrated thermocouple.

An elastic wave was generated in the magnetostrictive rod by a special encircling coil and pulser. Once the elastic wave was generated, it separated into an extensional wave and a torsional wave. For these conditions the rod diameter was much smaller than the ultrasonic wavelength, the velocity of the extensional mode waves was [2]:

$$
v_{e}=[E / \rho]^{1 / 2}
$$

and the velocity of the torsional mode wave was

$$
v_{t}=[\mu / \rho]^{1 / 2}
$$

where $E$ is the Young's modulus.

Kolsky [2] shows that the torsional velocity, $v_{t}$, and the shear velocity, $v_{S}$, are equal. Furthermore, the velocity is not dependent on wavelength. Hence, torsional velocities measured by the thin rod method can be used directly in interpreting the shear wave velocities measured on the large blocks.

For extensional waves, the actual velocity decreases with wavelength and the appropriate compensation must be made. Kolsky shows [2] that when the diameter-to-wavelength ratio is less than 0.1 , then the Rayleigh correction can be used. This correction expresses the measured extensional group velocity, $v_{e}{ }^{\prime}$ in terms of the limiting velocity, $v_{e}$ as follows: 


$$
v_{e}{ }^{\prime}=v_{e}\left(1-3 * v^{2} \pi^{2}(a / L)^{2}\right)
$$

where $\mathrm{v}$ is Poisson's ratio (typically 0.29 for steel), a is the rod diameter, and $L$ is the wavelength. When a/L equals 0.1 , the correction increases the limiting velocity approximately 38 for steel.

To derive the longitudinal velocity from the experimentally measured extensional velocity, additional information provided by the definition of Young's modulus is required:

$$
E=\frac{\mu(3 \lambda+2 \mu)}{\lambda+\mu}
$$

Equation 2.1 expresses the longitudinal velocity, $v_{L}$, in terms of the variables $\lambda$ and $\mu$. However, from the two measured velocities, the quantities $E / \rho$ and $[(\lambda+2 \mu) / \rho]$ are known. Therefore, by using equations 2.4 , and 2.6 to change variables, equation 2.1 for $V_{L}$ can be expressed in terms of the quantities $v_{t}$ and $v_{e}$ as follows:

$$
v_{L}=\left\{2 v_{t}^{2}-v_{t}^{2}\left[\frac{2 v_{t}^{2}-v_{e}^{2}}{3 v_{t}^{2}-v_{e}^{2}}\right]\right\}^{1 / 2}
$$

Because the longitudinal wave data collected in Phase II was limited, the analysis focussed on the shear wave data. Consequently, the conversion of the extensional mode velocities into longitudinal mode velocities has not been pursued further.

The National Bureau of standards is estimating the temperature dependence of shear and longitudinal mode velocities in steel. PNL will cooperate with NBS and utilize these data when they become available.

\subsubsection{Velocity versus Temperature Data for Steel Samples}

The average ultrasonic velocity was estimated by dividing the measured ultrasonic path length by the measured time of flight. The path length, however, varied with the thermal expansion and contraction of the specimen. To accurately estimate the ultrasonic velocity, the temperature-compensated path was estimated.

For plain carbon steels, thermal expansion/contraction can be separated into 3 components [3]: a) austenite temperature region ( $T$ > 650 degrees C), b) austenite to ferrite/pearlite phase change temperature region (650 to 790 degrees C), C)

$$
2-8
$$


ferrite/pearlite temperature region ( $T<650$ degrees $C$ ). The percent of thermal shrinkage for each component can be estimated from the appropriate regression equations (corrected to a constant transformation temperature of 650 degrees C).

A specimen cooled to room temperature from above 650 degrees C would pass through all three components. The percent shrinkage for the specimen would be the sum of the shrinkage/expansion from each region.

To investigate the relative impact of thermal shrinkage on the ultrasonic velocity to other velocity-modifying factors, shear wave velocities estimated in the thin rod velocity/temperature calibration experiments were recalculated using corrected path lengths (Table 2.1). A comparison of the shrinkage-corrected velocity curve to the original velocity calibration curve showed that the shear wave velocity was minimally affected by the thermal shrinkage (see Figure 2.4).

Table 2.1. Velocity Calibration Data for 1008 Thin Rod Tests

\begin{tabular}{|c|c|c|c|}
\hline $\begin{array}{l}\text { Temperature } \\
\text { (Celsius) }\end{array}$ & $\begin{array}{c}\text { Shear } \\
\text { velocity } \\
\text { (in/psec) }\end{array}$ & $\begin{array}{l}\text { Corrected } \\
\text { Velocity } \\
\text { (in/ } / \text { sec) }\end{array}$ & $\begin{array}{l}\text { \& Change } \\
\text { in Velocity }\end{array}$ \\
\hline 24 & 0.1294 & 0.1294 & 0.00 \\
\hline 137 & 0.1292 & 0.1294 & 0.17 \\
\hline 191 & 0.1290 & 0.1293 & 0.25 \\
\hline 263 & 0.1280 & 0.1285 & 0.36 \\
\hline 451 & 0.1220 & 0.1228 & 0.63 \\
\hline 561 & 0.1155 & 0.1164 & 0.80 \\
\hline 643 & 0.1076 & 0.1086 & 0.92 \\
\hline 650 & 0.1097 & 0.1102 & 0.48 \\
\hline 681 & 0.1061 & 0.1067 & 0.55 \\
\hline 690 & 0.1053 & 0.1059 & 0.57 \\
\hline 711 & 0.1030 & 0.1037 & 0.62 \\
\hline 733 & 0.1015 & 0.1022 & 0.67 \\
\hline 770 & 0.0986 & 0.0993 & 0.76 \\
\hline 793 & 0.0974 & 0.0982 & 0.81 \\
\hline 809 & 0.0965 & 0.0974 & 0.85 \\
\hline
\end{tabular}

Figure $2.4 \mathrm{~b}$ shows the data from Table 2.1 along with data from a second thin rod test. The unexpected increase in velocity at 650 degrees $C$ seen in the first test appears to be an anomaly caused by a change in the rate of heating. The comparison of the two tests shows that the expansion/contraction bias may be insignificant relative to intersample variations. 


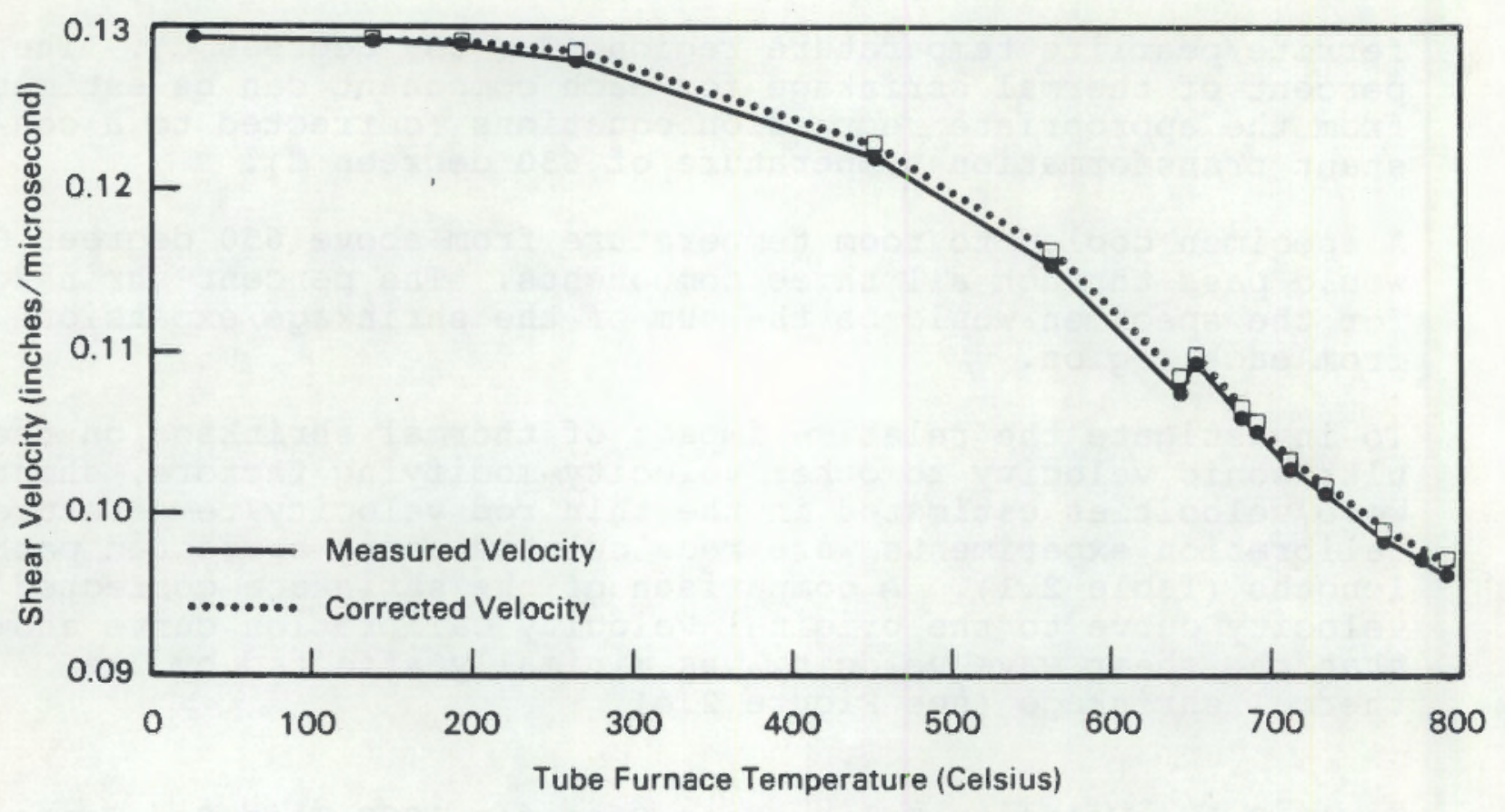

Figure 2.4a. Thin Rod Shear Wave Velocity Versus Temperature with and without Expansion Correction.

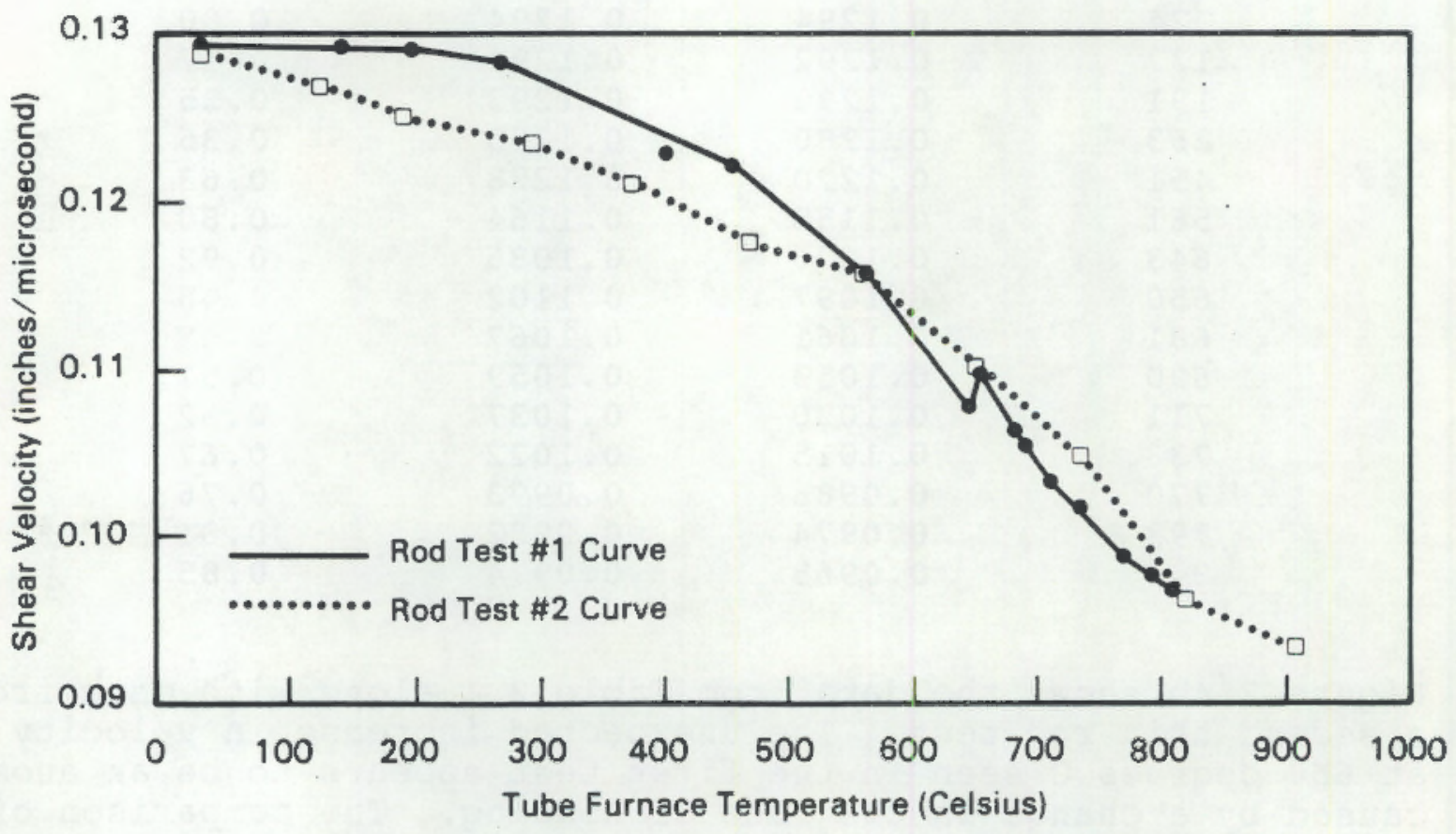

Figure 2.4b. Calibration on Temperature vs. Shear Velocity Data Obtained on Two Different Thin Rod Tests. 


\subsection{EXPERIMENTAL METHODS AND DATA COLLECTION ON FURNACE-HEATED BLOCKS}

\subsubsection{The Furnace and Heating Procedure}

A muffle furnace with silicon carbide resistance elements heated the solid steel specimens. It's protective atmosphere was an endothermic-gas-generated mixture of air and propane that had passed through a nickel alloy retort containing a 1100 degrees C catalyst. The propane was cracked into its basic constituents and combined with the oxygen. The air-propane ratio was adjusted to an atmosphere of $36 \%$ hydrogen and $18 \%$ carbon monoxide with traces of methane and carbon dioxide.

Figure 2.5 shows a steel block being removed from the furnace. When the door was opened a flame curtain was generated to maintain the protective atmosphere inside. The 5 and 6 inch thick blocks required approximately 3 hours to heat from room temperature to 900 degrees $c$. The test blocks, with thermocouples installed, showed uniform profile temperatures while heating to the target temperature.

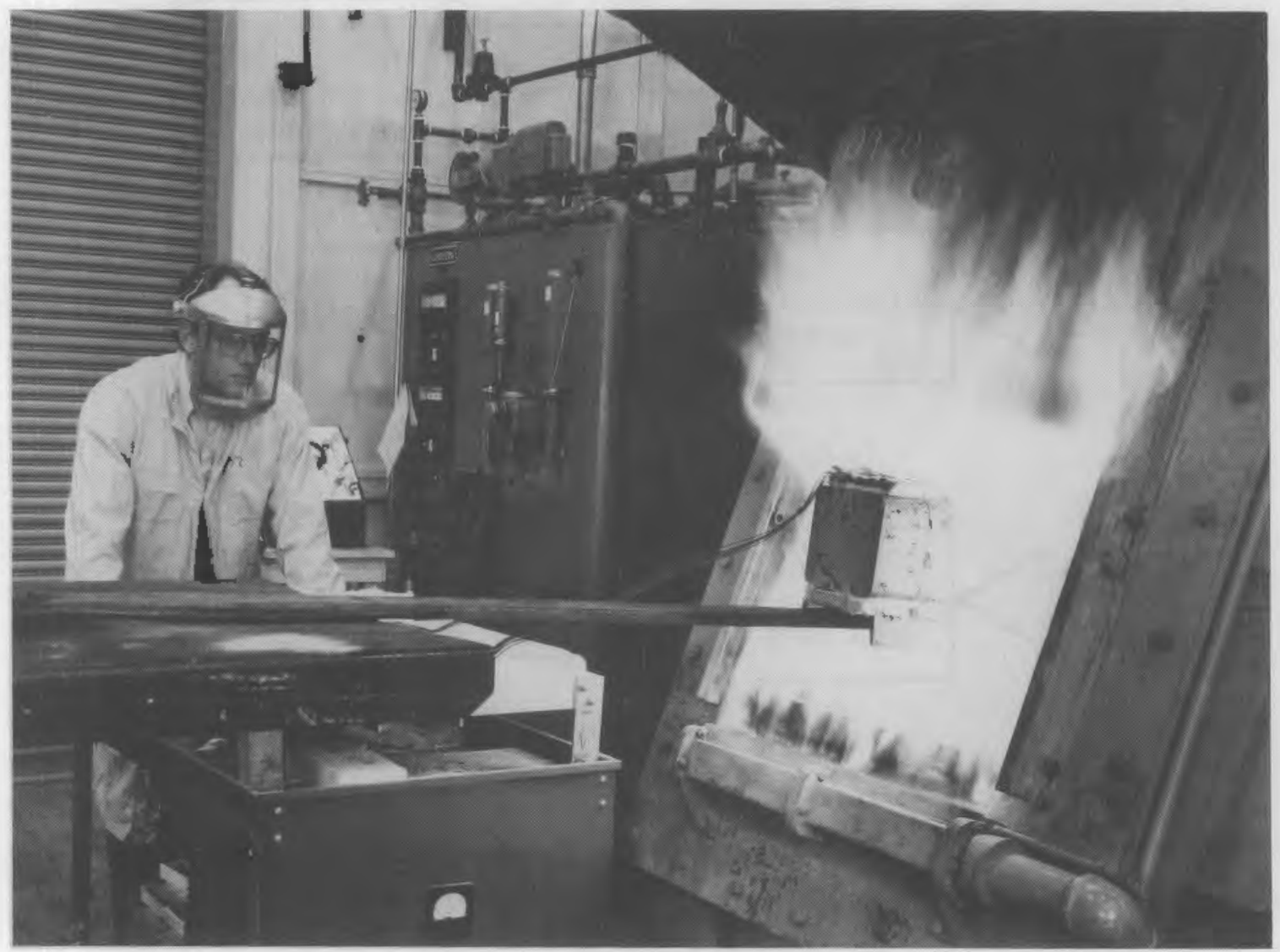

Figure 2.5. Photograph of a Hot Steel Block Being Removed from the Furnace. 
When the block reached the target temperature, it was removed from the furnace, placed on a cart, and partially insulated. The block was then rolled to the EMATs for testing.

\subsubsection{The EMAT and Thermocouple Data Acquisition System}

The data acquisition system is shown in block diagram form in Figure 2.6. The EMAT pulser/receiver subsystem is shown in more detail in Figure 2.7.

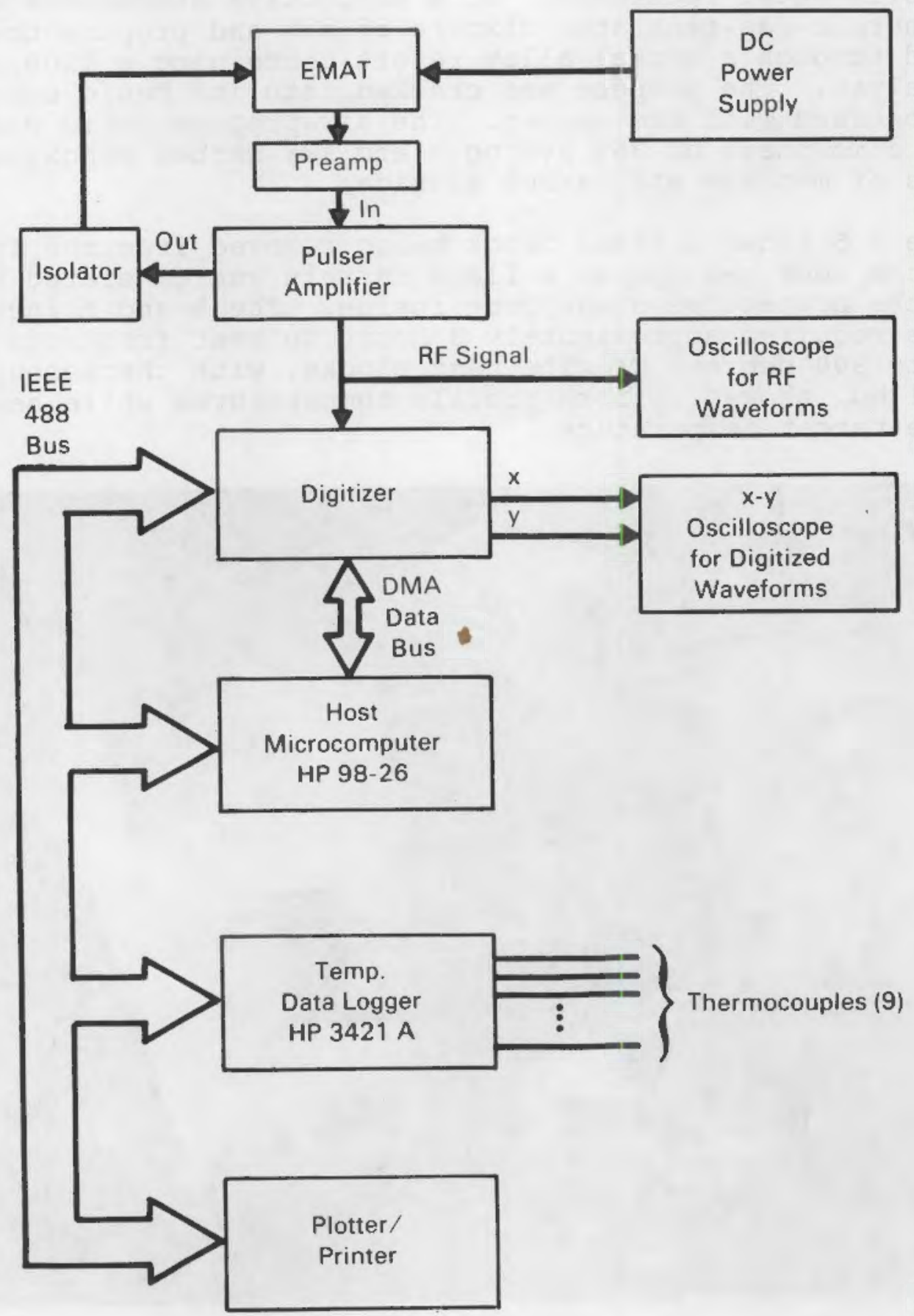

Figure 2.6. Block Diagram of the EMAT and Temperature Data Acquisition System. 


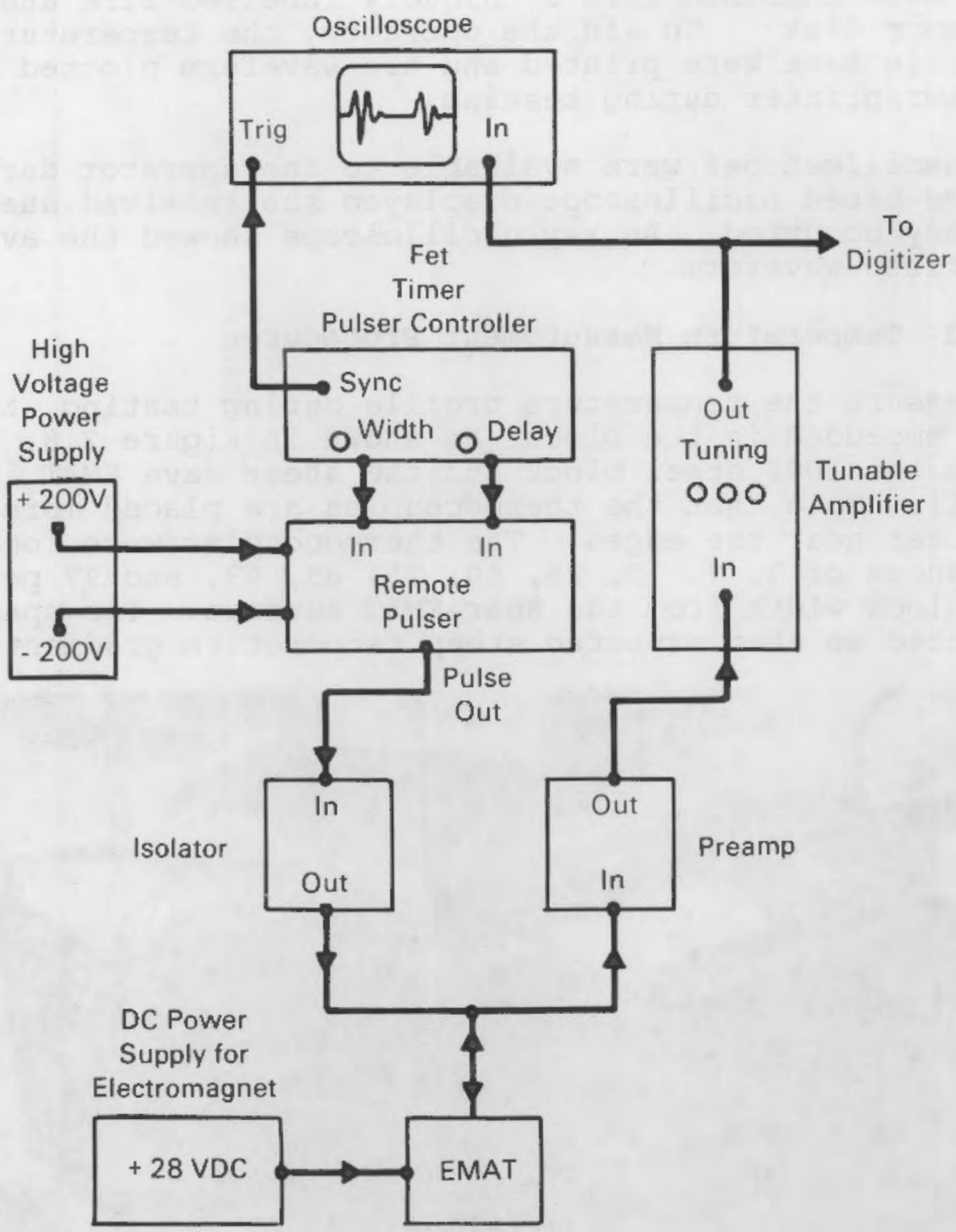

Figure 2.7. Detailed Diagram of the EMAT and Its Pulser/ Receiver system.

Data was collected in the following manner. The EMAT pulser/ receiver generated an ultrasonic pulse and received a return echo at a rate of $100 \mathrm{~Hz}$. The operator initiated echo recording using a "softkey" command on the microcomputer. The digitizer then captured and averaged ten waveform echoes, and output one averaged waveform per second. The data logger simultaneously sampled the nine thermocouple voltages and transferred the data to the computer. The averaged waveform was transferred to the computer over a high speed Direct Memory Access (DMA) bus to 
shorten the total transfer time. The temperature and waveform data were combined into a uniquely labelled file and stored on a floppy disk. To aid the operator, the temperature values and file name were printed and the waveform plotted on the plotter/printer during testing.

Two oscilloscopes were available to the operator during testing. A time-based oscilloscope displayed the received analog signals as they occurred. An $x-y$ oscilloscope showed the averaged, digitized waveform.

\subsubsection{Temperature Measurement Procedures}

To measure the temperature profile during testing, thermocouples were embedded in the blocks as shown in Figure 2.8. This figure shows the 1008 steel block and the shear wave EMAT in more detail. Note that the thermocouples are placed more closely together near the edges. The thermocouples were located at distances of $3,7,15,25,50,75,85,93$, and 97 percent of the block width from the near-EMAT surface. The spacing was selected so that expected steep temperature gradients near the

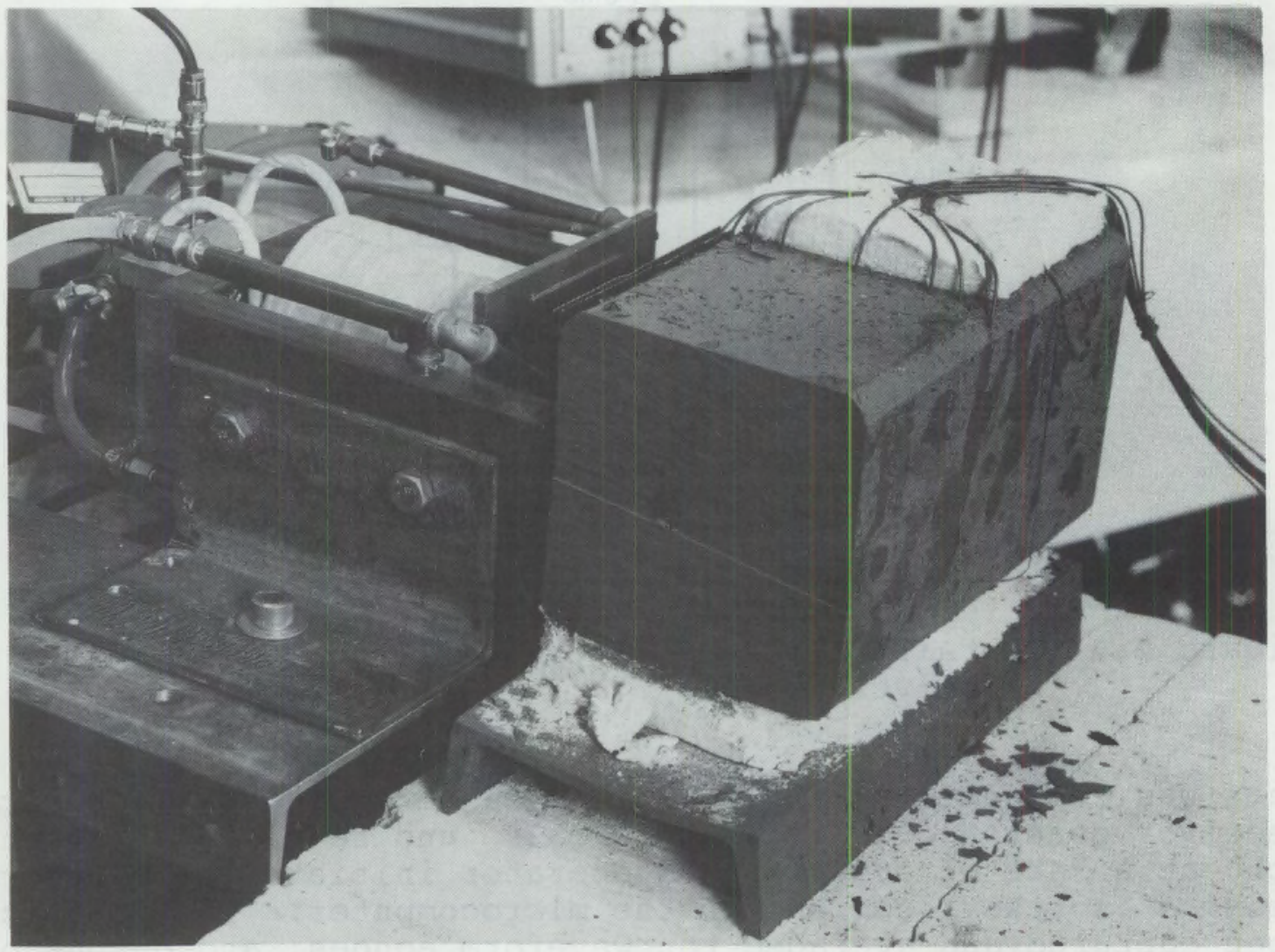

Figure 2.8. Close-up View of the Thermocouples Embedded in the 1008 steel Block. 
ends of the ultrasonic path could be sampled thoroughly. A near parabolic distribution was expected across the sampled dimensions. The test data supported this expectation.

The thermocouples extended one inch into the top surface of the block. The top, bottom, and ends of the block were insulated to minimize vertical and axial temperature gradients. (Note that in Figure 2.8 most insulation has been removed for clarity.) Thermodynamic modelling of the partially insulated block indicated that the gradients between the center and the insulated surfaces would be one-tenth the size of the gradients between the center and the noninsulated front and back faces. Consequently, the temperatures measured by the embedded thermocouples should be within a few degrees of the temperatures along the centered ultrasonic path.

One type $\mathrm{K}$ thermocouple was calibrated at four temperatures between 20 degrees $C$ and 1000 degrees $C$ by the thermocouple vendor. Temperature deviations were 1 degree $C$ at 540 degrees $C$ and 2 degrees $C$ at 1000 degrees $C$. These imply a positive bias of 0.28 . A standard 9 degree polynomial for type $K$ thermocouples converted millivolts to degrees with an accuracy of \pm 1 degree $C$. This thermocouple served as the reference or standard. The other thermocouples used in the experiments were fabricated from the same material lot and were assumed to have similar properties.

The thermocouple datalogger (a Hewlett-Packard $3421 \mathrm{~A}$ Data Acquisition and Control Unit) contained the reference junction and a calibrated thermistor to measure the junction temperature. The datalogger automatically compensated for the reference junction temperature and output the transformed thermocouple temperatures over the digital bus. The calibration of the reference junction compensation was periodically verified by immersing the test thermocouples in an ice bath. Through the above procedures the temperature inside the hot blocks were estimated.

The errors associated with the thermocouple measurements were small when compared with the expected accuracy of the ultrasonic estimation method ( 1 or 2 degrees C compared to 20 to 25 degrees C). Therefore, the embedded thermocouples provided a valid comparison for evaluating the accuracy of the ultrasonic method.

\subsubsection{Waveform Data Acquisition Procedures}

\section{Calibration Verification procedure and Results}

When operating within calibration specifications, the digitizer should have consistently sampled the signal amplitude at 0.05 $\mu$ second intervals for the sampling rate of $20 \mathrm{MHz}$. To evaluate the precision of the digitizer and verify its calibration, bursts

$$
2-15
$$


generated by a calibrated time mark generator were digitized. The known interburst time intervals ( $10 \mu \mathrm{sec}$ or $50 \mu \mathrm{sec}$ ) were compared with the time intervals estimated from the digitized signals.

The pulser generated two waveform sets of 5 and 9 waveforms with voltage spikes occurring every 10 and $50 \mu \mathrm{sec}$, respectively. The waveforms were digitized at an expected sampling rate of one sample per $0.05 \mu$ seconds with the voltage spikes appearing as sharp rising peaks (see Figure 2.9). Inter-peak times were estimated using the TOF program (see 3.0 , Software

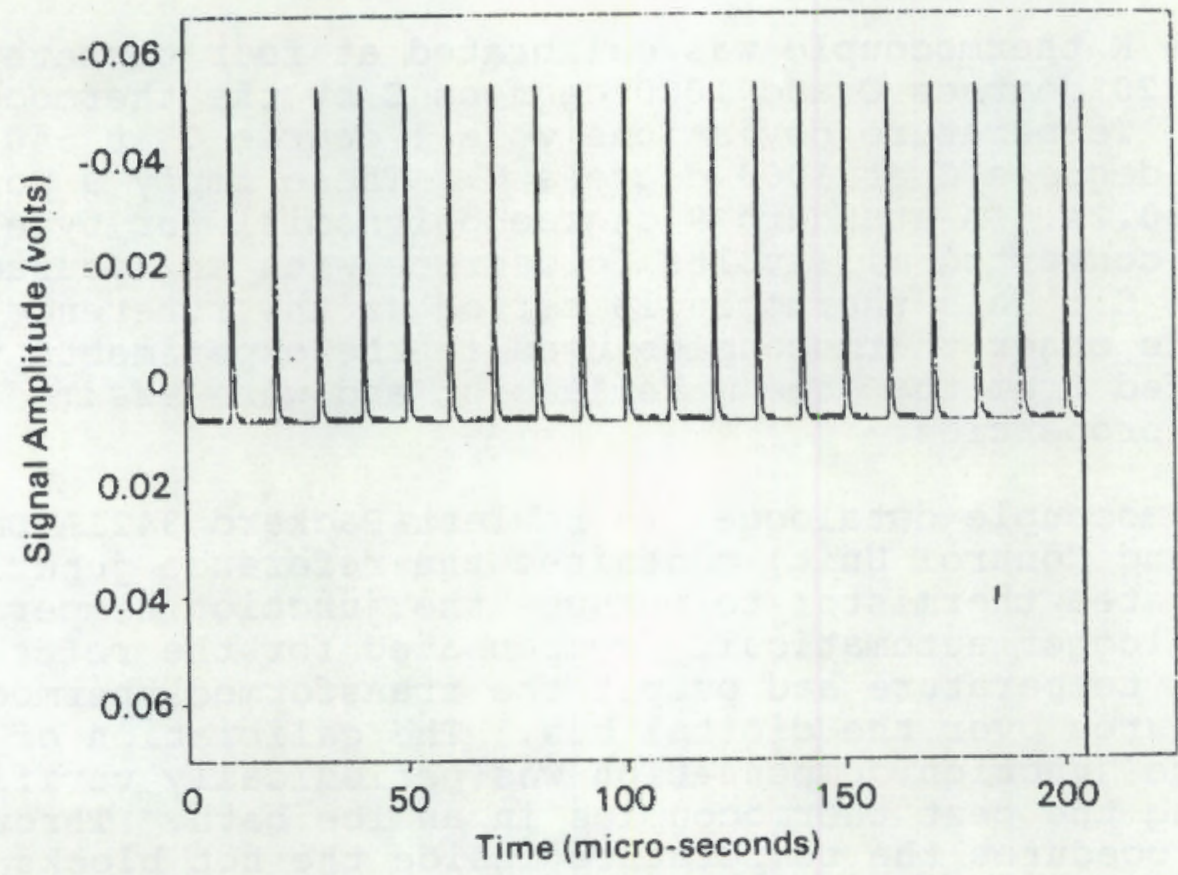

Figure 2.9. Graph of Pulses from a Calibrated Time Mark Generator to Verify Calibration of the Waveform Digitizer.

Development) with a noise threshold of 0.005 volts. An interpeak average time and standard deviation were then computed for each waveform. Figure 2.10 shows a detailed view of two successive peaks.

The verification results are summarized in Table 2.2 . 


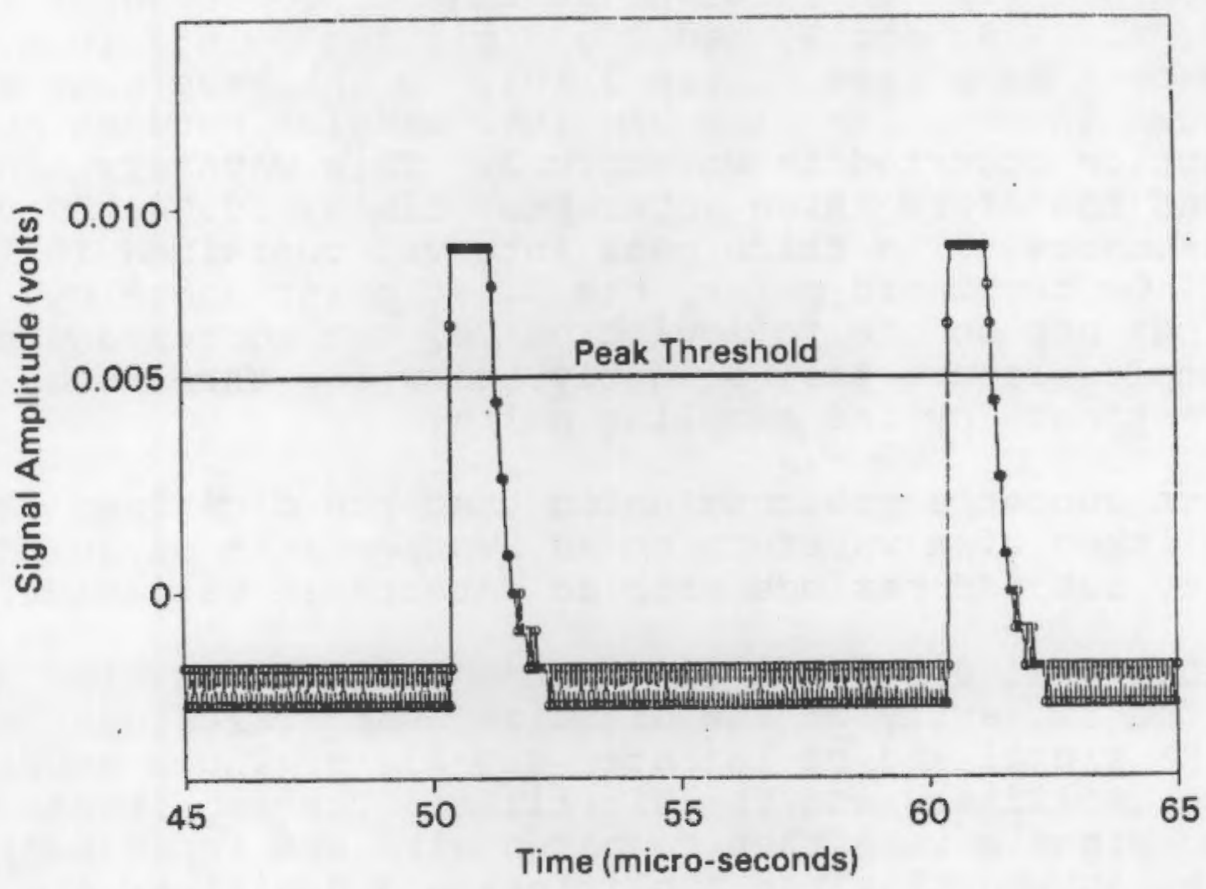

Figure 2.10. Detailed Graph of Two Successive Pulses from the Time Mark Generator.

Table 2.2. Time Intervals for Calibration Pulses

Waveform ID

1 CALIBR. 101

2 CALIBR. 102

3 CALIBR. 103

4 CALIBR. 104

5 CALIBR. 105

6 NEWCAL. 104

7 NEWCAL. 105

8 NEWCAL.106

9 NEWCAL. 107

10 NEWCAL. 108

11 NEWCAL.109

12 NEWCAL. 110

13 NEWCAL.111

14 CALIB6.101
Time

\begin{tabular}{|c|c|c|}
\hline Pulse & $\begin{array}{c}\text { Peak } \\
\text { Average }\end{array}$ & \begin{tabular}{l}
\multicolumn{1}{c}{ Peak } \\
Standard \\
Deviation
\end{tabular} \\
\hline
\end{tabular}

$$
10.0
$$

10.00

50.0

50.0

50.0

50.0

10.0

10.0

10.0

10.0

50.0

50.0

50.0

50.0

50.0

50.02

50.00

50.00

50.00

10.00

10.00

10.00

10.00

50.00

50.00

50.00

50.00

50.00
0.0

0.03

0.0

0.0

0.0

0.0

0.0

0.0

0.0

0.0

0.0

0.0

0.0

0.0
Peak

count

21

4

4

4

4

21

21

21

21

4

4

4

4

4 
Each waveform with an inter-pulse time of $10 \mu$ seconds (waveforms $1,6,7,8$, and 9) had 200 digitized points from peak mark to peak mark (see Figure 2.10). Eight waveforms with a $50 \mu$ second inter-pulse time had 1000 samples between pulses. An exception occurred in waveform 2. This waveform had four peaks and therefore three inter-peak times; 50.00, 50.00, and $50.05 \mu$ seconds. The third peak interval contained 1001 digitized points. On the third pulse, the first point above the threshold was found; but on the following pulse, the corresponding point, 1000 samples later, fell slightly below the threshold, causing an overestimate by one sampling point.

This data supports the conclusion that the digitizer samples the amplitude of a waveform at an average rate of $20 \mathrm{MHz}$ during 10 and $50 \mu$ second periods with no detectable variation.

Although signal amplitude was not as critical as time measurements, the linearity of the digitizer was evaluated. A calibrated RF signal source injected signals of known amplitude into the amplifiers and the digitizer. The amplitudes of the recorded signals were then compared with the input amplitudes. This test showed that the amplifiers and digitizer are linear.

\section{Waveform Description}

A digitized waveform contained serially ordered samples of the amplitude of an EMAT's received signal. Digitizing began prior to pulse transmission and continued until 4096 samples were collected. The elapsed time spanned by the digitized waveform was dependent upon the sampling (digitization) rate. The sampling rate for this testing was $20 \mathrm{MHz}$ so that $204.8 \mu$ seconds of signal were digitized. Ten sequential waveforms were digitized and integrated to reduce background noise. The integrated waveform was stored for later analysis.

The $20 \mathrm{MHz}$ digitization rate allowed times of flight (TOF) to be estimated to within typically $0.10 \mu$ seconds. Times of flight were calculated using the computer program TOF (see section 3.3.3, Developed Software, for a description of the program). The TOF program located significant peaks within each signal and computed the time between successive round-trip echo signals.

A digitized ultrasonic waveform began with $10 \mu$ seconds of background noise (Plots $2 \mathrm{~A}$ and $2 \mathrm{~B}$ ). The next $7 \mu$ seconds contained the transmitted UT pulse. The remaining $192 \mu$ seconds contained the UT echoes integrated with the recorded background noise. The maximum amplitude of the recorded background noise was typically -0.005 volts to +0.005 volts, while the transmitted UT pulse saturated the sensor at \pm 0.13 volts. The maximum variation observed in the ultrasonic echoes was 0.06 volts to -0.06 volts, Variation in echo amplitude was dependent upon 
wave mode type, specimen composition, specimen dimensions, and block temperature for the most part.

\section{EMAT Set Up Procedures}

A difficult, but extremely important, procedure was to properly set up and match the pulser and receiver frequencies. The pulser/receiver unit allows the operator to select from one to eight current pulses per pulse packet to be generated. Experience showed that 3 pulses was a good compromise. One pulse gives greater bandwidth and time resolution but with the accompanying greater background noise that comes with bandwidth. More than three pulses causes the pulse packet to be so long in time that peak resolution is lost. A second adjustment sets the pulse width. The EMATs were designed to operate between $0.5 \mathrm{MHz}$ and $1.0 \mathrm{MHz}$. A pulse period of 1 millisecond was selected since it is the one wavelength period at frequency. (The current pulse was monitored by using a clip-on current probe.) The last step tuned the receiver amplifier to match the frequency of the returned echo. The return echo was observed on an oscilloscope and the filter adjusted until a maximum amplitude was achieved.

The set-up procedure was executed at 20 degrees $C$ for the shear wave EMAT since it operated well at room temperature. The process was complicated by the fact that the steel block's conductivity and permeability changed with heating. These properties influenced the impedance of the EMAT coil and hence its operation. Tuning the longitudinal mode EMAT was more difficult still because its signals cannot be detected at room temperature. So its tuning was optimized during testing on hot steel. 


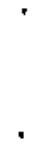

· 


\section{SECTION 3.0 \\ WAVEFORM ANALYSIS SOFTWARE}

\subsection{SOFTWARE OVERVIEW}

A series of software programs were written to transfer and reformat the data, compute times of flight, calculate weighted average temperature, correct for block expansion, and plot the data. Programs were written in Fortran for many of the applications. Other applications were handled through widely used, commercially available software such as the statistical Analysis Software package (SAS). The following describes the structure of the data files that were transferred to a DEC VAX 11/780 for analysis and the Fortran programs written to manipulate these data files.

\subsection{DATA FILE STRUCTURE}

A transferred data file, or raw waveform file, was ASCII coded and contained 417 records, each having 10 integer values. The first seven records were header information transferred as the decimal equivalent of ASCII code. The following 410 records contained the digitized waveform values stored as ASCII integers. The header information contained the waveform ID, block ID, date, time, waveform type, time of flight, sampling rate, data recording voltage range, and the temperature data. The temperature data was the nine thermocouple temperatures in degrees $C$ listed in location order from the near-EMAT surface to the far surface. The temperatures were recorded at the same time the ultrasound pulse was sent into the block. The waveform data was 4096 samples of the received signal amplitude.

\subsection{FORTRAN PROGRAMS}

\subsubsection{Program RDCHECK}

RDCHECK automated the review of the transferred files. The program was driven by a list of the waveform IDs which also functioned as VAX filenames. The program read a filename from the list and then processed the file before addressing the next waveform. The program read header information from each data file and output the translated header information into a summary file listing the waveform ID, whether or not the transferred file contained both temperature and waveform data, waveform type (longitudinal or shear wave), date, and time. With the summary list the descriptions of each ultrasonic sample from a cycle were quickly scanned. 
The RDCHECK sumary file was the driver file for the following analysis programs after sorting the file on the Date and Time.

\subsubsection{Program RDSTEEL}

RDSTEEL converted the raw transferred cata to a form compatible with the analysis environment. The program transformed the integer coded amplitudes to voltages. The temperature data was split from the header and waveform, and written to a cycle summary file containing the chronologically ordered temperature profiles for the cycle being processed.

RDSTEEL read the RDCHECK-produced waveform list, processing the data files one at a time. The program calculated the elapsed time since sampling began, converting sampling time to cycle seconds elapsed.

RDSTEEL converted the waveform units. Each waveform, the integrated sum of four digitized sequential waveforms, contained 4096 sample points at 10-bit amplitude resolution. Each waveform amplitude was subsequently divided by four and translated to voltages by the following formula:

$$
\begin{aligned}
\text { millivolts }= & {[((\text { integer amplitude-512)/80.)/512]* }} \\
& {[\text { data recording range]. }}
\end{aligned}
$$

RDSTEEL output an ASCII waveform file for each raw waveform file read in. The output waveform file contained header information in records 1 through 17 as follows:

\begin{tabular}{cl}
$\begin{array}{r}\text { Record } \\
\text { No. }\end{array}$ & Name \\
\hline 1 & file \\
2 & block \\
3 & date \\
4 & time \\
5 & prop \\
6 & flight \\
7 & samp \\
8 & range \\
9 & temp 1 \\
10 & temp 2 \\
11 & temp 3 \\
12 & temp 4 \\
13 & temp 5 \\
14 & temp 6 \\
15 & temp 7 \\
16 & temp 8 \\
17 & temp 9
\end{tabular}

\section{Description}

waveform ID (waveform filename) block type (1008, 1038, Armco) sampling date sampling time propagation mode (wave type) time of flight (missing value) sampling zate (digitization rate) amplitude voltage range near-EMAT thermocouple temperature thermocouple temperature 2 thermocouple temperature 3 thermocouple temperature 4 mid-block thermocouple temperature thermocouple temperature 6 thermocouple temperature 7 thermocouple temperature 8 far-EMAT thermocouple temperature 
The header information in an output waveform file was followed by 512 records of converted waveform amplitude samples, eight per record.

RDSTEEL also output a chronologically ordered sumary temperature file containing one record for each waveform file processed. The record contained the waveform ID, date, time, elapsed time, wave type, time of flight (still a missing value at this point), and the nine temperature profile values.

\subsubsection{Program TOF}

Program TOF located peaks in the digitized waveform and calculated the time interval between successive peaks, called the time of flight (TOF).

Like RDSTEEL, TOF was list driven. TOF processed, one at a time, only those files that contained waveform data as indicated by the "wave type" variable and skipped "temperature only" files.

The TOF program searched the 4096 points in the waveform for amplitudes beyond a set threshold. The peak threshold, set in a program data statement, was estimated from field plots of the waveforms generated during the experiment. The peak threshold was set between the noise level and the minimum of all the peaks. The TOF program then searched a subset of the waveform point by point for the first value in each set of values above the peak threshold and recorded its index (Plot 24). The program successfully found the peaks and ignored the noise.

To speed up processing, search windows were set for the peaks. From the plots, sample indices were identified where the program should start searching for the first peak and subsequent peaks. The search window location can also be calculated from calibration velocities, temperature, and block thickness. The threshold was also lowered for each successive search window. The search window indices were set in data statements. During processing, the program searched for a peak in the first search window. When TOF found a peak, it recorded the index of the first point above the peak threshold. After finding a peak, the program immediately skipped to the next search window.

To calculate the time of flight between two peaks, the first sample index was subtracted from the second sample index. If only one peak, the input amplitude, was found, no time of flight was calculated. To convert units from sample index to $\mu$ seconds, the time of flights were divided by the sampling rate of 20 MHz. TOF chose the first calculated time of flight as the representative time of flight for that waveform. 
TOF output two files. The first file contained the time of flights and peak positions along with the same header information as the input temperature file, created by RDSTEEL. The second file was an update of the input temperature file, the missing value code in the time of fight column replaced by the calculated time of flight.

\subsubsection{Program GRID}

The temperature data was not evenly spaced spatially nor temporally. An evenly spaced grid had to be estimated to plot the temperature profile surface for a cycle. The gridded temperature surface was estimated from the location as a decimal percent block thickness ( $\mathrm{X}$ axis), elapsed time or average temperature ( $Y$ axis), and local temperature ( $Z$ axis). The nine location values $(0.03,0.07,0.15,0.25,0.50,0.75,0.85,0.93$, and $0.97)$ were placed in a data statement in the program code. The temperature in degrees $c$ and time in seconds or average temperature were read from the input temperature data file.

The program used the IMSL routines "ICSICU" and "ICSEVU" [4] for cubic spline interpolation to grid the surface. "IsCICU" calculated gridding parameters and "ICSEVu" used these to interpolate between data points to estimate an evenly spaced grid. The user specified the density of the grid. GRID interpolated twice; first along the $Y$ axis and then along the location axis. It wrote the gridded temperature surface data to an output data file. The output file had three columns; location, time, and temperature where each record represented one grid node.

\subsubsection{Program RAW}

RAW reformatted the ungridded time and temperatures from the RDSTEEL temperature file to match the GRID program output. Both the raw and gridded output files were then input to the same plotting routine. RAW operated like GRID, storing the nine location values in data statements and reading the temperature and time values from the input temperature file.

\subsubsection{Graph Production Programs}

SAS, a widely used commercial software package, along with Minigraph, a Battelle in-house plotting package, were used to graph all two-dimensional plots.

PLOT3D, a modified version of a DISSPLA 3-D plotting routine plotted the temperature surfaces. The plots graphically displayed the cooling of the steel blocks over time. 
PLOT3D produced 3-D plots of the gridded and raw temperature data. The data plots of the GRID program output are smooth. Plots of the data from the RAW program have spikes showing where data were sampled. The height of the spike corresponded to the observed thermocouple temperature value. 
• 


\section{SECTION 4.0 \\ DATA ANALYSIS AND RESULTS}

\subsection{EXPERIMENTS ON 1008 STEEL}

During the first heating, the internal temperature of the 1008 steel block reached 895 degrees $C$. The block was removed from the furnace and data were collected over a 16-minute period. The back of the block was insulated and the front face was exposed to the EMAT. At the end of this period, the front surface temperature had cooled to 754 degrees $C$ and the back surface temperature had cooled to 831 degrees $c$. The block was then placed into the furnace to be reheated.

After one hour the block temperature reached 950 degrees $\mathrm{C}$. The block was removed from the furnace and insulated only on the top, bottom, and ends. The front and back surfaces were exposed to ambient conditions. The L-wave EMAT was placed in contact with the block and signals were transmitted every two or three minutes during cooling. When the near-EMAT thermocouple temperature was 789 degrees $C$ and the center temperature was 874 degrees $C$, the longitudinal wave signals first became detectable. The amplitude of the signals increased for a few records and then decreased as cooling continued. These waveforms are shown in Figure 4.1. After the near-EMAT thermocouple temperature was 721 degrees $C$ and the center temperature was 771 degrees $C$, the longitudinal wave signals were undetectable.

Data from the second cooling cycle of the 1008 specimen have been analyzed and are reported in this section. The ultrasonic waveforms were recorded approximately every two minutes over a 63-minute cooling cycle. The initial mid-block temperature of 942 degrees $C$ declined to 524 degrees $C$ at an average cooling rate of 6.63 degrees $C$ per minute. After early frequent sampling, sampling frequency decreased just minutes prior to cycle termination. A smoothed graph of temperature versus thermocouple location versus average profile temperature (Figure 4.2) shows the evolution of the temperature profile throughout the cooling cycle. The supporting data for the smoothed surface is found in the spike plot (Figure 4.3) where each vertical line indicates a sampled temperature.

The change in the temperature gradient across the temperature profile surface is sharply illustrated by the smoothed graph of the thermocouple temperature minus the integrated average profile temperature versus location versus integrated average profile temperature (Figure 4.4). As seen, the early interiorto-surface differences of 60 degrees $C$ or more decrease to differences of 20 degrees $C$ or less. The profiles for this run retained symmetric surface to surface cooling throughout the cooling cycle. 

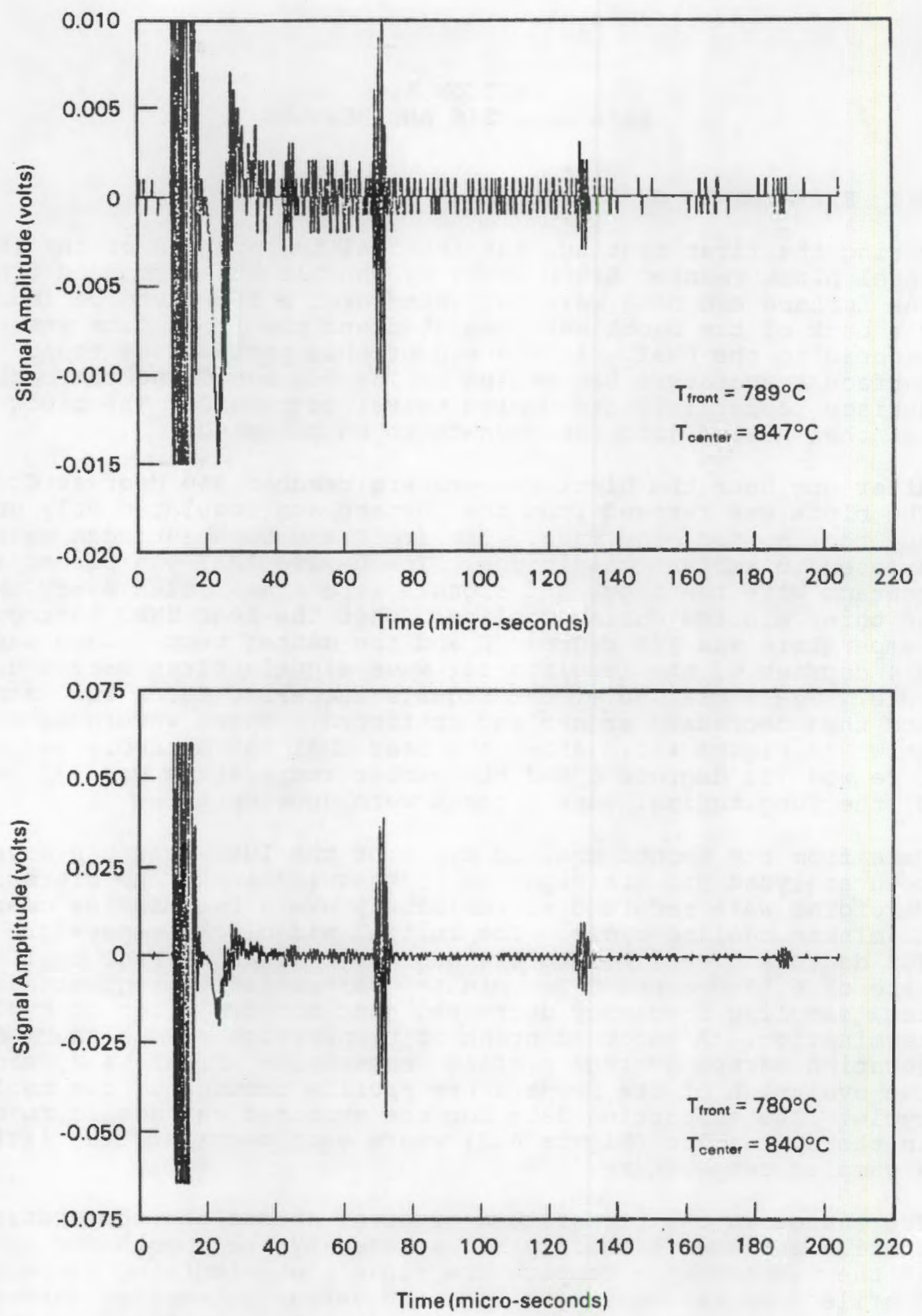

Figure 4.1. Plots of Longitudinal Mode Waveforms from the 1008 Steel Block. Temperatures are noted on each panel. 

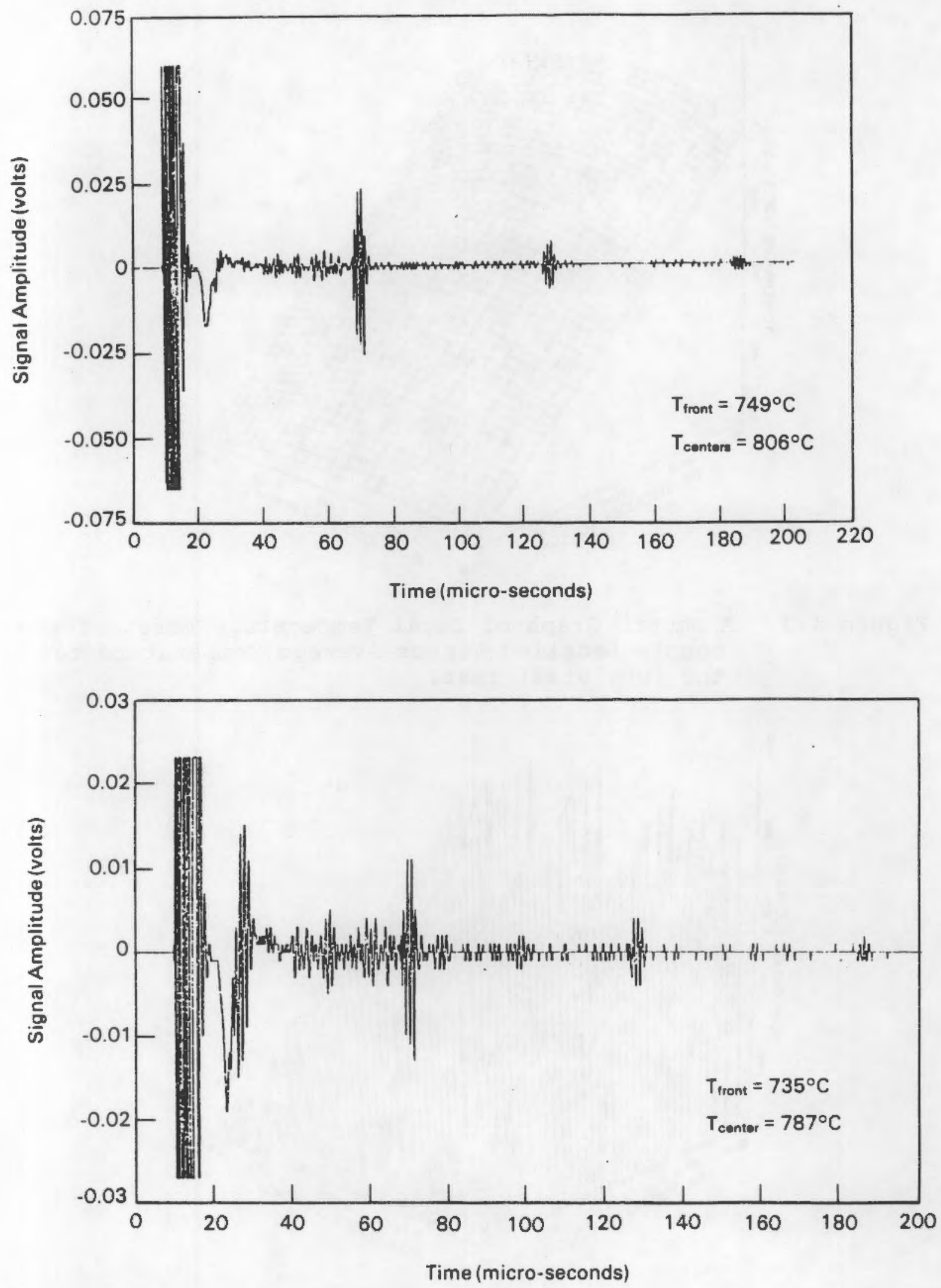

Figure 4.1 (cont'd) 


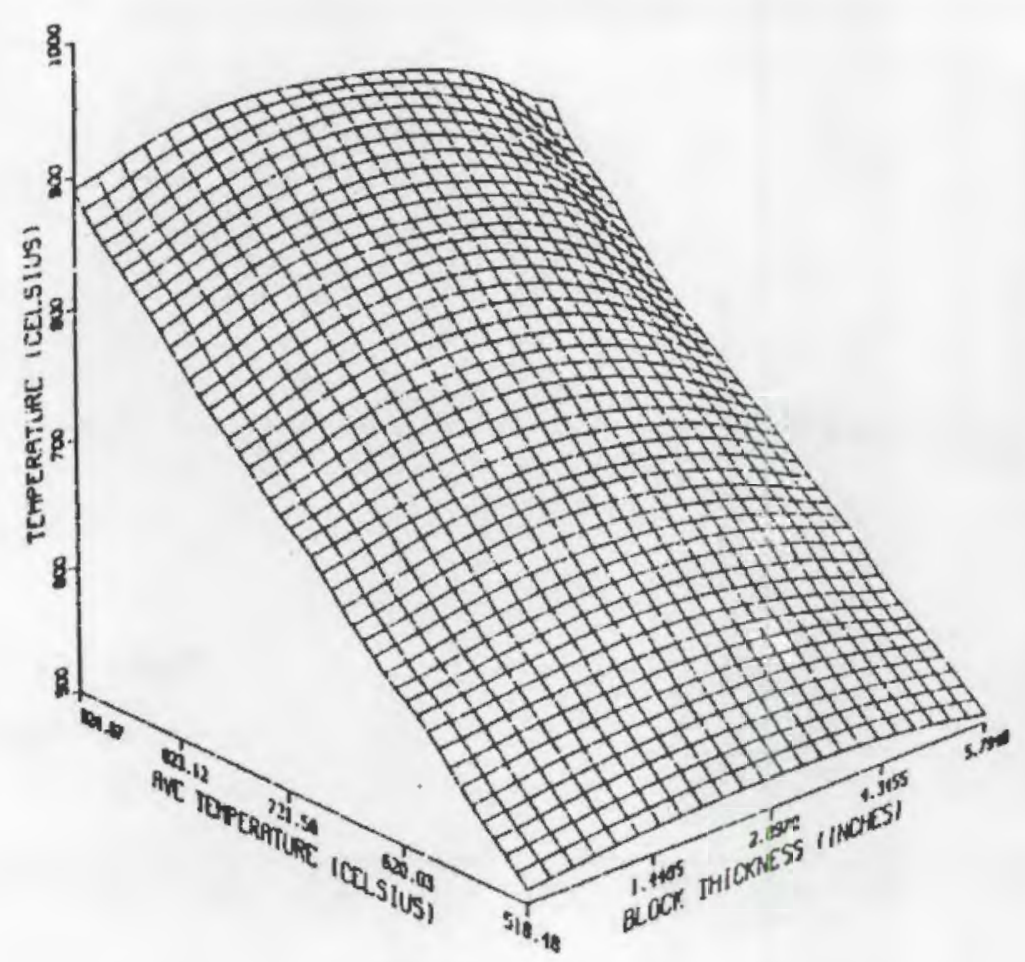

Figure 4.2. A Smooth Graph of Local Temperature Versus Thermocouple Location Versus Average Temperature for the 1008 steel Test.

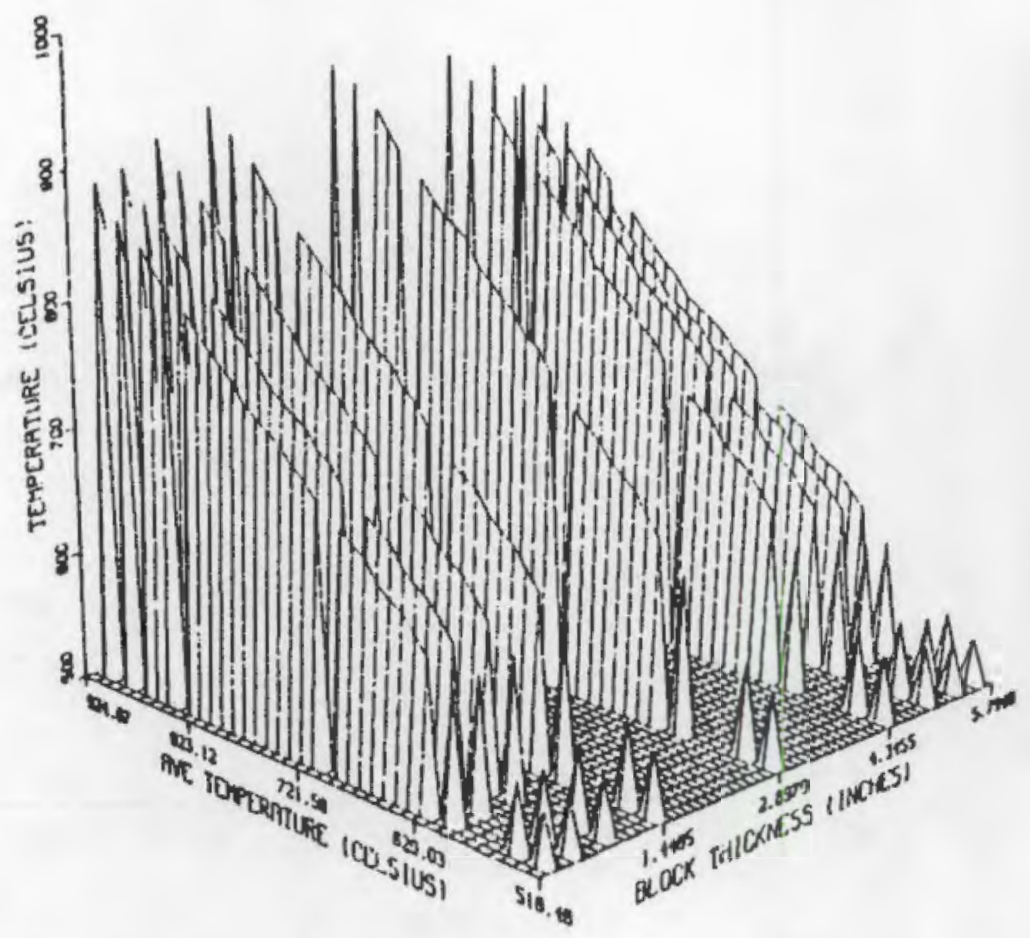

Figure 4.3. The Supporting Data for the Temperature Surface Shown in Figure 4.2 


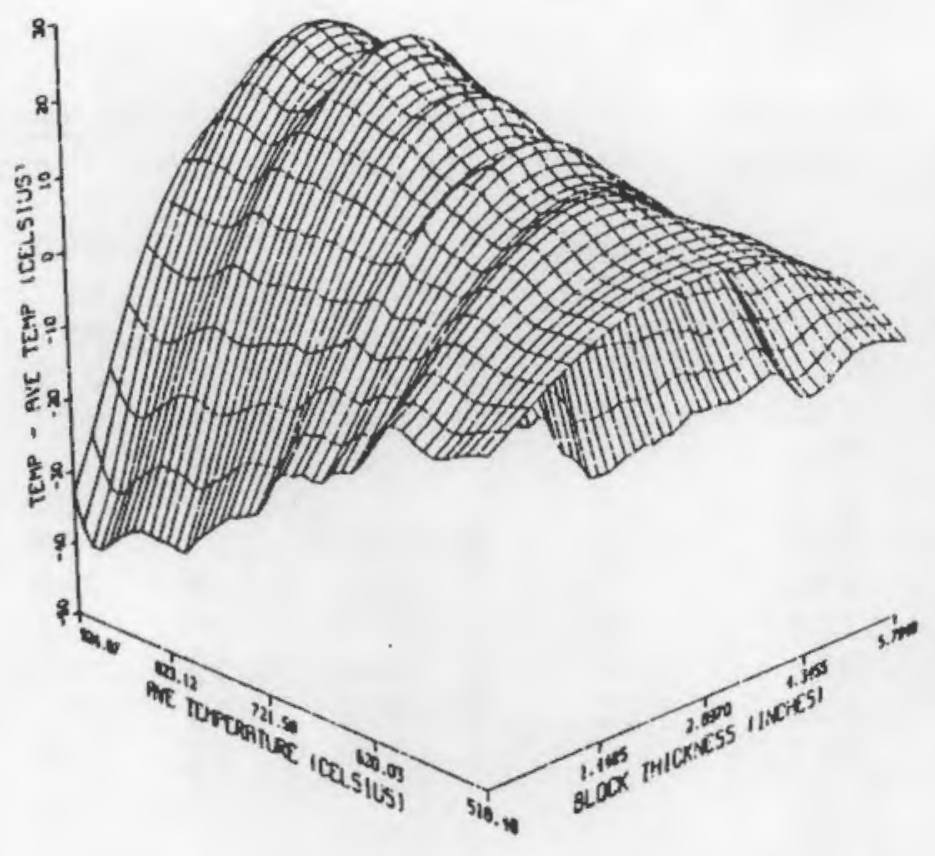

Figure 4.4. Graph of the Thermocouple Temperature Minus the Average Temperature as a Function of Location and Average Temperature.

As documented in Table 4.1, echoes were not detected and velocities could not be calculated for the first seven waveform samples. Longitudinal velocities were found for the next nine samples while the EMAT's magnetic field was enhanced during the phase transformation of the steel sample (see Figure 4.5). The mid-block temperature during the enhancement period ranged from 847 degrees C to 778 degrees C. Velocities fluctuated between 0.1941 inches/second and 0.1995 inches/second. The up-down-up relationship between longitudinal velocities and block temperature found for this run was not expected nor supported by the literature [4]. Visual examination of the waveforms found low signal-to-noise ratios. The TOF program could not accurately estimate a representative time of flight. Therefore, the velocity values for the two lower temperatures and the highest temperature are considered suspect.

The run showed that longitudinal waveforms can be detected and longitudinal velocities calculated if the signal-to-noise ratio is adequate. However, the temperature/TOF relationship for longitudinal waveforms must be further clarified. 
Table 4.1. Velocity as a Function of Temperature for the 1008 Steel

Waveform ID $1008 \mathrm{H} 2.101$ $1008 \mathrm{H} 2.102$ $1008 \mathrm{H} 2.103$ $1008 \mathrm{H} 2.104$ $1008 \mathrm{H} 2.105$ $1008 \mathrm{H} 2.106$ $1008 \mathrm{H} 2.107$ $1008 \mathrm{H} 2.108$ $1008 \mathrm{H} 2.109$ $1008 \mathrm{H} 2.110$ $1008 \mathrm{H} 2.111$ $1008 \mathrm{H} 2.112$ $1008 \mathrm{H} 2.113$ $1008 \mathrm{H} 2.114$ $1008 \mathrm{H} 2.115$ $1008 \mathrm{H} 2.116$ $1008 \mathrm{H} 2.117$ $1008 \mathrm{H} 2.118$ $1008 \mathrm{H} 2.119$ $1008 \mathrm{H} 2.120$ $1008 \mathrm{H} 3.101$ $1008 \mathrm{H} 3.102$ $1008 \mathrm{H} 3.103$ $1008 \mathrm{H} 3.104$ $1008 \mathrm{H} 3.105$ $1008 \mathrm{H} 3.106$ $1008 \mathrm{H} 3.107$ $1008 \mathrm{H} 3.108$ 1008H3.109 $1008 \mathrm{H} 3.110$ 1008H 3.111 $1008 \mathrm{H} 3.112$ $1008 \mathrm{H} 3.113$ 1008H 3.114
Elapsed Time

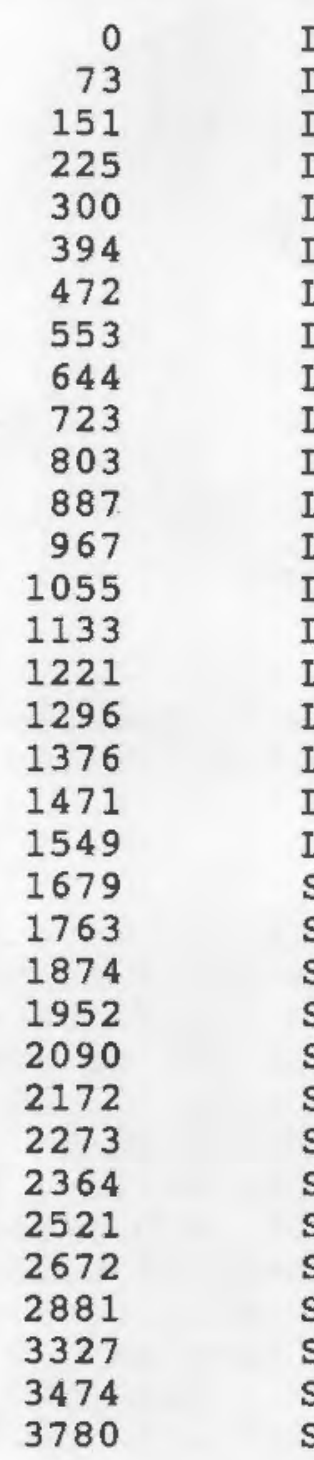

Wave Velocity Mode in/usec.
Block Temperature (Cel.)

$\begin{array}{llllll}\text { L } & \quad & 924 & 890 & 942 & 891\end{array}$

$\begin{array}{llllll}\mathrm{L} & \quad & 907 & 867 & 932 & 866\end{array}$

$\begin{array}{llllll}\mathrm{L} & \text {. } & 891 & 851 & 917 & 849\end{array}$

$\begin{array}{llllll}\mathrm{L} & \text {. } & 877 & 839 & 903 & 836\end{array}$

$\begin{array}{llllll}\mathrm{L} & . & 864 & 827 & 888 & 825\end{array}$

$\begin{array}{llllll}\mathrm{L} & \text {. } & 848 & 812 & 871 & 804\end{array}$

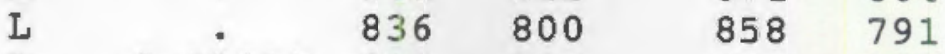

$\begin{array}{llllll}L & 0.1941 * & 825 & 789 & 847 & 780\end{array}$

$\begin{array}{llllll}\mathrm{L} & 0.1974 & 816 & 780 & 841 & 769\end{array}$

$\begin{array}{llllll}\mathrm{L} & 0.1978 & 807 & 771 & 834 & 761\end{array}$

$\begin{array}{llllll}\mathrm{L} & 0.1981 & 799 & 763 & 825 & 753\end{array}$

$\begin{array}{llllll}\mathrm{L} & 0.1984 & 790 & 757 & 815 & 746\end{array}$

$\begin{array}{llllll}\text { L } & 0.1989 & 782 & 749 & 806 & 739\end{array}$

$\begin{array}{llllll}\mathrm{L} & 0.1995 & 773 & 742 & 796 & 732\end{array}$

$\begin{array}{llllll}\text { L } & 0.1971 & 765 & 735 & 787 & 725\end{array}$

L $\quad 0.1943^{*} 757 \quad 728 \quad 778 \quad 718$

$\begin{array}{llllll}\mathrm{L} & \text {. } & 750 & 722 & 771 & 712\end{array}$

$\begin{array}{llllll}\mathrm{L} & \text {. } & 743 & 715 & 764 & 706\end{array}$

$\begin{array}{llllll}\mathrm{L} & \text {. } & 735 & 708 & 756 & 699\end{array}$

$\begin{array}{llllll}\mathrm{L} & \text {. } & 728 & 702 & 749 & 693\end{array}$

$\begin{array}{llllll}\text { S } & 0.1035 & 714 & 692 & 732 & 682\end{array}$

$\begin{array}{llllll}S & 0.1040 & 707 & 687 & 724 & 676\end{array}$

$\begin{array}{llllll}S & 0.1046 & 699 & 679 & 715 & 668\end{array}$

$\begin{array}{llllll}\mathrm{S} & 0.1051 & 693 & 673 & 708 & 663\end{array}$

$\begin{array}{llllll}\mathrm{S} & 0.1059 & 682 & 663 & 697 & 653\end{array}$

$\begin{array}{llllll}S & 0.1064 & 676 & 657 & 693 & 648\end{array}$

$\begin{array}{llllll}\mathrm{S} & 0.1070 & 668 & 649 & 685 & 641\end{array}$

$\begin{array}{llllll}S & 0.1076 & 661 & 643 & 676 & 635\end{array}$

$\begin{array}{llllll}S & 0.1084 & 647 & 630 & 660 & 623\end{array}$

$\begin{array}{llllll}\mathrm{S} & 0.1090 & 634 & 618 & 646 & 612\end{array}$

$\begin{array}{llllll}\mathrm{S} & 0.1100 & 613 & 603 & 625 & 589\end{array}$

$\begin{array}{llllll}S & 0.1119 & 564 & 553 & 572 & 548\end{array}$

$\begin{array}{llllll}S & 0.1124 & 549 & 539 & 556 & 535\end{array}$

$\begin{array}{llllll}\text { S } & 0.1135 & 518 & 510 & 524 & 506\end{array}$

* indicates that velocity values are expected to be spurious. 


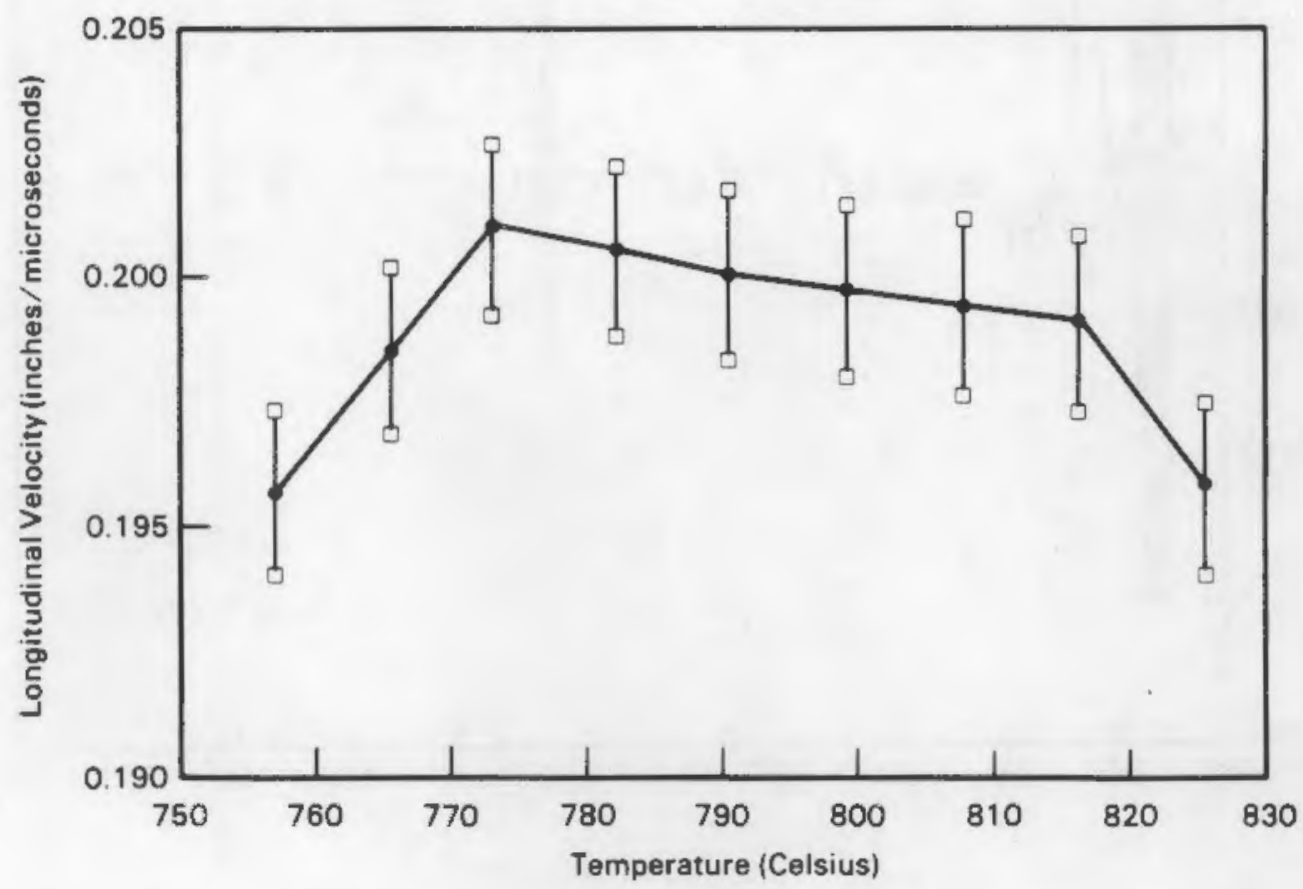

Figure 4.5. Graph of Average Longitudinal Velocity Versus Average Temperature for the 1008 Steel Block.

As the specimen cooled further, waveform sampling continued with the shear wave EMAT. The initial mid-block temperature for this series was 732 degrees $C$. Shear velocities for 14 consecutive samples were calculated. Selected waveforms are shown in Figure 4.6. The velocity-versus-temperature data is shown in Figure 4.7 .

The results for the second cooling cycle of the 1008 steel specimen are listed in Table 4.1 .

\subsection{EXPERIMENTS ON 1038 STEEL}

T'wo cooling cycles for the 1038 continuously cast steel block were examined. The first had 11 waveform samples and the second 27 samples. The second run is discussed here.

Mid-block temperatures varied from 875 degrees $C$ at the start of the second run to 520 degrees $C$ when monitoring ceased 37 minutes later (see Figure 4.8 ). The average rate of cooling was 9.59 degrees $C / m i n u t e$ (875-520 degrees $C$ ). Mid-block to surface 

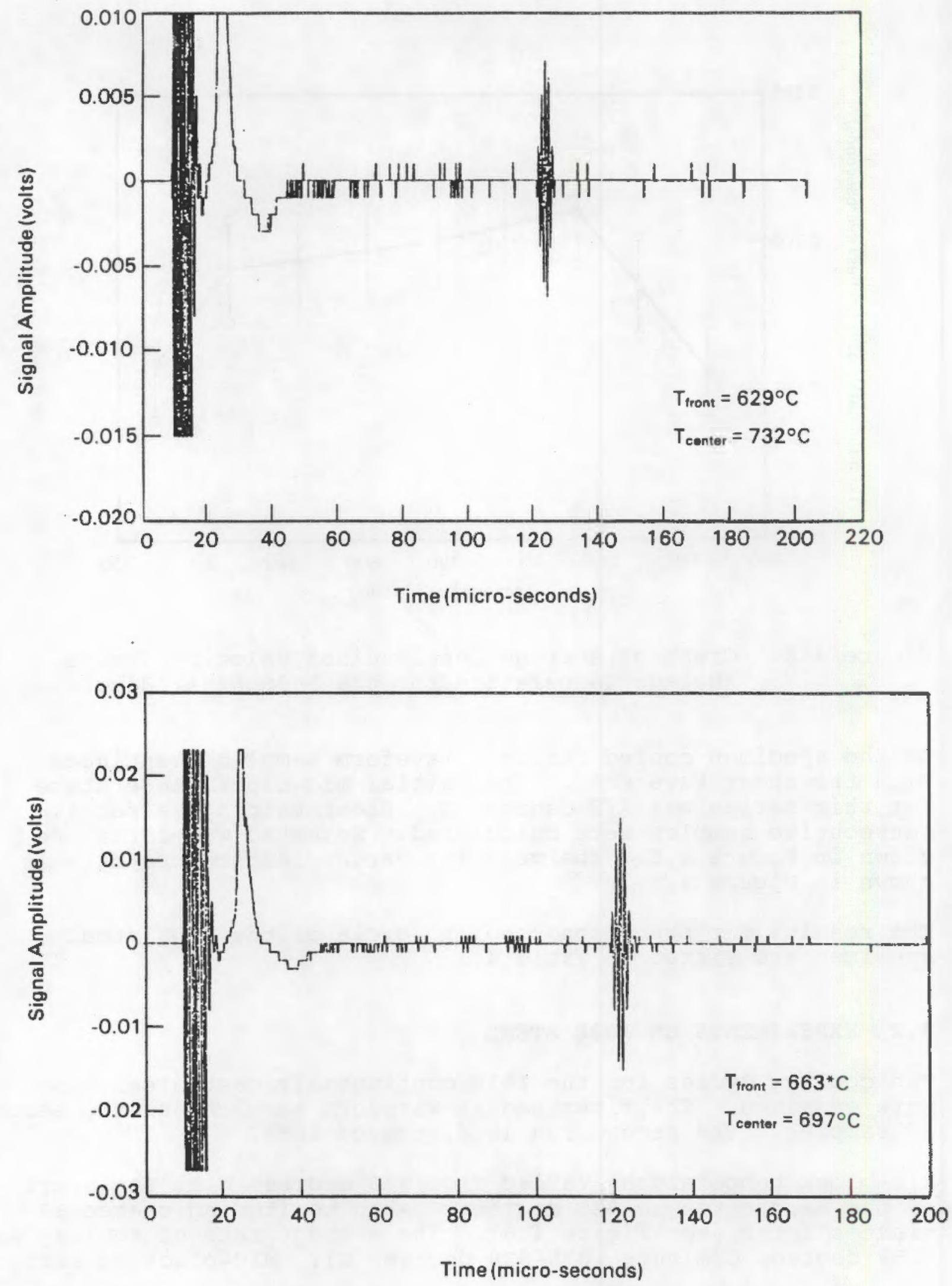

Figure 4.6. Selected Shear Mode Waveforms from the 1008 Steel Block Test. 

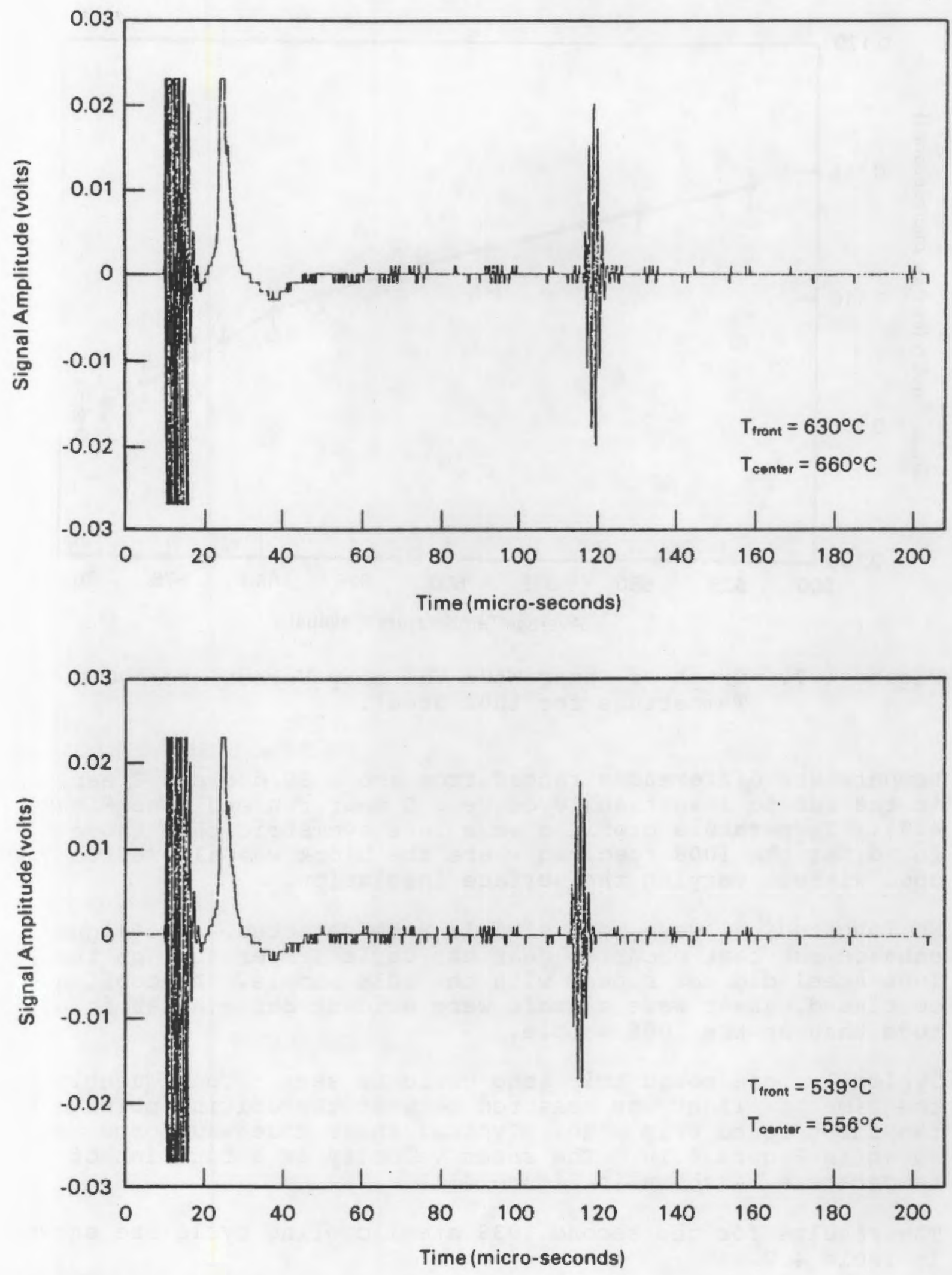

Figure 4.6 (cont'd) 


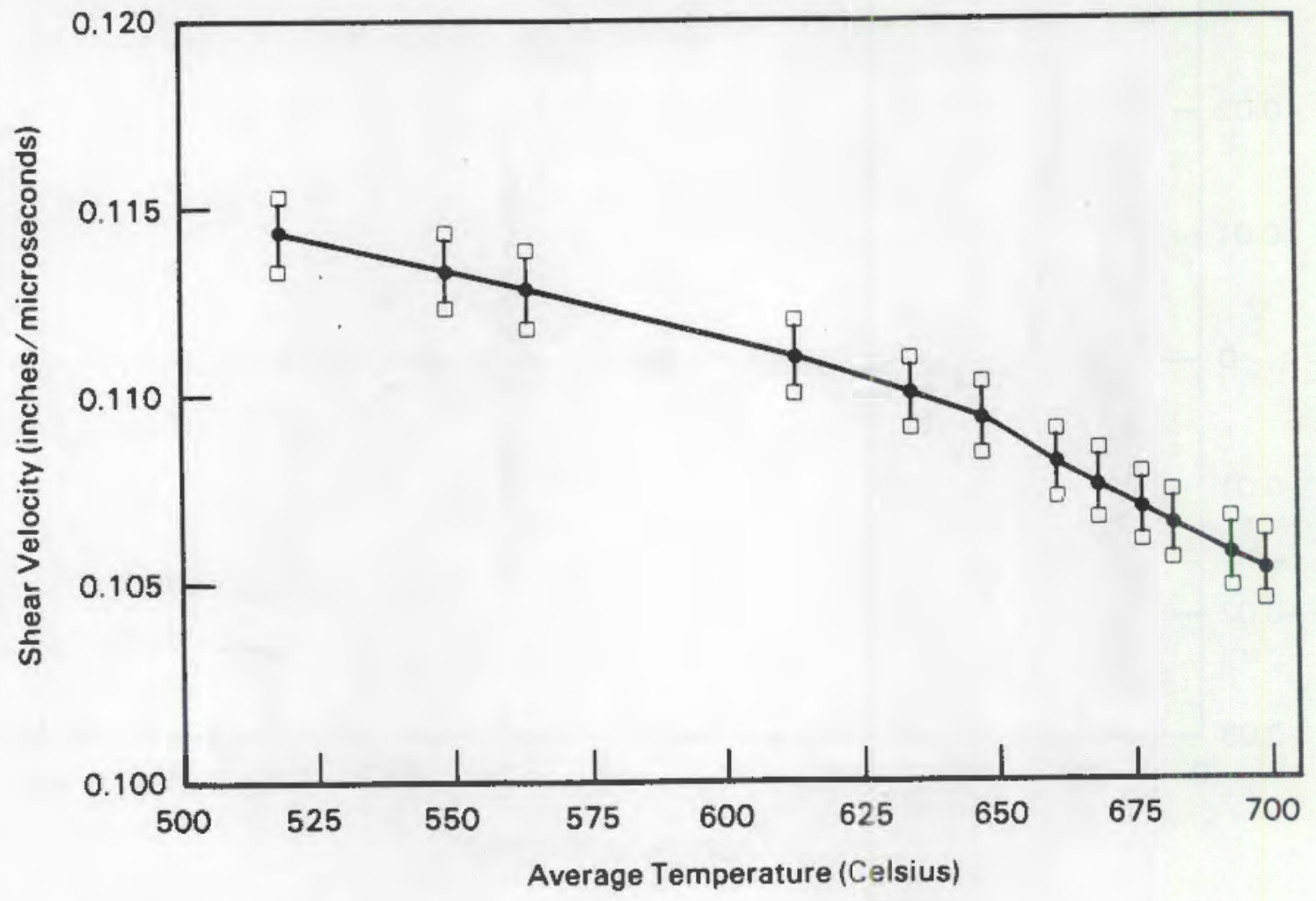

Figure 4.7. Graph of Shear Wave Velocity Versus Average Temperture for 1008 Steel.

temperature differences ranged from above 80 degrees $C$ early in the run to less than 20 degrees $C$ near run end (see Figure 4.9). Temperature profiles were less symmetric than those found for the 1008 specimen where the block was allowed to cool without varying the surface insulation.

No longitudinal wave mode signals were detected. The signal enhancement that occurred near the Curie Temperature on the 1008 steel did not appear with the 1038 sample. As cooling continued, shear wave signals were evident but smaller in amplitude than on the 1008 sample.

Typically, one round trip echo could be seen. Consequently, the time of flight was measured between the driving pulse and the first round trip echo. Typical shear mode waveforms are shown in Figure 4.10. The shear velocity as a function of temperature is shown in Figure 4.11.

The results for the second 1038 steel cooling cycle are shown in Table 4.2. 


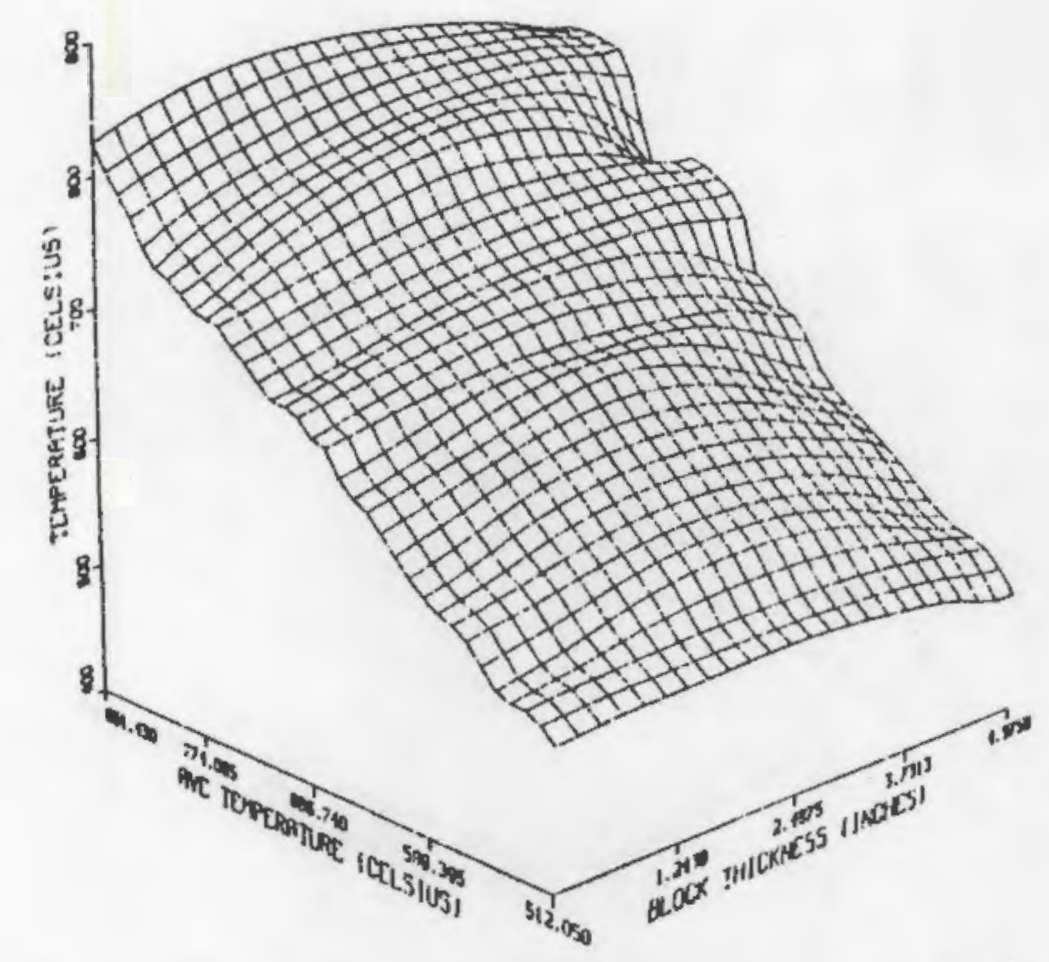

Figure 4.8a. Temperature Surface as a Function of Location and Average Temperature.

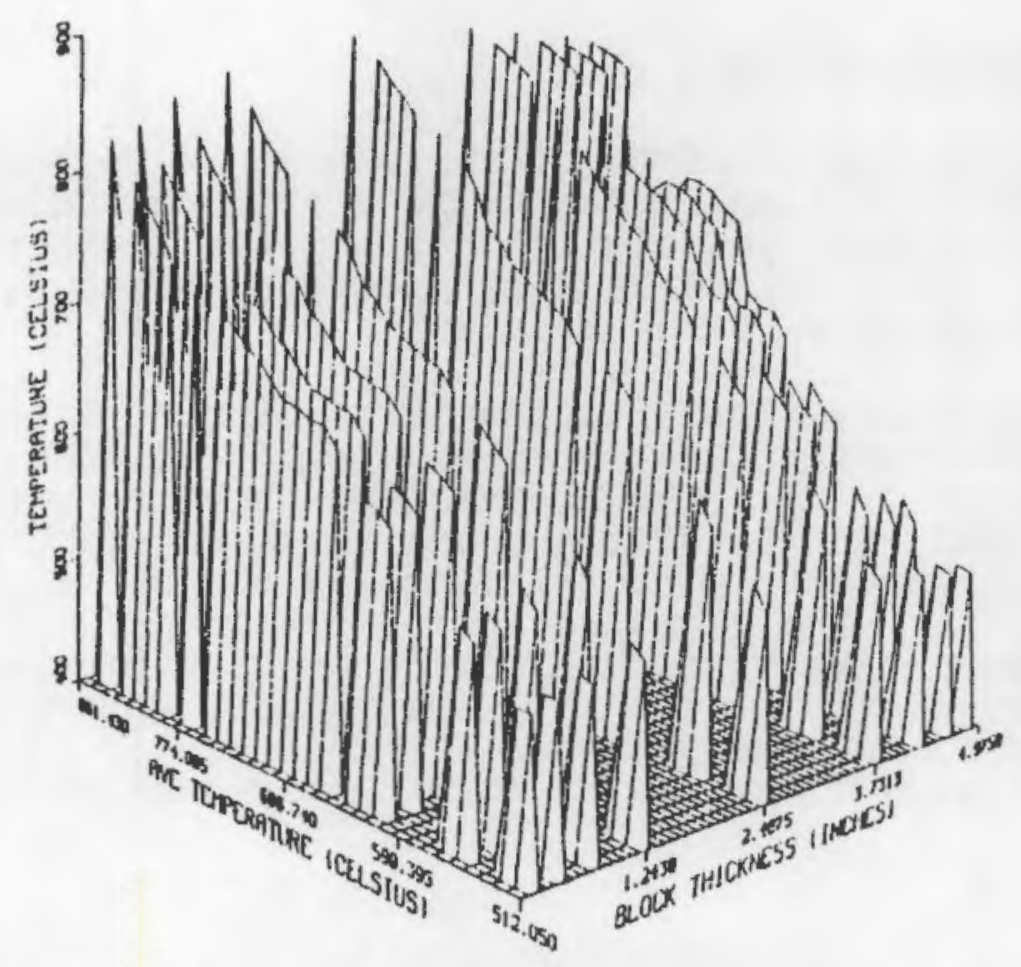

Figure $4.8 \mathrm{~b}$. Temperature Measurements that Support the Graph in Figure $4.8 \mathrm{a}$. 


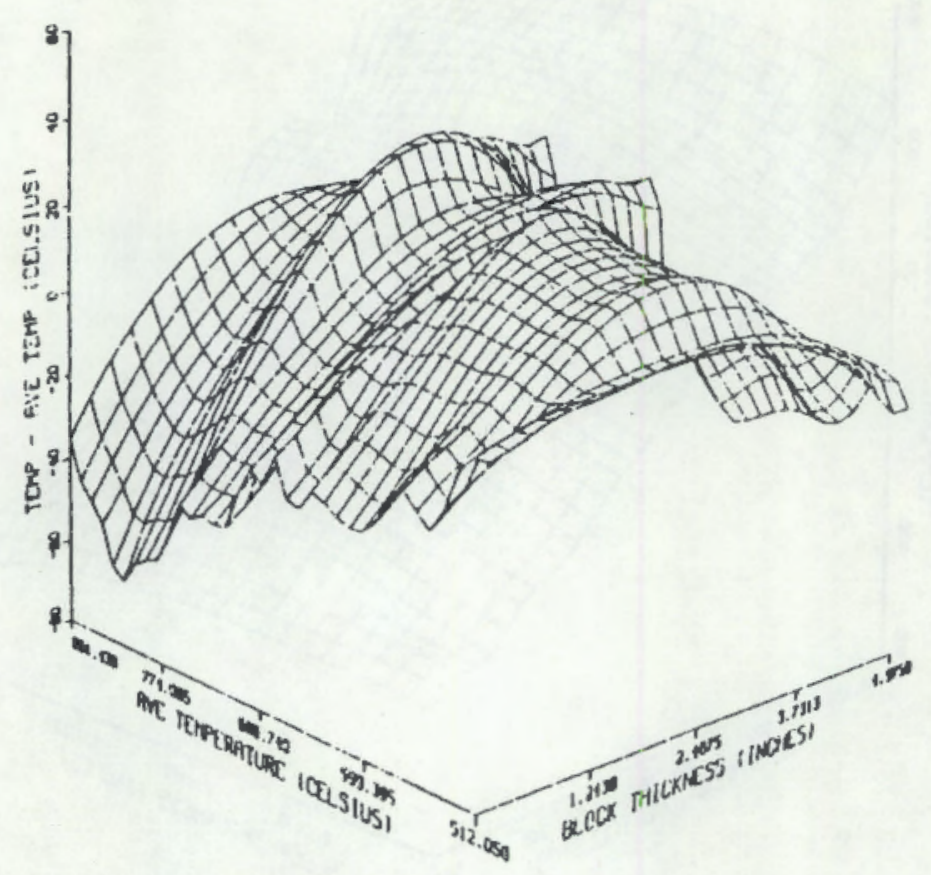

Figure 4.9. Graph of Local Temperature Minus Average Temperature as a Function of Location and Average Temperature.

\subsection{EXPERIMENTS WITH ARMCO IRON}

Eight temperature cycles of the iron specimen were analyzed. Three runs contained significant numbers of longitudinal EMAT samples while two runs had significant numbers of shear EMAT samples. The runs produced 78 digitized waveforms; 39 longitudinal and 39 shear wave samples.

The major longitudinal EMAT run lasted 13 minutes with an initial mid-block temperature of 854 degrees $C$ which declined to 745 degrees $C$ (Figure 4.12). The average cooling rate was 8.38 degrees $\mathrm{C} / \mathrm{minute.} \mathrm{The} \mathrm{largest} \mathrm{and} \mathrm{smallest} \mathrm{temperature} \mathrm{differ-}$ ences within a temperature profile were 40 and 30 degrees $C$ (see Figure 4.13). The signal-to-noise ratio was so low in most cases that a time of flight could not be estimated. Figure 4.14 shows the waveforms from this test. only waveform ARMC07.105 had a high enough signal-to-noise ratio in the longitudinal mode that a TOF could be confidently determined. 

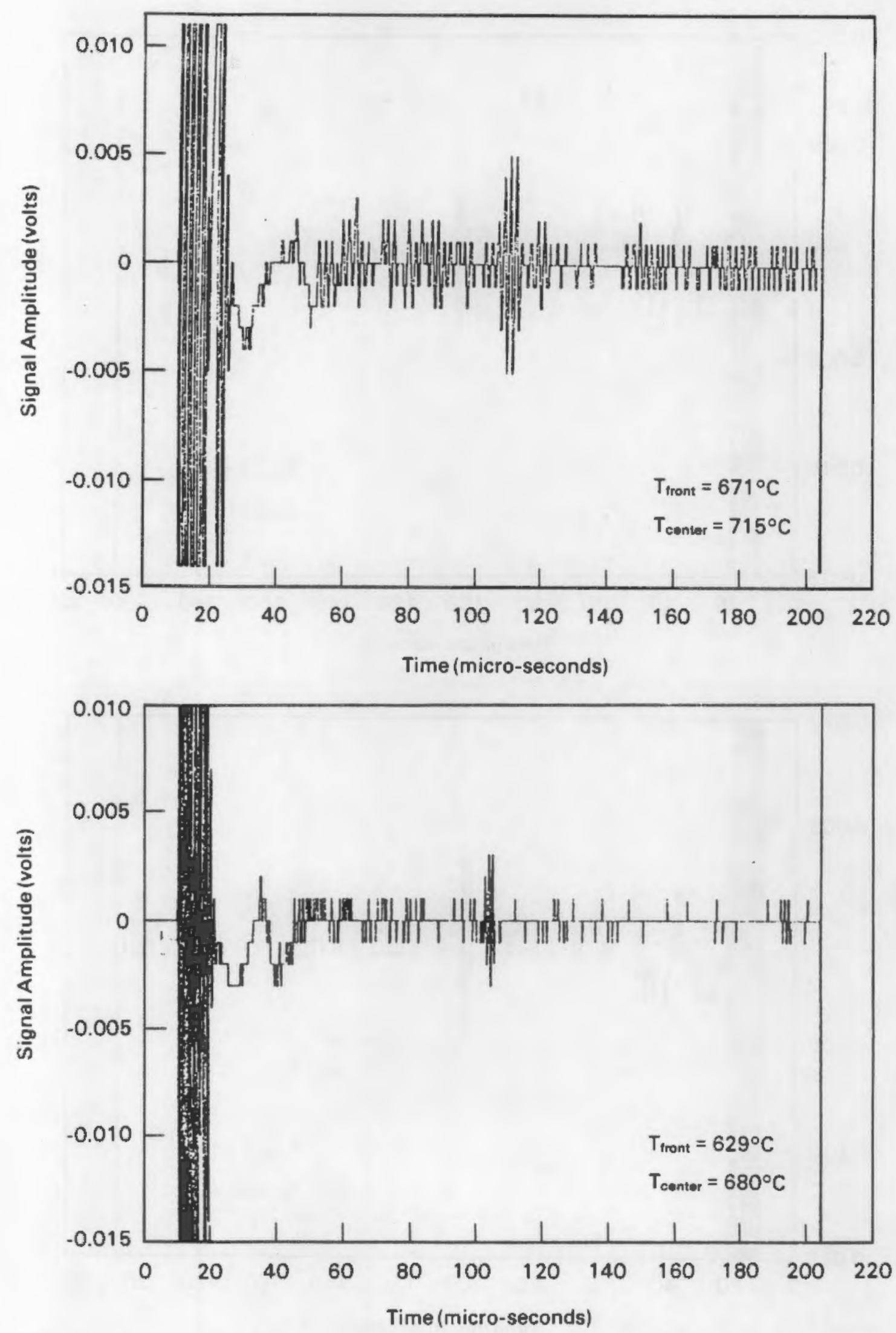

Figure 4.10. Examples of Shear Mode Waveforms from a 1038 Steel Block Test. 

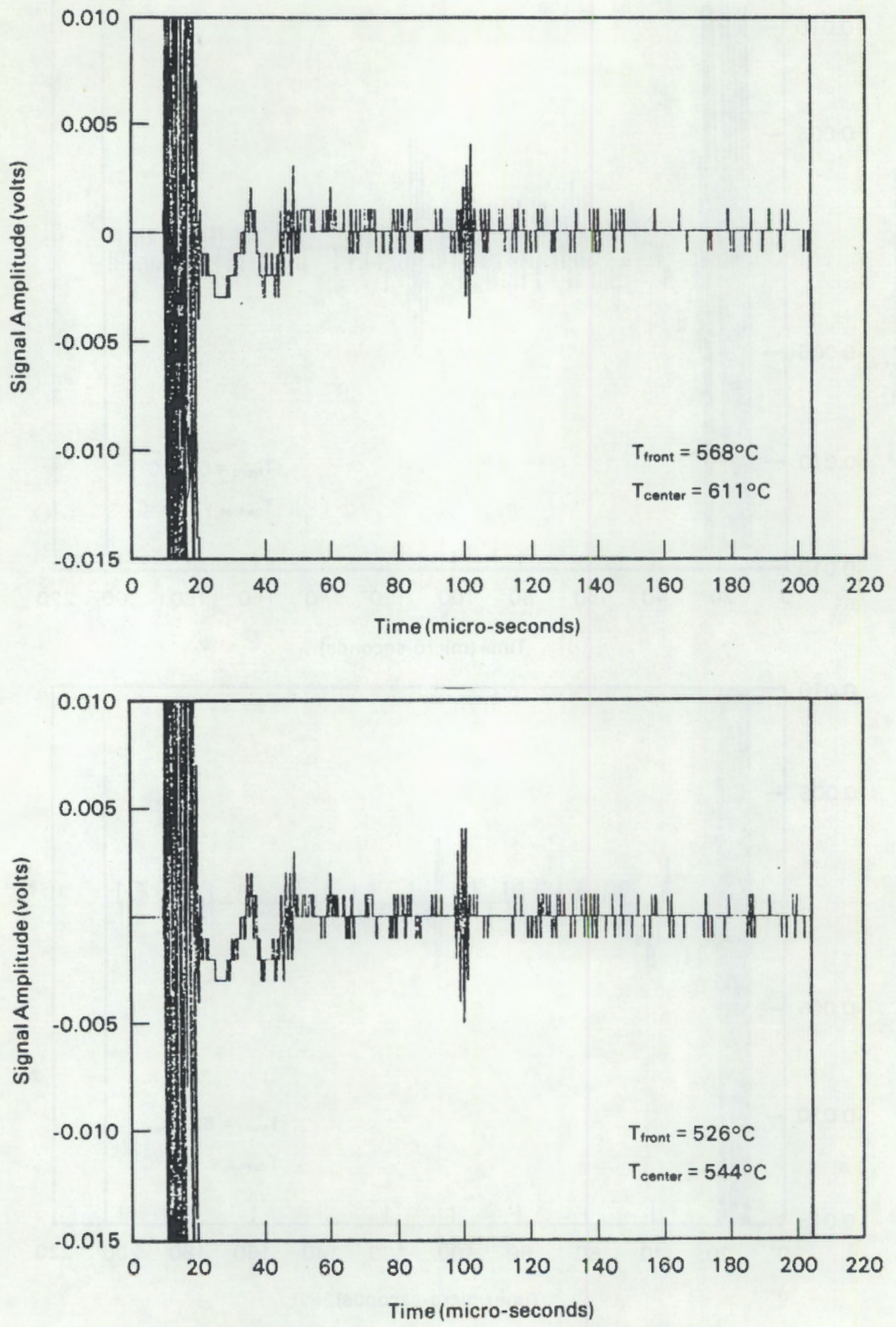

Figure 4.10 (cont'd) 


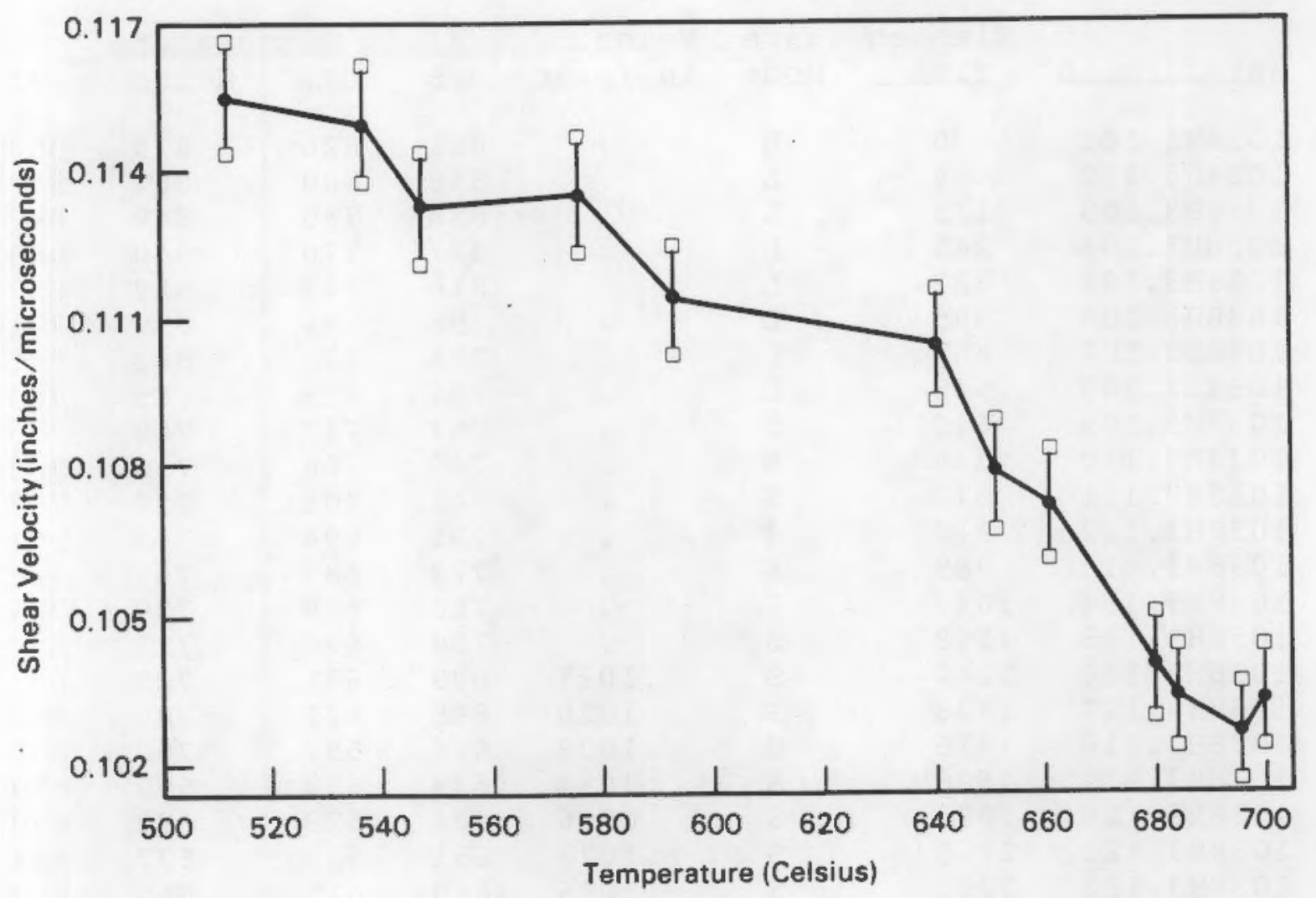

Figure 4.11. Graph of Shear Wave Velocity Versus Temperature for a 1038 steel Test.

The most closely examined shear wave cycle had a mid-block temperature range of 653 degrees $C$ to 332 degrees $C$ over the 45-minute cycle with an average cooling rate of 7.13 degrees $\mathrm{C} /$ minute (Figure 4.15). Temperature differences within a profile ranged from 24 degrees $C$ to 5 degrees $C$ (Figure 4.16). Typical waveforms are shown in Figure 4.17 . Figure 4.18 is a plot of shear wave velocity versus temperature. 
Table 4.2. Velocity versus temperature data for 1038 steel.

\begin{tabular}{|c|c|c|c|c|c|c|c|}
\hline & Elapsed & Wave & velocity & $\mathrm{BlOC}$ & $k$ Temp & erature & \\
\hline Waveform ID & Time & Mode & in. $/ \mu \sec$ & Ave. & Near & Center & Far \\
\hline $1038 \mathrm{H} 3.101$ & 0 & L & . & 861 & 824 & 875 & 850 \\
\hline $1038 \mathrm{H} 3.102$ & 88 & L & - & 848 & 800 & 862 & 850 \\
\hline $1038 \mathrm{H} 3.103$ & 175 & L & . & 836 & 785 & 849 & 847 \\
\hline $1038 \mathrm{H} 3.104$ & 245 & L & . & 827 & 770 & 840 & 843 \\
\hline $1038 \mathrm{H} 3.105$ & 327 & L & - & 816 & 749 & 829 & 837 \\
\hline $038 \mathrm{H} 3.106$ & 395 & L & - & 798 & 738 & 819 & 771 \\
\hline $038 \mathrm{H} 3.107$ & 467 & L & - & 776 & 721 & 803 & 740 \\
\hline $1038 \mathrm{H} 3.108$ & 548 & L & - & 766 & 719 & 785 & 763 \\
\hline $1038 \mathrm{H} 3.109$ & 646 & $\mathbf{S}$ & . & 757 & 717 & 769 & 765 \\
\hline $1038 \mathrm{H} 3.110$ & 735 & $\mathbf{s}$ & . & 749 & 706 & 759 & 762 \\
\hline $1038 \mathrm{H} 3.111$ & 827 & s & - & 741 & 701 & 750 & 757 \\
\hline $1038 \mathrm{H} 3.112$ & 910 & s & . & 735 & 694 & 743 & 751 \\
\hline $1038 \mathrm{H} 3.113$ & 989 & s & . & 729 & 688 & 737 & 746 \\
\hline $1038 \mathrm{H} 3.114$ & 1097 & $\mathbf{s}$ & . & 720 & 678 & 729 & 739 \\
\hline $1038 \mathrm{H} 3.115$ & 1168 & $\mathrm{~s}$ & & 708 & 676 & 723 & 686 \\
\hline $1038 \mathrm{H} 3.116$ & 1249 & $\mathbf{S}$ & .1027 & 699 & 671 & 715 & 677 \\
\hline 1038 Н3. 117 & 1338 & s & .1020 & 695 & 671 & 709 & 676 \\
\hline $1038 \mathrm{H} 3.118$ & 1476 & $\mathrm{~s}$ & .1028 & 684 & 657 & 700 & 658 \\
\hline $1038 \mathrm{H} 3.119$ & 1606 & $\mathbf{s}$ & .1034 & 679 & 658 & 692 & 659 \\
\hline $1038 \mathrm{H} 3.120$ & 1883 & $\mathrm{~s}$ & .1066 & 661 & 629 & 680 & 630 \\
\hline $1038 \mathrm{H} 3.121$ & 2115 & $\mathrm{~s}$ & .1072 & 651 & 625 & 677 & 614 \\
\hline $1038 \mathrm{H} 3.122$ & 2221 & s & .1095 & 640 & 615 & 665 & 603 \\
\hline $1038 \mathrm{H} 4.101$ & 2493 & $s$ & .1104 & 592 & 568 & 611 & 562 \\
\hline $1038 \mathrm{H} 4.102$ & 2594 & $\mathbf{s}$ & .1126 & 575 & 559 & 592 & 545 \\
\hline $1038 \mathrm{H} 4.103$ & 2765 & s & .1124 & 547 & 526 & 562 & 525 \\
\hline $1038 \mathrm{H} 4.104$ & 2894 & s & .1140 & 536 & 526 & 544 & 522 \\
\hline $1038 \mathrm{H} 4.105$ & 3062 & $\mathbf{s}$ & .1146 & 51.2 & 509 & 520 & 493 \\
\hline
\end{tabular}




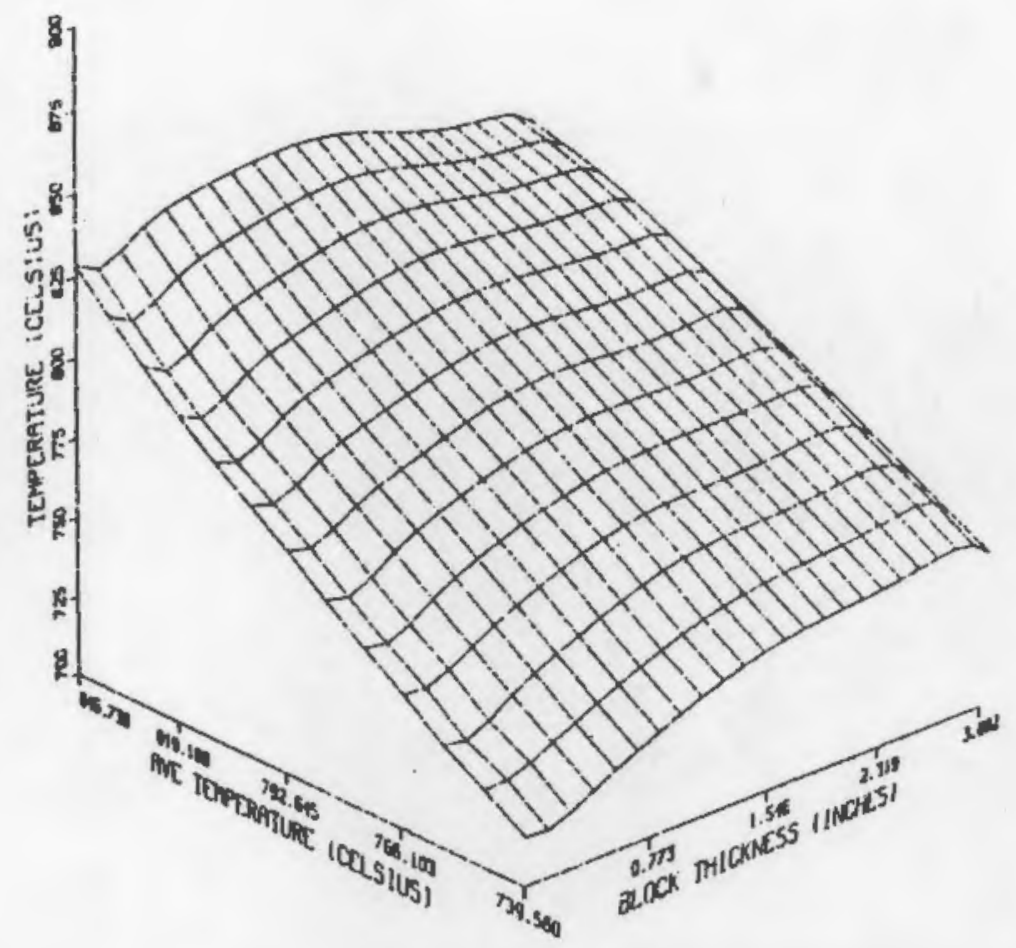

Figure 4.12a. Temperature Surface for the Armco Iron Block Test.

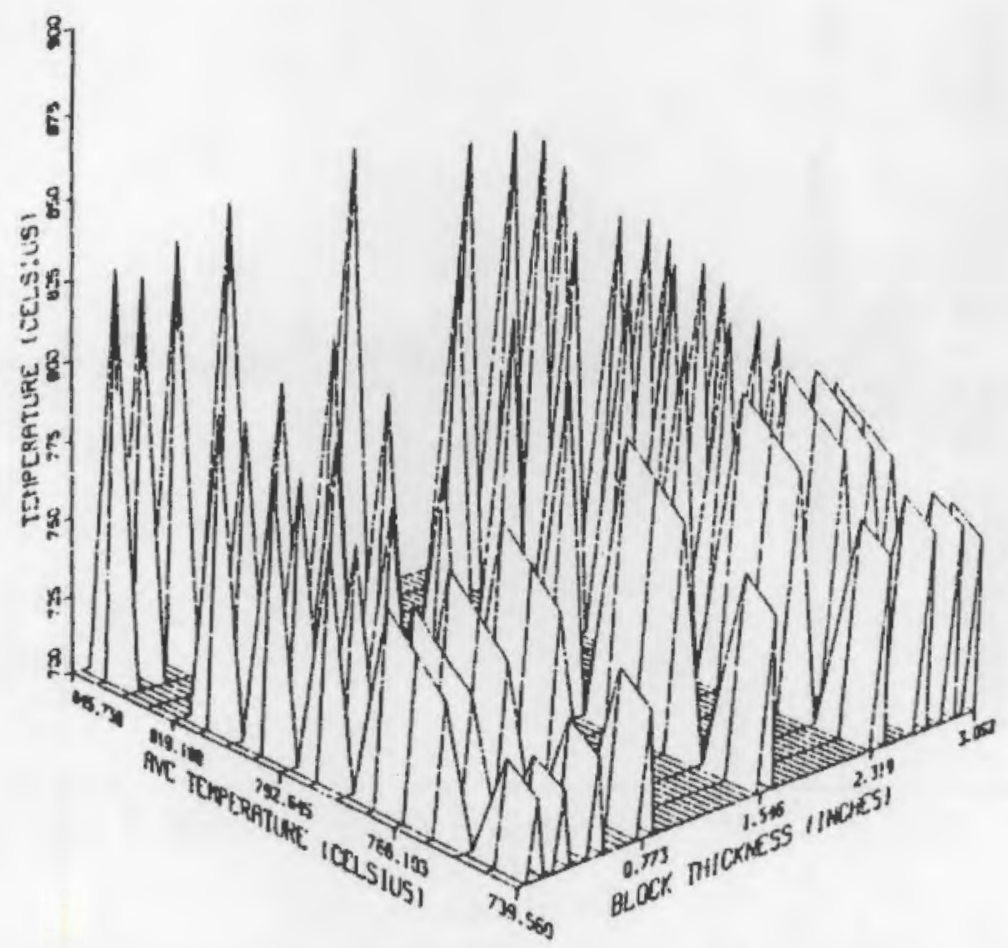

Figure 4.12b. Thermocouple Data Points for the Armco Iron Test. 


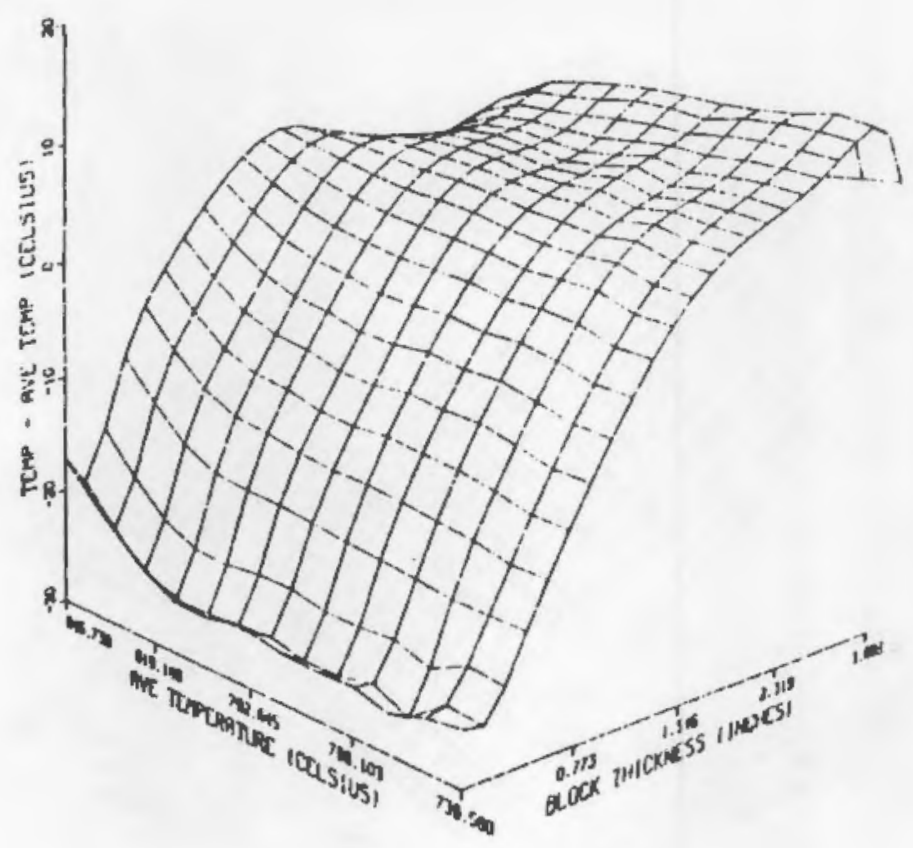

Figure 4.13. Surface Showing the Local Temperature Minus Average Temperature Versus Average Temperature and Location.

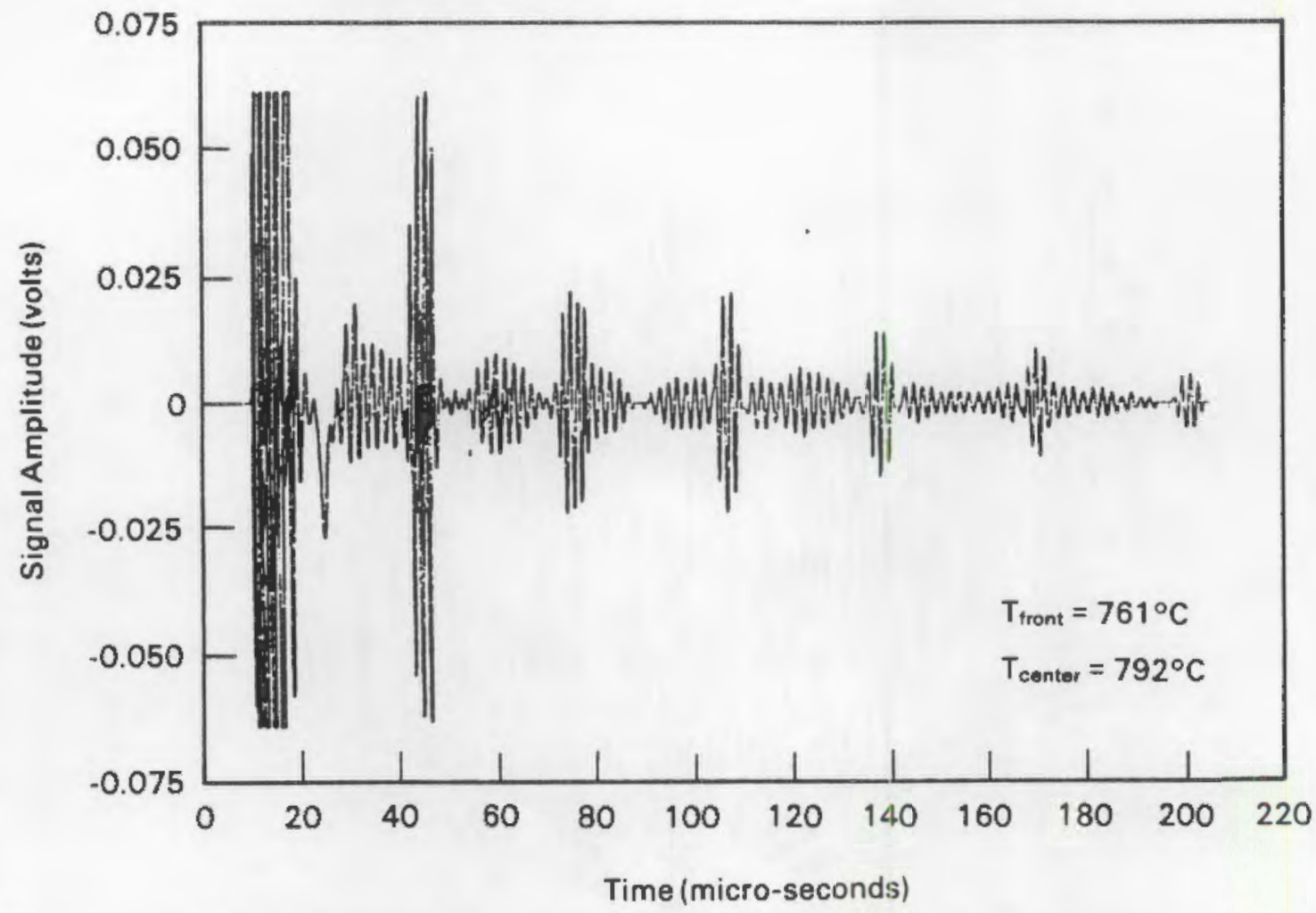

Figure 4.14. Examples of Longitudinal Mode Waveforms from the Armco Iron Block Test. 

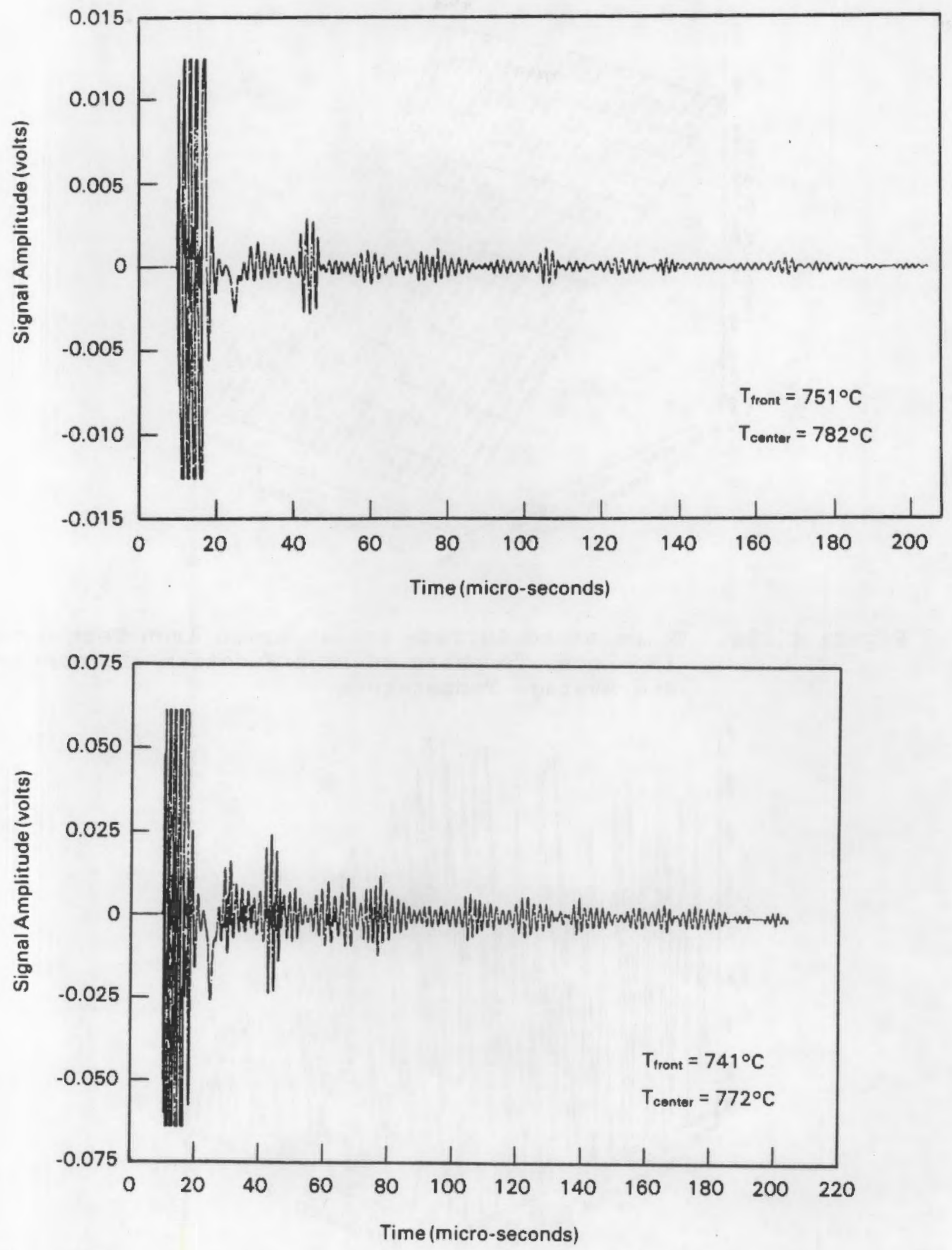

Figure 4.14 (cont'd) 


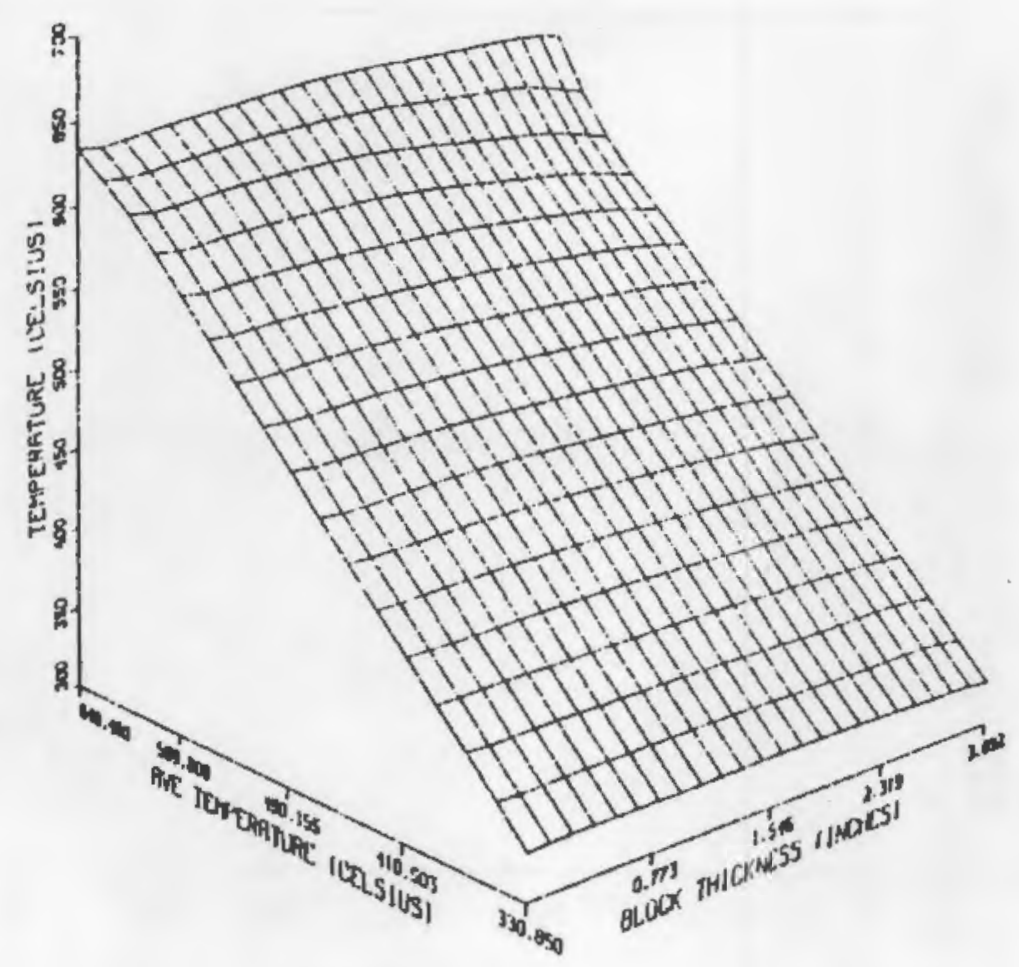

Figure 4.15a. Temperature Surface for an Armco Iron Test Showing Local Temperature as a Function of Location and Average Temperature.

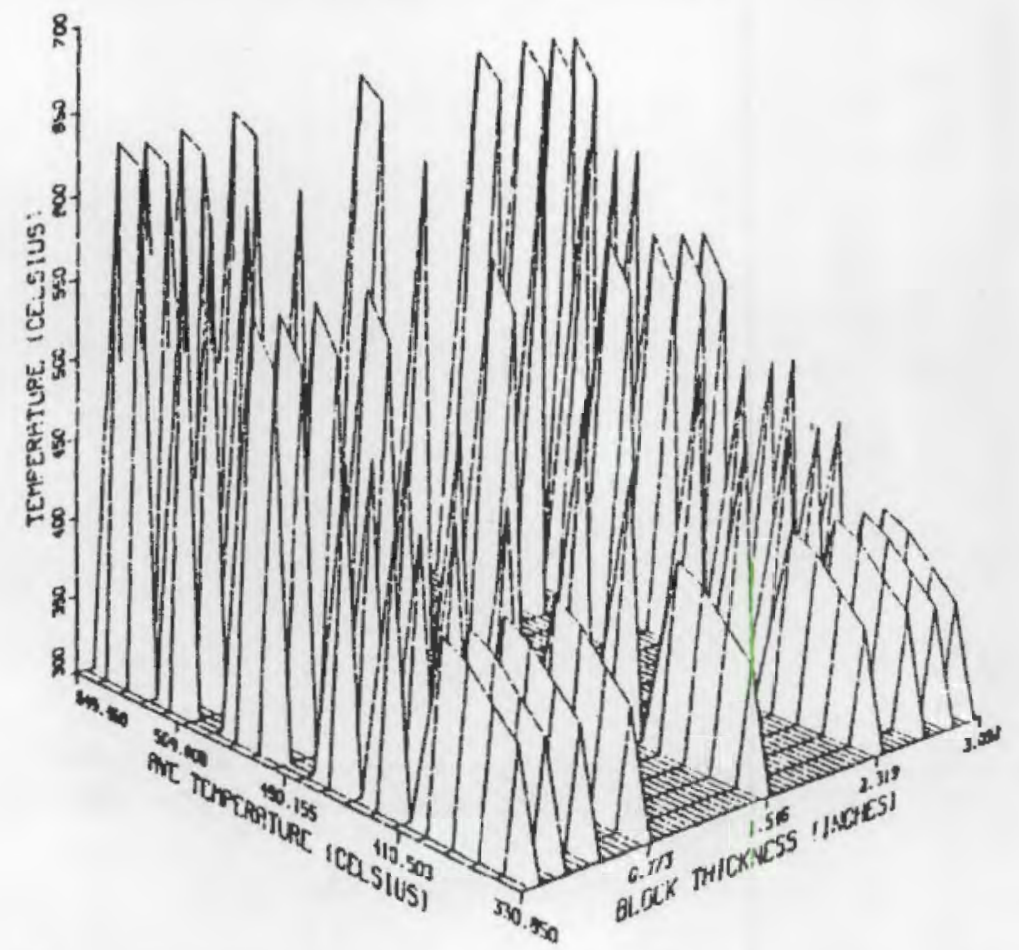

Figure 4.15b. Thermocouple Data that Supports the Graph in Figure 4.15a. 


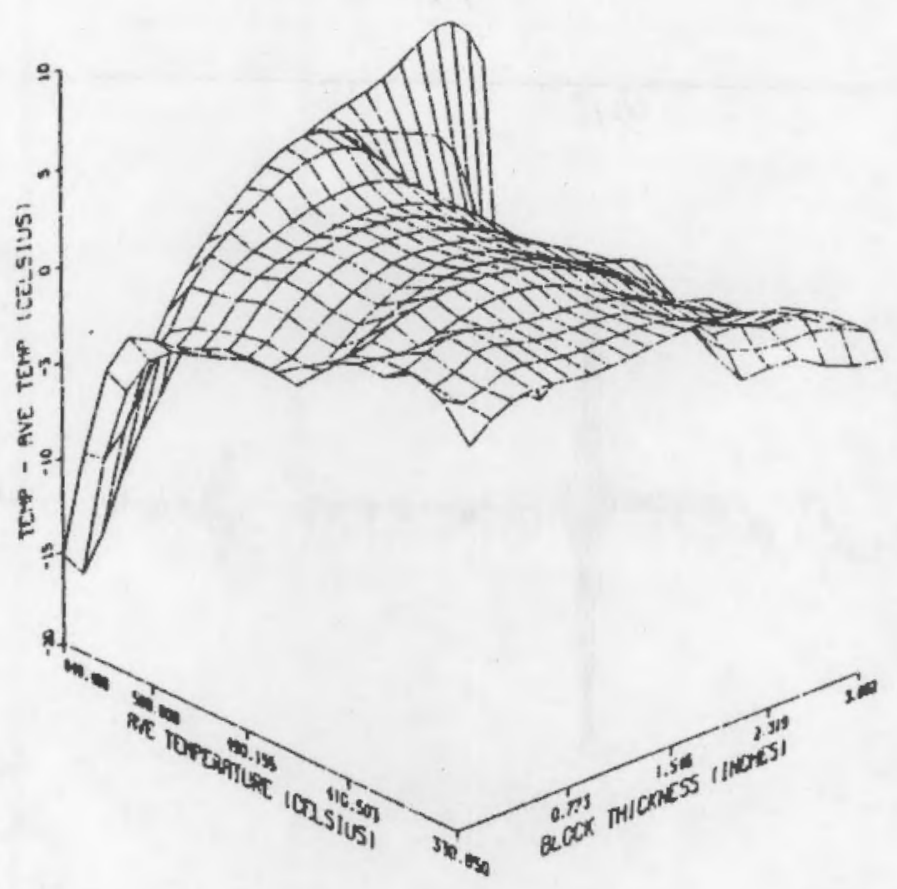

Figure 4.16. Graph of Local Temperature Minus Average Temperature for an Armco Iron Longitudinal Test.

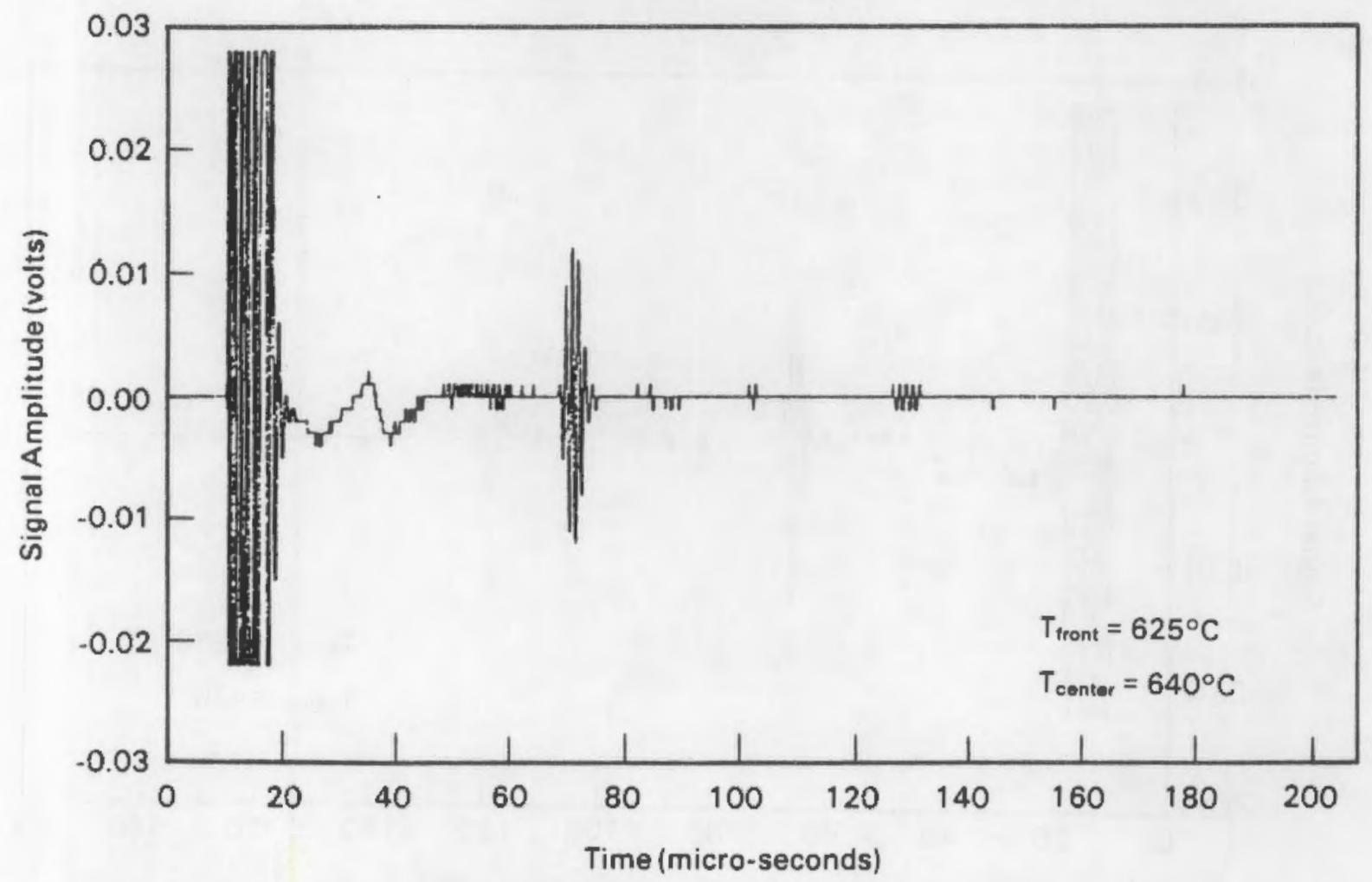

Figure 4.17. Selected Shear Mode Waveforms for the Armco Iron Tests. 

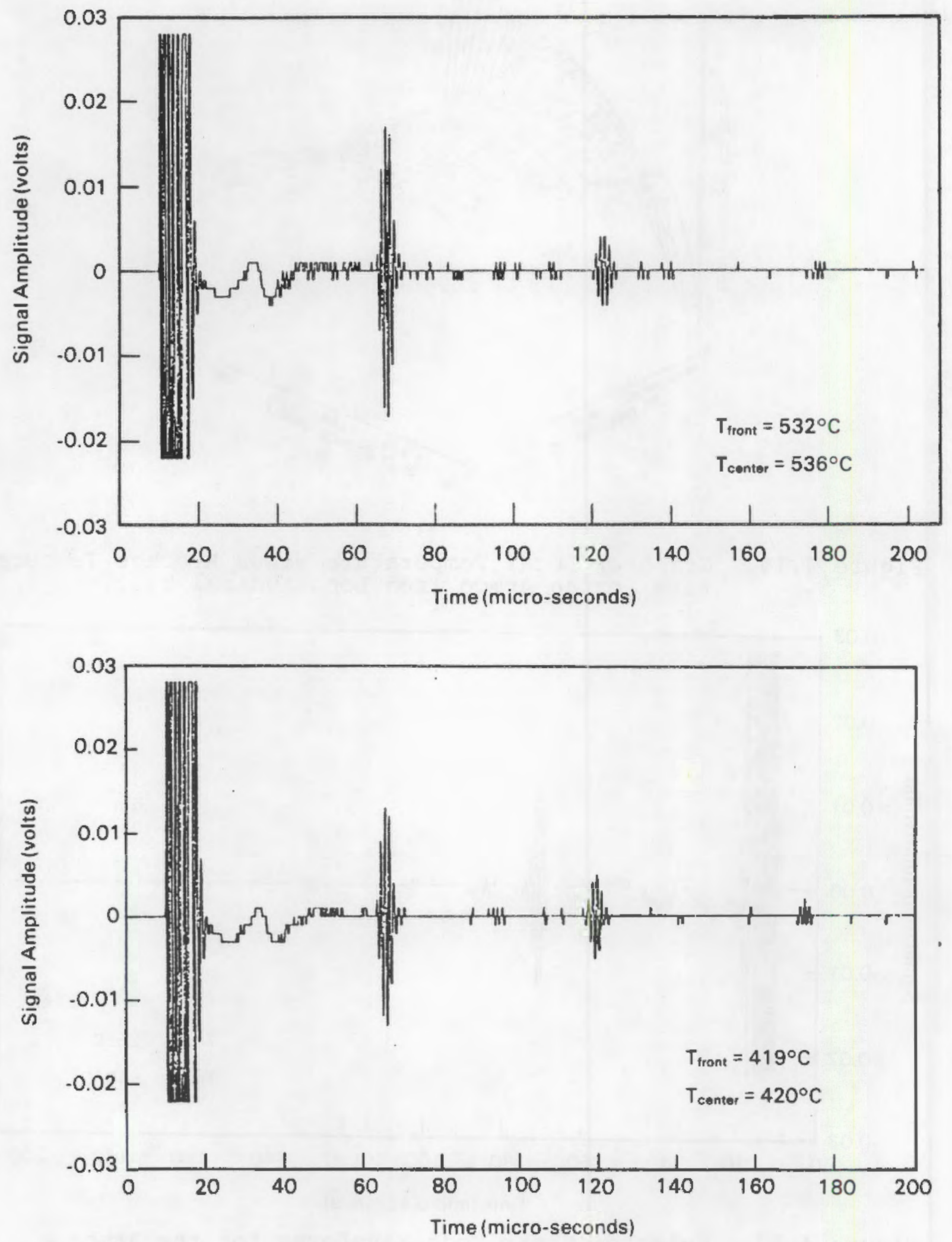

Figure 4.17 (cont'd) 


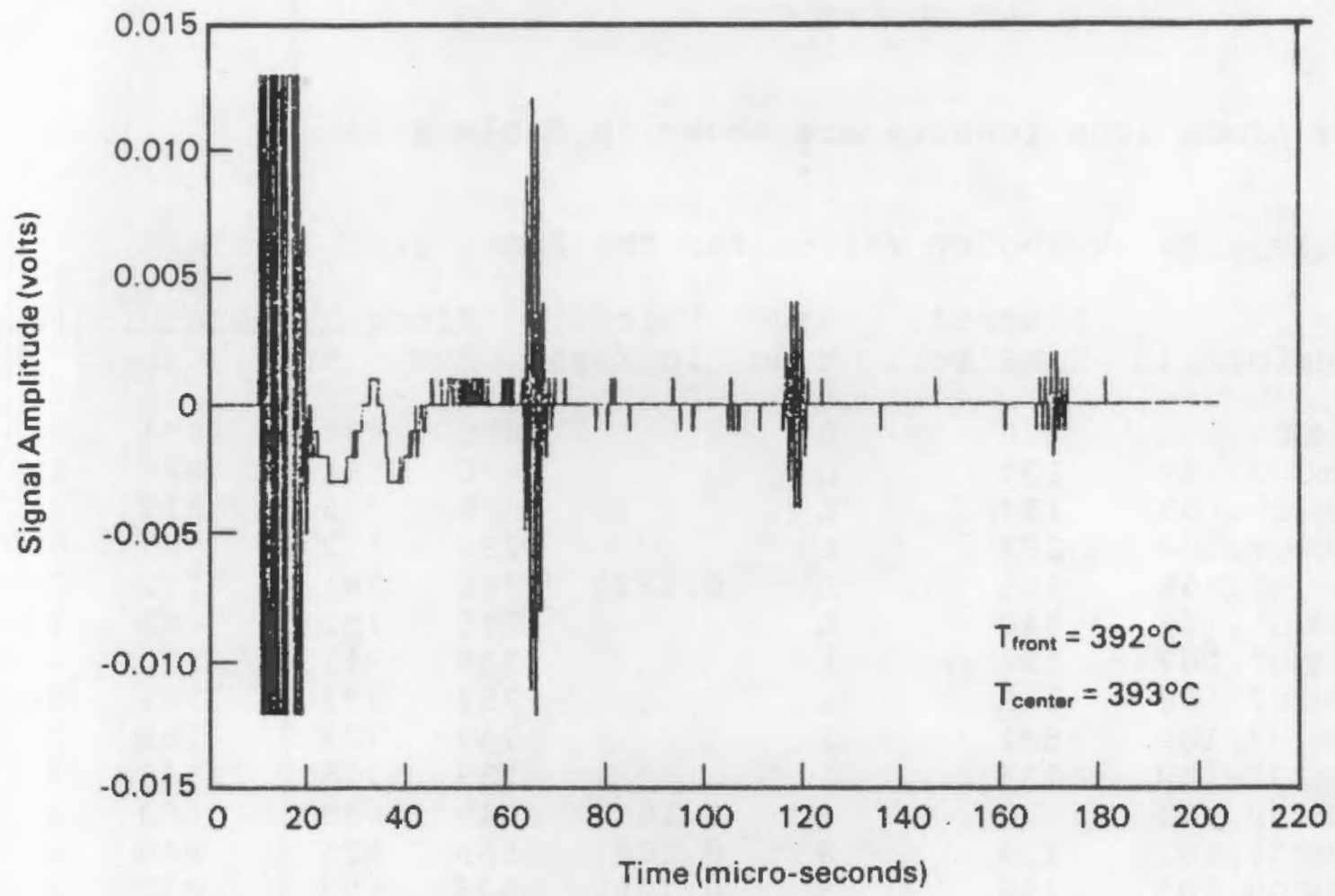

Figure 4.17 (cont'd)

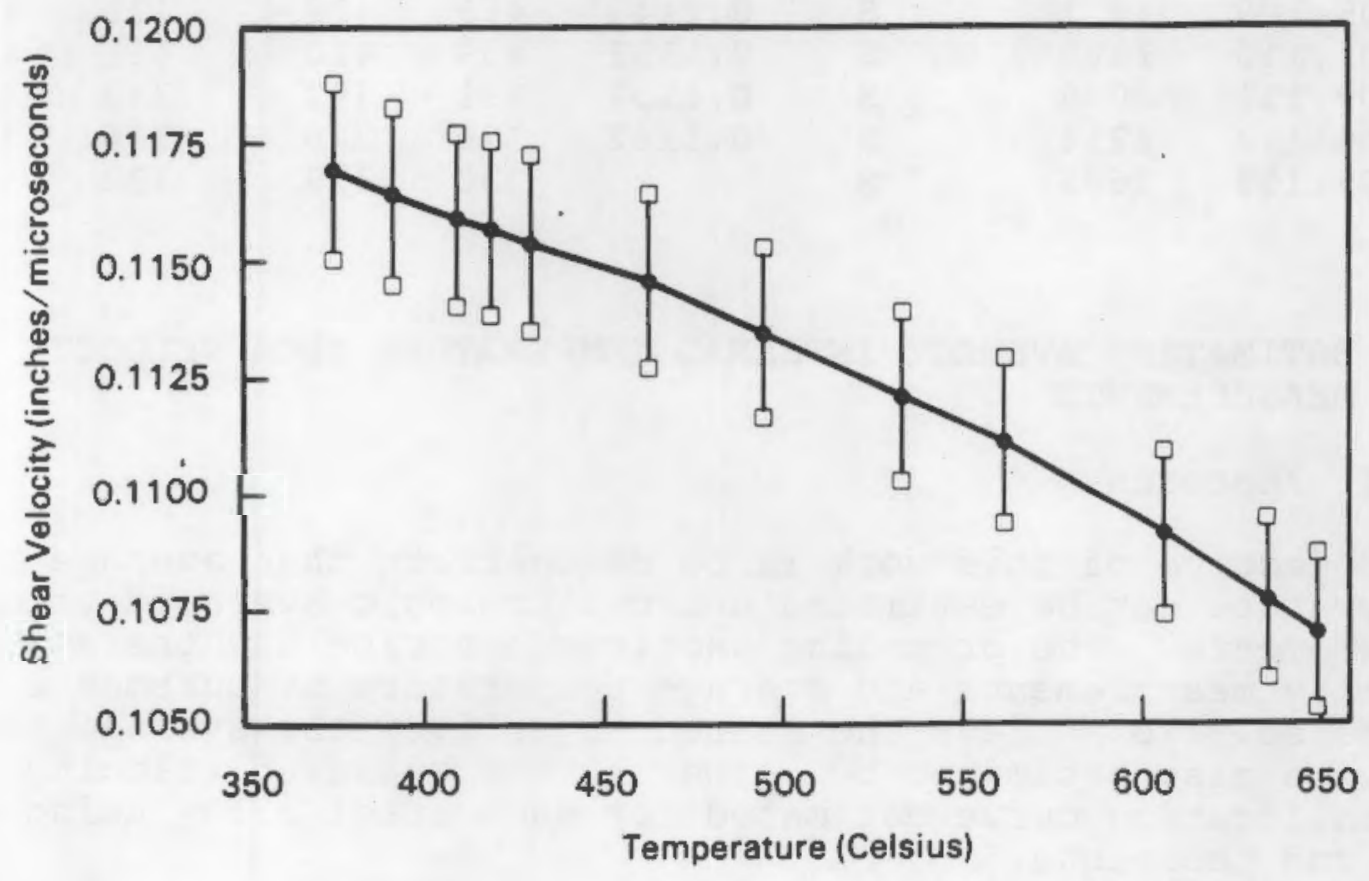

Figure 4.18. Graph of Measured Average Shear Velocity Versus Measured Average Temperature for an Armco Iron Shear Wave Test. 
The Armco iron results are shown in Table 4.3.

Table 4.3. Velocity Values for the Armco Iron Test

Elapsed Wave Velocity Block Temperature (C.)

Waveform ID Time(sec) Mode in./usec. Ave. Near center Far

\begin{tabular}{|c|c|c|c|c|c|c|c|}
\hline ARMCO 7.101 & 0 & L & & 845 & 830 & 854 & 835 \\
\hline ARMCO 7.102 & 134 & L & & 820 & 798 & 828 & 821 \\
\hline ARMCO 7.103 & 198 & L & & 810 & 786 & 817 & 812 \\
\hline ARMCO 7.104 & 288 & L & & 796 & 772 & 803 & 800 \\
\hline ARMCO 7.105 & 361 & L & 0.1334 & 785 & 761 & 792 & 791 \\
\hline ARMCO7.106 & 440 & L & & 776 & 751 & 782 & 782 \\
\hline ARMCO 7.107 & 524 & L & & 766 & 741 & 772 & 773 \\
\hline ARMCO 7.108 & 603 & L & & 757 & 732 & 764 & 765 \\
\hline $\mathrm{ARMCO} 7.109$ & 681 & L & & 749 & 724 & 755 & 757 \\
\hline ARMCO 7.110 & 776 & L & & 739 & 715 & 745 & 748 \\
\hline ARMCO9.101 & 0 & S & 0.1060 & 649 & 635 & 653 & 656 \\
\hline ARMCO9. 102 & 116 & $\mathbf{S}$ & 0.1067 & 635 & 625 & 640 & 632 \\
\hline ARMCO9.103 & 259 & $\mathbf{S}$ & 0.1082 & 606 & 603 & 612 & 594 \\
\hline ARMCO9.104 & 585 & $\mathbf{S}$ & 0.1102 & 561 & 560 & 565 & 553 \\
\hline ARMCO9.105 & 805 & S & 0.1112 & 533 & 532 & 536 & 526 \\
\hline ARMCO9.106 & 1141 & S & 0.1126 & 494 & 494 & 497 & 489 \\
\hline ARMCO9.107 & 1442 & S & 0.1138 & 463 & 462 & 465 & 458 \\
\hline ARMCO9.108 & 1691 & $S$ & 0.1146 & 430 & 430 & 432 & 423 \\
\hline ARMCO9.109 & 1811 & S & 0.1149 & 419 & 419 & 421 & 413 \\
\hline ARMCO9. 110 & 1899 & $\mathbf{S}$ & 0.1152 & 409 & 410 & 411 & 404 \\
\hline ARMCO9.111 & 2056 & S & 0.1157 & 391 & 392 & 393 & 387 \\
\hline ARMCO9.112 & 2214 & S & 0.1162 & 374 & 376 & 376 & 370 \\
\hline ARMCO9.113 & 2689 & $\mathbf{S}$ & & 330 & 329 & 332 & 327 \\
\hline
\end{tabular}

\subsection{ESTIMATING AVERAGE INTERNAL TEMPERATURE FROM VELOCITY MEASUREMENTS}

\subsubsection{Approach}

The objective of this work is to demonstrate that average profile temperature can be estimated using ultrasonic averaged velocity measurements. The preceding sections describe how the average velocity measurements and average temperature measurements are estimated. To achieve the stated objective, the average temperature was also estimated by comparing the measured velocity to the calibration curve estimated for each steel alloy using the thin rod technique.

The estimation procedure has a few simple steps: 
1. Determine the ultrasonic velocity-versus-temperature relationship for each steel alloy using the long, thin rod technique under isothermal conditions. (This relationship is complicated by the fact that the velocity at a given temperature is dependent on the rate of temperature change and whether the specimen is heating or cooling. The influence of this effect on the temperature estimate must be further investigated).

2. Calculate the average ultrasonic velocity in the hot test block from the time of flight and block thickness.

3. Estimate the true average test block temperature by integrating the temperature data from the thermocouples over the block thickness.

4. Use the velocity-versus-temperature calibration data (described in 1 . above) to estimate the average internal temperature. Compare the actual average temperature (from thermocouples) to the estimated average temperature (from ultrasonic velocity).

\subsubsection{Error Analysis of Temperature Estimation Technique}

Estimated wave velocity is the ratio of the measured block thickness to the measured time of flight. One component of the error in estimating the true velocity is, therefore, a function of the measurement errors associated with the thickness and TOF measurements.

This component of velocity error was estimated by Propagation of Error techniques. Thus, this error component for a velocity for a given temperature was estimated by the following formula:

$$
S(V)=\left[S^{2}(H) /(T O F)^{2}+\left((H)^{2} /(T O F)^{4}\right) * S^{2}(T O F)\right]^{1 / 2}
$$

where: $S(V)=$ error (standard deviation) in estimate of average velocity

$\mathrm{S}(\mathrm{H})=$ error (standard deviation) in measurement of block thickness

$S(T O F)=$ error (standard deviation) in measurement of time of flight

$\mathrm{H}=$ block thickness

TOF = time of flight.

$\mathrm{S}(\mathrm{H})$ was conservatively estimated to be 0.05 inches, while S(TOF) was estimated as $0.10 \mu s e c o n d s . ~ B o t h$ of these measurement errors are assumed to be normally distributed. Table 4.4 gives the data in tabular form. 
Table 4.4. Measured Shear Velocity and Standard Deviation or Measurement Errors for 1008 steel.

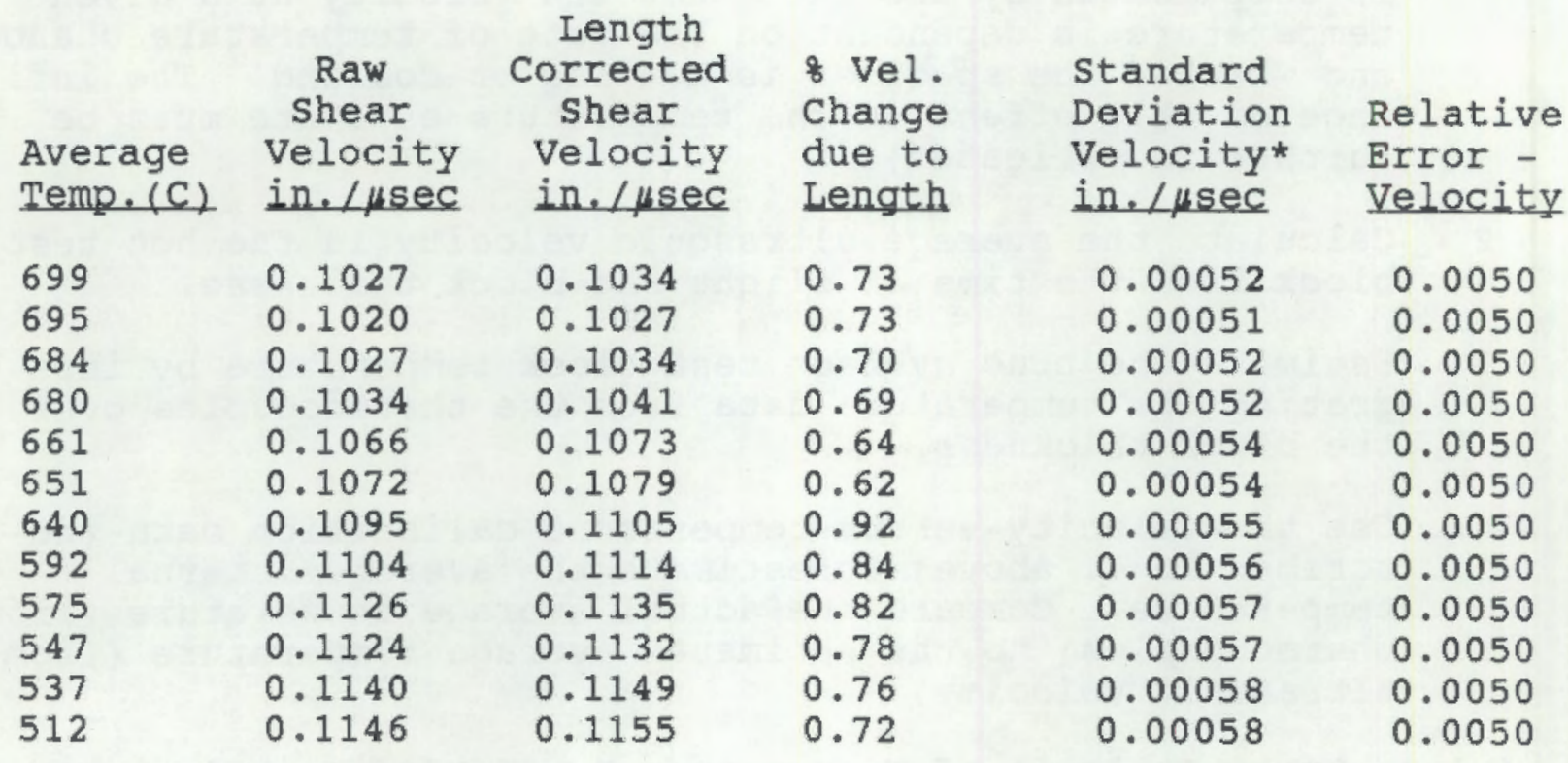

* Standard deviation values, S(V), are defined in eq. 4.1.

For the examined 1008 steel shear data, the estimate of velocity measurement error is shown in Figure 4.7. A similar plot for a test on Armco iron is shown in Figure 4.18. The error bounds shown are the two standard deviation limits. (The two standard deviation boundaries are the limits within which one would expect 958 of a group of measurements to occur.)

\subsection{RESULTS OF TEMPERATURE ESTIMATIONS}

The best data to evaluate this temperature estimation technique came from the second cooling cycle of the 1008 steel block (described previously). Following the procedure described above, the average internal temperature (based on thermocouple data) and the average ultrasonic velocity were calculated. The average velocity was located on the thin rod temperature-versus-velocity curve and the predicted average temperature obtained. Figure 4.19 is a plot of the average predicted temperature (based on ultrasonic velocity and calibration data) and the measured average temperature. The data is also given in Table 4.5. 


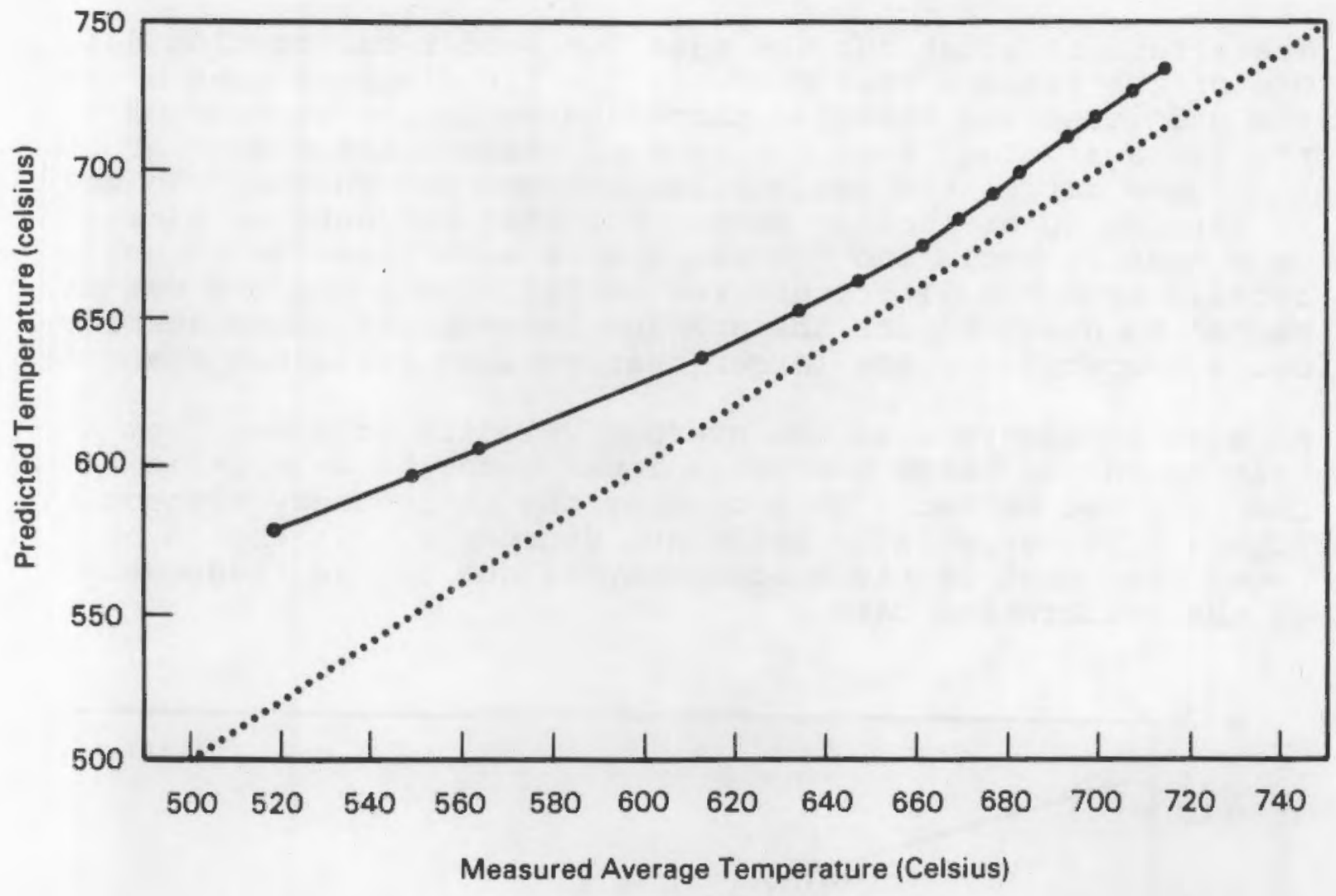

Figure 4.19. Plot of Average Estimated Temperature Versus Actual Temperature for a 1008 Steel Test.

Table 4.5. Measured and Predicted Average Block Temperature and Average Shear Wave Velocity for 1008 Steel

Average Temperature (Celsius)

Waveform ID

$1008 \mathrm{H} 3.101$

$1008 \mathrm{H} 3.102$

$1008 \mathrm{H} 3.103$

$1008 \mathrm{H} 3.104$

$1008 \mathrm{H} 3.105$

$1008 \mathrm{H} 3.106$

$1008 \mathrm{H} 3.107$

$1008 \mathrm{H} 3.108$

$1008 \mathrm{H} 3.109$

$1008 \mathrm{H} 3.110$

$1008 \mathrm{H} 3.111$

$1008 \mathrm{H} 3.112$

$1008 \mathrm{H} 3.113$

$1008 \mathrm{H} 3.114$

Shear Wave Velocity Measured (in./ $/ \mathrm{sec}$ )
714

707

699

693

682

677

669

661

647

634

613

564

549

518

\section{Predicted}

697

692

686

681

674

670

644

646

649

618

608

589

584

573
0.1046

0.1050

0.1057

0.1061

0.1069

0.1074

0.1080

0.1086

0.1094

0.1100

0.1110

0.1128

0.1133

0.1143 
These results point out the need for better calibration data. One of the factors that accounts for the discrepancies between the predicted and measured temperatures is the dependence of the average velocity on the rate of temperature change of the thin rods during the calibration process and whether the rod is heating up or cooling down. The thin rod data were taken on a heating cycle and the block data were taken on a cooling cycle. From the literature review [4], the technique was expected to overestimate the average temperature since heating cycle temperatures are larger than cooling cycle temperatures.

As seen in Figure 4.20 the average velocity inferred from the testing on the large blocks is lower than the velocities from the thin rod method. This creates the discrepancy evident in Figure 4.19, especially below 600 degrees $C$. It should be noted that most of the discrepancy is due to the inadequacy of the calibration data.

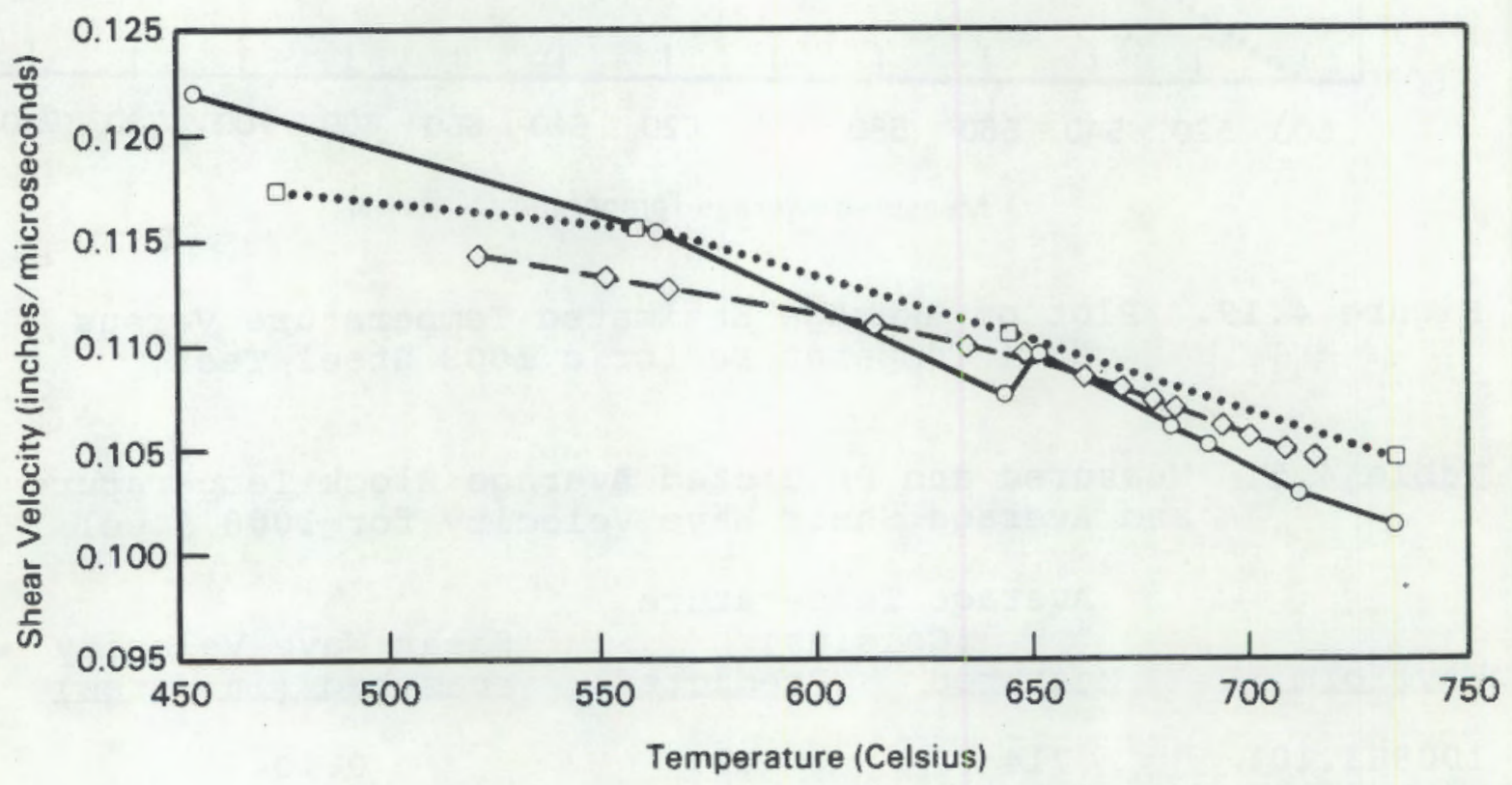

Figure 4.20. Plot of Shear Wave Velocities Versus Temperature for Three Replications with 1008 steel.

The results of the analysis for the 1038 steel, shear wave tests, are presented in Figure 4.21. Panel (a) of 4.21 is a plot of both the measured and predicted temperatures as a function of shear wave velocity. In panel (b) of the figure, the predicted temperature is plotted versus the measured temperature. Similary, the analysis results for the Armco iron tests are presented in Figure $4.22 \mathrm{a}$ and $4.22 \mathrm{~b}$. 


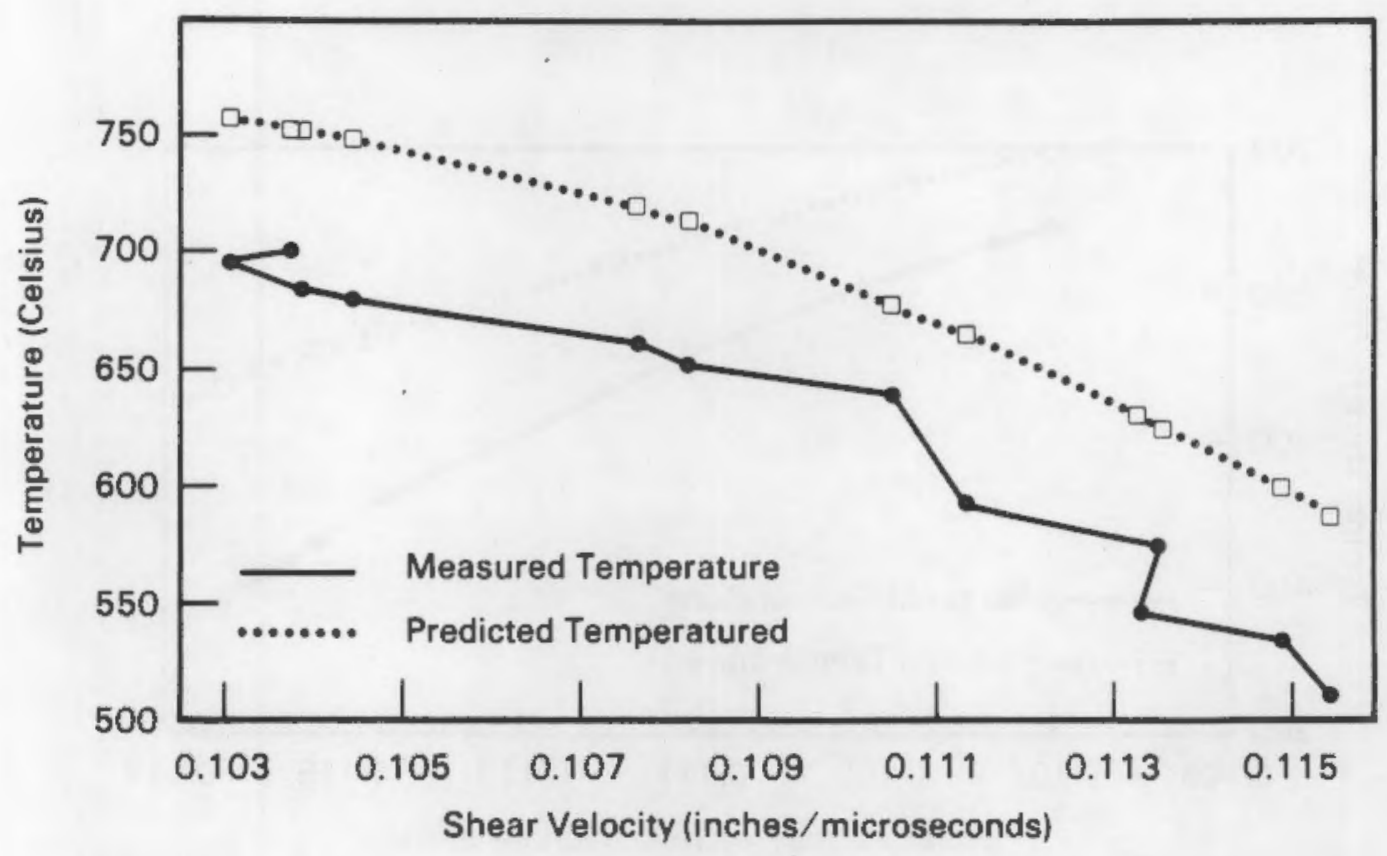

Figure 4.21a. Measured and Predicted Temperature Versus Velocity for a 1038 Steel Test.

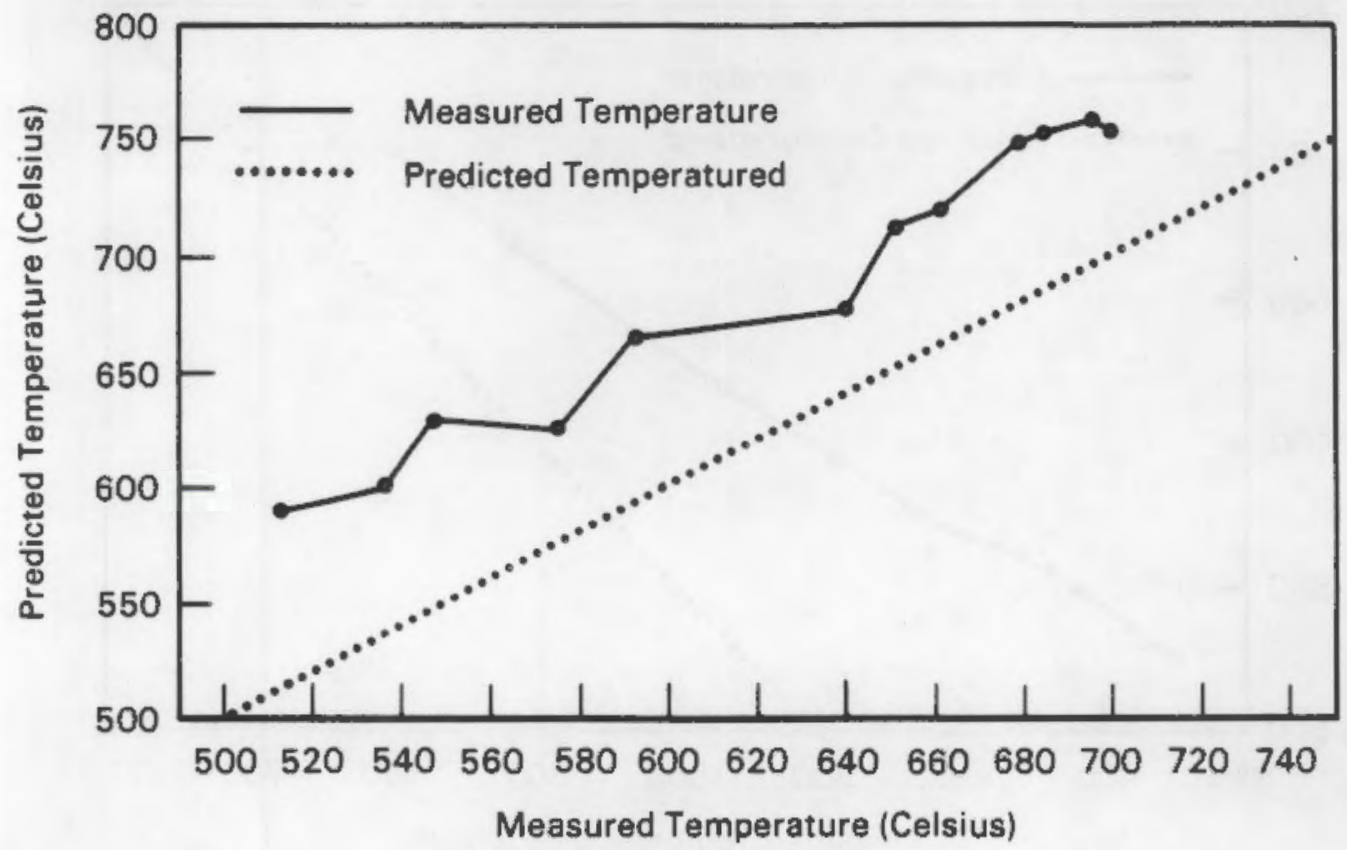

Figure 4.2lb. Predicted Temperature Plotted Versus Measured Temperature for a 1038 Steel Test. 


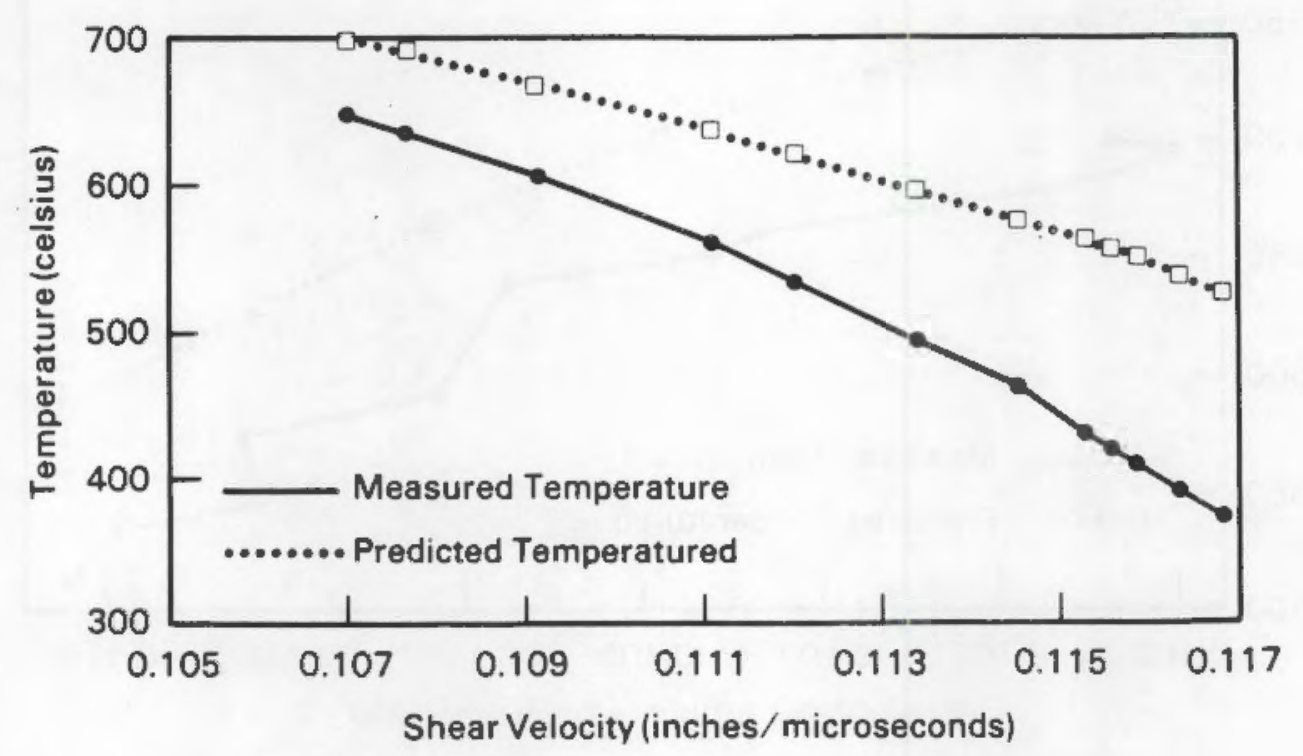

Figure 4.22a. Measured and Predicted Temperature Plotted Versus Velocity for an Armco Iron Test.

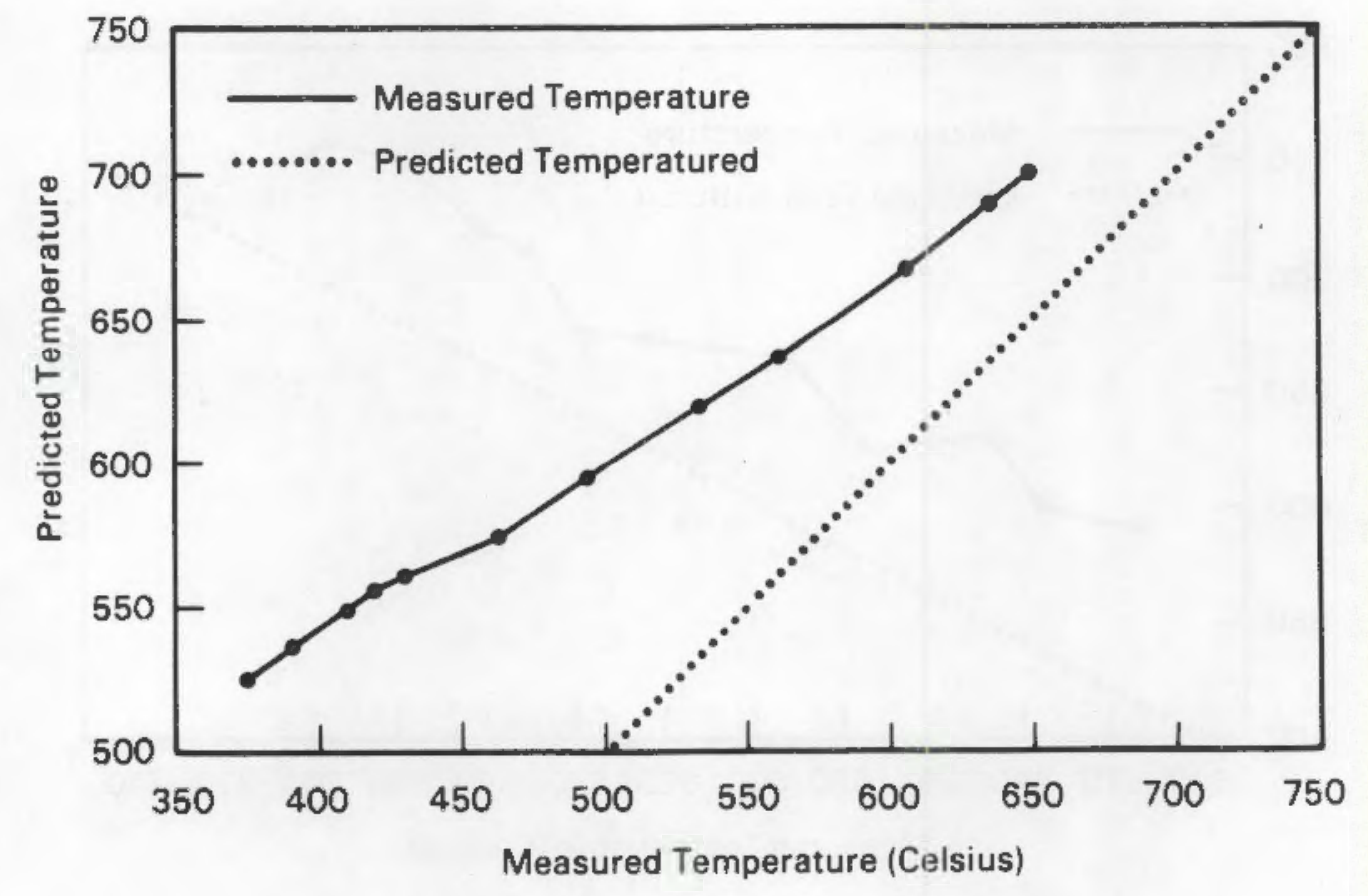

Figure 4.22b. Predicted Versus Measured Temperature for an Armco Iron Test. 


\section{SECTION 5.0 \\ CONCLUSIONS AND RECOMMENDATIONS}

\subsection{CONCLUSIONS}

The FY85 project work brought about several positive accomplishments and identified key areas where additional technical information and sensor system developments are needed. Each major technical accomplishment demonstrated both the capabilities and limitations of the existing approach and equipment. The scope of the research and development work needed to reach overall project objectives are much better understood now than they were a year ago.

The chief accomplishments and conclusions are best described in relationship to the two major technical areas of work: the technical approach and the sensor/instrument system. The major conclusions in each of these areas are the following:

Conclusions Regarding the Technical Approach:

- The concept of using average velocity measurements to estimate average internal temperature shows promise and merits further investigation. Two of the key remaining questions yet to be resolved are: 1) can a prediction accuracy of 20 degrees Celsius be achieved?, and 2) can signals be transmitted and received on steel specimens hotter than 800 degrees C?

The two major factors for improving accuracy are signalto-noise ratio in the ultrasonic signals and the calibration curve relating temperature to velocity.

- The method for calibrating velocity to temperature must be re-evaluated. In particular, the effect of temperature change rate and direction must be quantified and factored into the calibration procedure.

Conclusions Regarding the Sensor Instrument system:

- The present shear wave EMAT is capable of generating and detecting ultrasonic signals in blocks up to 6 inches thick at temperatures up to the magnetic transition point (approximately 770 degrees $C$ ). The signal-to-noise ratios for waveforms from Armco iron and 1008 steel were acceptable for analysis. The waveforms from the continuously cast section of 1038 steel were significantly weaker and the analysis results show much wider errors. 
- The current longitudinal wave EMAT can only generate and detect ultrasonic signals over a narrow range of temperatures near the magnetic transition point. Strong signals were observed when testing Armco iron and 1008 steel, but no signals could be observed when testing the 1038 steel. The enhancement of signals in the transition area is presumably caused by the concentration of magnetic flux in a thin, magnetic layer on the surface of the block.

- Instead of using an EMAT as both the pulsing and receiving sensor, use a high energy, pulsed laser for a transmitter and an EMAT for a receiver.

In order to satisfy the needs of AISI, adequate signals must be obtained on steel specimens at temperatures at least as high as 1100 degrees Celsius (2000 degrees F.) and potentially as high as 1300 degrees Celsius (2400 degrees F.) The EMAT transmitters simply do not generate sufficient energy to be detected under these conditions. Although more powerful EMATs could be produced and may be useable for some applications, a more certain and feasible approach is to use a pulsed laser to generate the ultrasonic energy. The pulsed laser technique for ultrasound generation is being pursued by the National Bureau of Standards and has shown great promise for this type of application.

\section{5:2 RECOMMENDATIONS}

In June 1985 a Project Review Meeting was held at PNL with representatives of DOE, AISI, and PNL. At that time the progress and conclusions were reviewed and preliminary recommendations for future work were formulated. In October, 1985 another Project Review meeting was held at DOE headquarters with representatives of DOE/OIP, AISI, NBS, and the principal investigator from PNL. At the second review meeting the following course of action and recommendations were agreed upon:

1. PNL's FY86 work should concentrate on developing and testing an EMAT with improved sensitivity and ability to withstand repeated exposure to high temperatures. The EMAT should be tested at PNL with a high energy laser as the transmitter or pulser.

2. The characterization of the temperature-velocity relationships for various steel alloys should be conducted by the National Bureau of standards. PNL will cooperate and communicate with NBS in applying the calibration data to the PNL experiments. 
3. After the new generation EMAT has been tested at PNL, a model should be loaned to NBS for their evaluation. Periodic review meetings involving NBS, AISI, and PNL will be held to ensure that all work is coordinated and directed in the most beneficial manner.

4. After the evaluation is completed as described in item 3 above, PNL will work with DOE/OIP and AISI to define PNL's next tasks in this area. Two major activities that have been previously identified for future work are: 1) developing a field-hardened system that can be applied in a steel production plant, and 2) applying the technique to a steel ingot with a liquid phase core (this is important in assessing the applicability of this technology to monitoring continuous casters). 


\section{SECTION 6.0}

REFERENCES

1. Gaspar, T.A. and Lownie, H.W., Jr., "Research Options for the Development of Sensors to Measure the Thermal state of Solid steel Bodies," Battelle Columbus Laboratories, Columbus, $\mathrm{OH}, 1982$.

2. Kolsky, stress Waves in solids, Oxford Press.

3. Speich, G.R. and Schoable, A.J., "Thermal Shrinkage of Plain Carbon Steels," United States Steel, August 1982. Restricted report.

4. Papadakis, E.P., et al., "Ultrasonic Attenuation and Velocity in Hot Specimens by the Momentary Contact Method withopressure Coupling, and Some Results on steel to $1200 \mathrm{C}$, "The Journal of the Acoustic Society of America, September 1971 . 


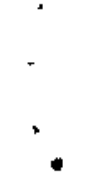


APPENDIX A

\section{CASTING OF SMALI INGOTS}

The equipment for melting was a $200 \mathrm{~kW} 3 \mathrm{kHz}$ solid-state induction power source. A free-standing 908 Mgo crucible, 8.5 inch $O D \times 12.5$ inch tall with a 0.5 -inch wall having a steel capacity of $100 \mathrm{lbs}$, was rammed into place.

An ingot mold 5.5 inch $\times 5.5$ inch $x 14$ inch deep was fabricated from 0.75 -inch thick mild steel plate. The mold was clamped with set screws at the bottom and "C" clamps at the top. It was planned that after pouring, the sides of the mold could be quickly removed and the solidified sides of the ingot could then contact the coil of the transducer before the center of the ingot solidified. The mold assembly was placed on a hydraulic lift cart beneath the pouring spout of the crucible and coil assembly. The base of the mold rested on a water-cooled copper chill plate to ensure a bottom-to-top solidification mode. Flexible water lines allowed the mold cart to be repositioned after pouring.

Prior to melting, the preheated mold parts were brushed with a mold wash of 508 fused $\mathrm{SiO}_{2}$ and 508 fused $\mathrm{Al}_{2}{ }^{\mathrm{O}_{3}}$ cement mixed with water.

Raw materials for melting were 15 lb half round ingots of both AISI 1008 and 1038 steels. A calcium silicon alloy deoxident containing 23-32 weight percent calcium, 60-65 weight percent silicon, and a 5 weight percent maximum iron was an initial slagging addition. A ferro-titanium alloy of approximately 70 weight percent titanium balance iron was the final deoxident.

The first heat was to evaluate the operation of the power source and crucible assembly. No deoxidation practice was used on the 1008 steel and the metal was poured into a mold made from 0.38 -inch thick plates held together with "C" clamps. The mold plates warped, some metal leaked out, and some fusion of the mold plates to the ingot took place. (The mold with the thick side plates and water-cooled copper chill plate was constructed after this experience.) Radiographs of this ingot showed it to be permeated with spherical porosity because no deoxidation had been used prior to pouring.

The AISI 1008 steel was melted for heat No. 2. The duration of the melt was 63 minutes, with twenty-five minutes at maximum power of $40 \mathrm{~kW}$. Ninety grams of the calcium-silicon alloy were added two minutes prior to pouring. The surface of the melt was skimmed, 75 grams of the ferro-titanium alloy were added and the metal poured. The pouring temperature was estimated as 1530 degrees $C$ from optical pyrometer readings. Six 
minutes after pouring, removal of the mold sides commenced. The set screws at the bottom of the mold seized extending the removal operation another four minutes. Mold leakage or fusion of the ingot to the side plates was not evident. The mold plates warped during this heat and were straightened before the plates were assembled for heat No. 3 .

The AISI 1038 steel was melted for heat No. 3. The duration of the melt was about 64 minutes with 19 minutes spent at maximum power of $40 \mathrm{~kW}$. The deoxidation practice was the same as that described for heat No. 2 . The pouring temperature was 1590 degrees $C$ as read by an optical pyrometer. The mold for this heat had three thermocouples located in a horizontal plane six inches up from the base. The high density aluminum oxide protection tubes covering the thermocouples extended through the wall of the mold and into a counter bore on the opposite side. The metal was poured over the center tube and against the far side. Two of the thermocouples were platinum Type $\mathbf{s}$ and the other was $W-5 \%$ Re vs $W-26 \%$ Re. All three thermocouples failed during the pour. The mold side that received the impinging metal stream and half of the mold base fused to the ingot.

\section{Future considerations}

Techniques were developed for casting the 1008 and 1038 steels although no ingots with liquid metal in the interiors were made available for ultrasonic measurements. To accomplish this, one must pour the metal into the mold, remove the mold sides at the appropriate time to ensure that the metal will not run out of the mold but is still molten in the interior, then get the ingot side wall to the transducer before the interior solidifies. It is doubtful that this can be accomplished with 100 lbs of steel, which is the limit of the present crucible and coil assembly. Future work will consider a larger ingot (300-500 lbs) and perhaps a large, end-down mold that can be lifted off the ingot with an overhead crane. 


\section{DISTRIBUTION}

No of.

cepies

5 Ralph Sheneman DOE Office of Industrial programs

Forrestal Building 1000 Independance Ave. washington, DC 20555

Dr. James R. Cook

Armco Incorporated

Research Center

Curtiss Center

Middletown, OH 45043

Dr. Willian E. Dennis American Iron and steel Institute 1000 16th street N.W. Washington, DC 20036

$12 \mathrm{Mr}$. Robert $\mathrm{D}$. Jeffress American Iron and steel Institute 100016 th street N.W. Washington, DC 20036

3 Hayden N, G. Wadley Metallurgy Division National Bureau of standards MATLS A-163

Washington, DC 20234

30 DOE Technical Information Center
No. of

copies

DOE Richland operations office

D. R. Segna

30. Pacific Northwest Laboratory

M. Clement

D. S. Daly (3)

J. V. Dovey

D. K. Lemon (15)

R. A. Pappas

N. J. Olson

P. D. Sperline

Publishing Coordination (2)

Technical Information 
